\title{
The Application of Living Walls for Acoustic CoMfort
}

\author{
by
}

\author{
Magdaleen H Bahour \\ (B.Arch, American University of Beirut, 2016)
}

A Major Research Project

Presented to Ryerson University

in Partial Fulfillment of the Requirements for the Degree of Master of Building Science (MBSc) in the Graduate Program of Building Science

Toronto, Ontario, Canada

(C) Magdaleen H Bahour, 2017 
I hereby declare that I am the sole author of this MRP. This is a true copy of the MRP, including any required final revisions.

I authorize Ryerson University to lend this MRP to other institutions or individuals for the purpose of scholarly research.

I further authorize Ryerson University to reproduce this MRP by photocopying or by other means, in total or in part, at the request of other institutions or individuals for the purpose of scholarly research. I understand that my MRP may be made electronically available to the public. 


\title{
The Application of Living Walls for Acoustic Comfort
}

\author{
Masters of Building Science 2017 \\ Magdaleen H Bahour \\ Graduate Program in Building Science \\ Ryerson University
}

Interior space comfort encompasses design performance criteria beyond the thermal qualities of the space. The acoustic performance has shown to be an essential factor for the productivity levels of the users of the space, and is essential for overall indoor environment quality to be maintained. This research focuses on the potential of integrating living walls within indoor spaces, such as atriums and halls, to provide a passive strategy for noise insulation. The procedure is conducted through a series of acoustic measurements and calculations to determine the sound absorption coefficient of living walls in-situ. A case study space is used to evaluate the integration of living walls to provide acoustic comfort. 
Indoor environment occupant comfort encompasses space performance attributes, expanding beyond the thermal qualities of the space. Acoustic performance of indoor rooms is seen to have a direct effect on the productivity levels of the occupants of the space [1]. The integration of greenery systems such as living wall has shown in previous studies a possible sound insulation strategy. The aim of this research is evaluate the potential of integrating living walls in interior spaces as passive sound insulation strategies, to provide indoor acoustic comfort. The sound absorption coefficient of one of the four living walls was calculated, through conducting a set of acoustic measurements and evaluating the overall acoustic performance of the living wall systems in four in-situ locations.

Through the conducted acoustic measurements and calculations carried out on the obtained results from location 1, the sound absorption coefficient of the living wall showed low absorption in the frequency range of $125 \mathrm{~Hz}$ with a coefficient of 0.1 and higher absorption in the higher frequencies with 1.00. The values obtained from the in-situ measurements showed inconsistencies, predicted as extra noise caused by the mechanical system running the living wall and influencing the background noise levels. In some cases, the presence of the waterfall additionally raised the background noise level within the space.

A case study application was carried out to assess the potential of integrating the living wall within the Paul Cocker Gallery, at Ryerson University' Department of Architectural Sciences, demonstrated negative outcomes. These outcomes were influenced by the existing poor acoustic conditions of the space as it is.

It is concluded that the tested living walls modules were influenced with the running waterfall next to the living wall, in addition to the pump and fan system operating the living walls mechanism, which must be highly regulated and redesigned for noise control measures to permit the sound absorption of the living wall to be at full potential.

\section{KEYWORDS:}

Sustainable design; acoustics; indoor environment quality; green wall; living wall; vertical greenery systems; acoustic simulation; material absorption coefficient 
I would like to thank my professor and research advisor Dr. Ramani Ramakrishnan, for supporting and encouraging my interest in architectural and room acoustics, and for providing direction and reassurance throughout my research journey, pushing me to achieve the completion of this project, and teaching me all I know about acoustics. I would also like to thank my second advisor, Dr. Umberto Berardi for his constructive guidance of this research and anticipation of my pursue of acoustics.

I would also like to thank my parents for always encouraging me to achieve higher and dream further. Their support is my driving force. 


\section{TABLE OF CONTENTS}

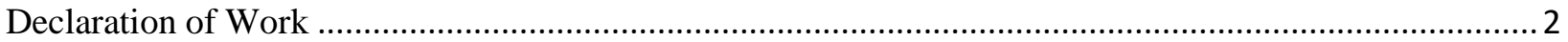

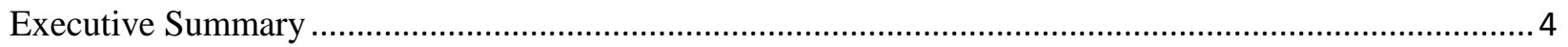

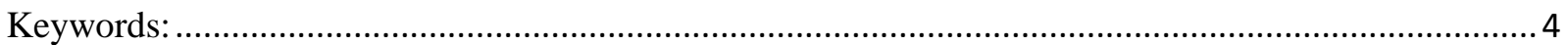

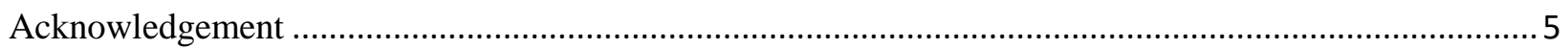

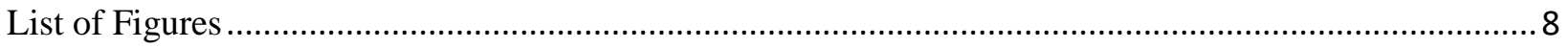

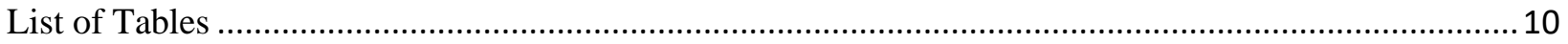

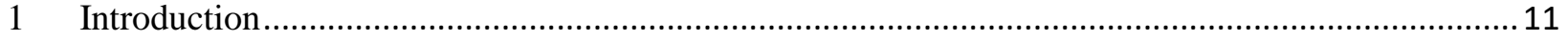

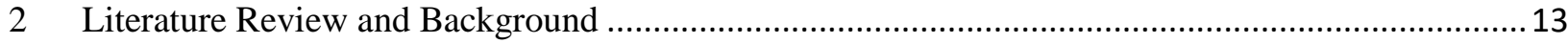

3 Specifications for Acoustic Comfort within Internal Spaces ...........................................................15

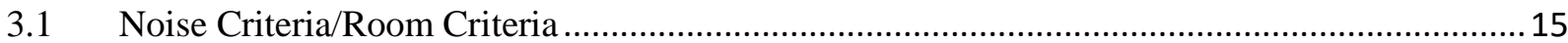

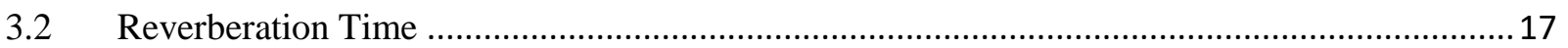

3.3 Overall Sound Distribution within the Space.......................................................................... 18

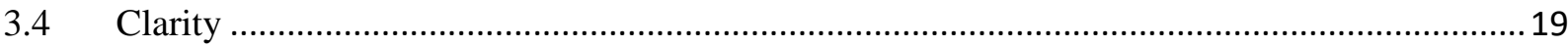

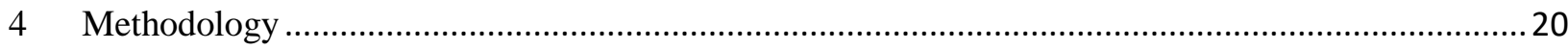

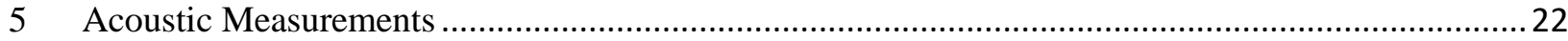

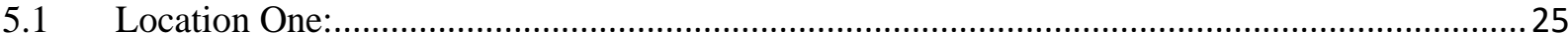

5.1.1 Measurement Results for Location One.....................................................................26

5.1.2 Room Criteria Curves for Location One ..........................................................................28

5.1.3 Calculating the absorption coefficient of the living wall ..............................................29

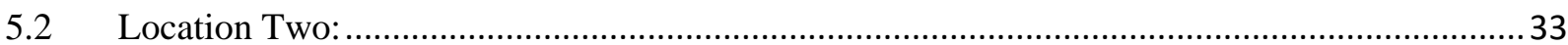

5.2.1 Measurement Results for Location Two ................................................................... 35

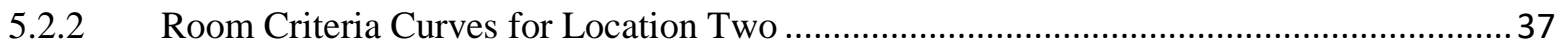

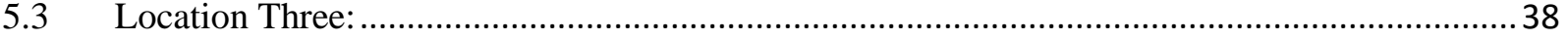

5.3.1 Measurement Results for Location Three ...................................................................... 39

5.3.2 Room Criteria Curves for Location Three ..................................................................... 40

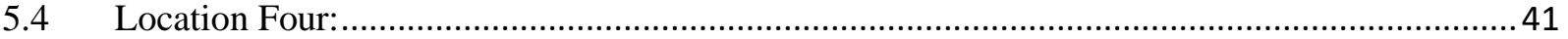

5.4.1 Measurement Results for Location Four........................................................................ 41

5.4.2 Room Criteria Curves for Location Four ....................................................................... 44

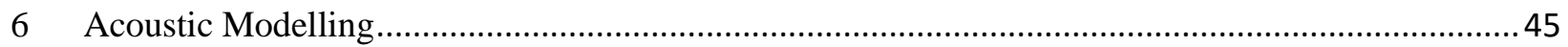

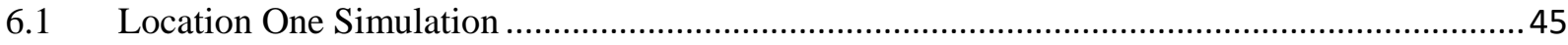

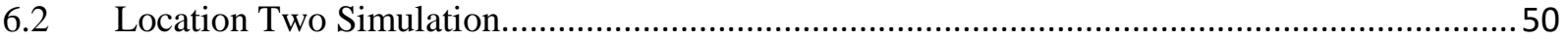

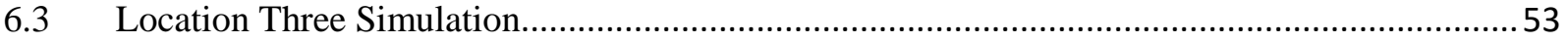


$7 \quad$ Living Wall Case Study: Application of Living Wall to Paul Cocker Gallery .................................56

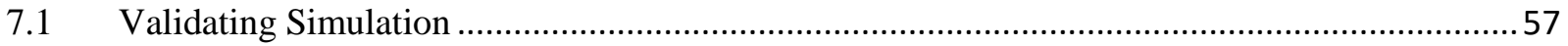

7.2 Evaluating Acoustic Parameters in Gallery …......................................................................5

7.3 Application of Living Wall in Gallery ............................................................................... 58

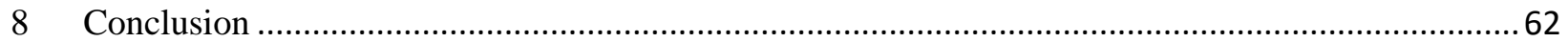

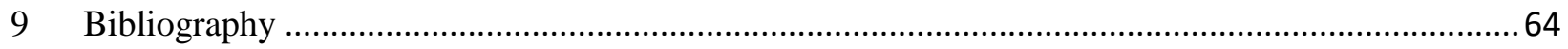

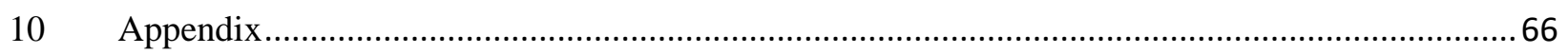

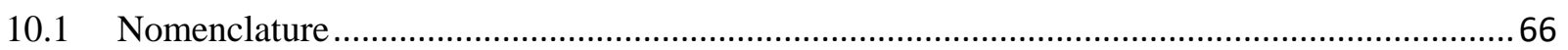

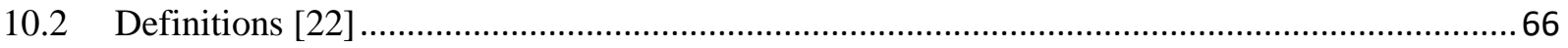

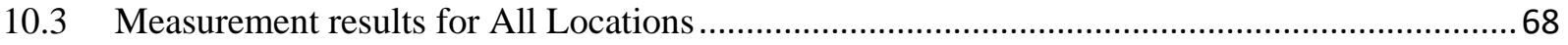

10.3.1 Acoustic Measurements for Location 1 ......................................................................6

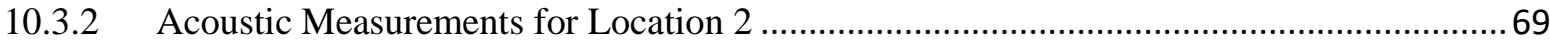

10.3.3 Acoustic Measurements for Location 3 …................................................................... 71

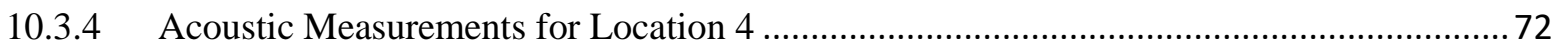




\section{LIST OF FIGURES}

Figure 1: Noise Criteria Curves [Source: http://www.spectratechltd.com/images/NC\%20curves.jpg] .....15

Figure 2: Room Criteria Curve . 16

Figure 3: Range of acceptable reverberation time. [Source:

https://msis.jsc.nasa.gov/images/Section05/Image169.gif] 17

Figure 4: Relationship between RT and Clarity [Source: Mehta et. al] ....

Figure 6: Location 1 - Restaurant Dining Room

Area

Figure 7: Location 2 - Church Common

Figure 8: Location 3 - Community Center $\quad$ Figure 9: Location 4 - College Library.......................23

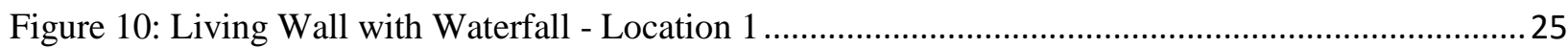

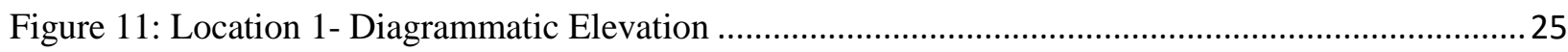

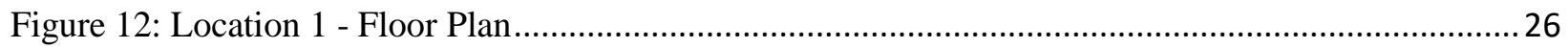

Figure 13: Comparing measured RT to Optimum RT for Location 1 ....................................................2

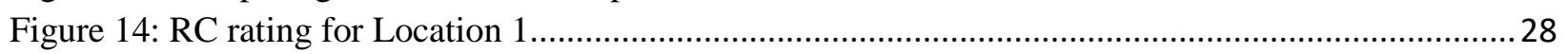

Figure 15: Restaurant 3D model with material surfaces .................................................................29

Figure 16: Comparing the calculated absorption coefficient of the living wall from the measurements done at location 1, with that found in the literature review from Thomazelli et al [18] ...........................31

Figure 17: Calibrated Absorption Coefficient of the Living Wall ........................................................32

Figure 18: Living Wall - Location 1 Figure 19: Main Lobby with Living Wall - Location 1 ................33

Figure 20: Location 2 - Diagrammatic Elevation .......................................................................... 33

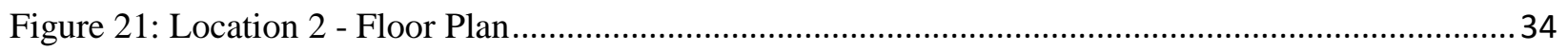

Figure 22: Testing with covered portion Location 2 .............................................................................36

Figure 23: Comparing average measured RT, covered and uncovered, with Optimum RT for Location 236

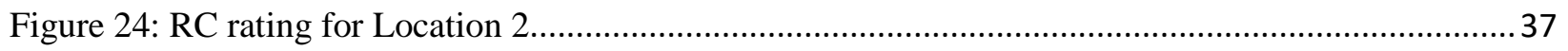

Figure 25: Living Wall - Location $3 \quad$ Figure 26: Location 3 - Floor Plan.............................. 38

Figure 27: Comparing measured and optimum reverberation time for Location 3 ................................40

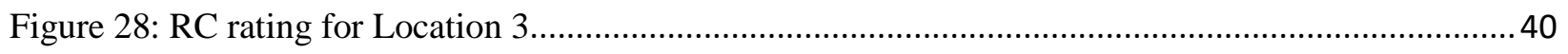

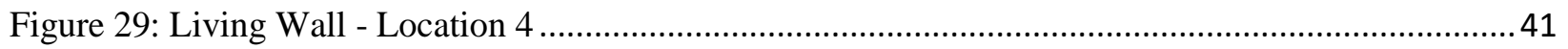

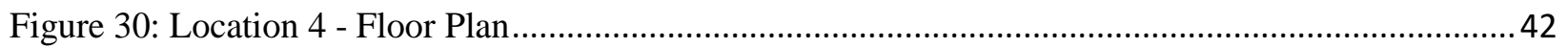

Figure 31: Reverberation Time, average measured and optimum, Location 4 ..................................... 43

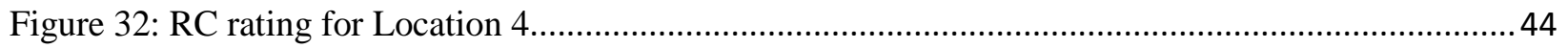

Figure 33: Location 1_Simulation Run 1: Reverberation Time........................................................... 45

Figure 34: Location 1_Simulation Run 2: Reverberation Time........................................................... 46

Figure 35: Location 1_Simulation Run 3: Reverberation Time.........................................................4 47

Figure 36: Location 1_Final Iteration Reverberation Time ............................................................ 47

Figure 37: Sound Pressure Level distribution within Location 1 - at 250, 500, and $1000 \mathrm{~Hz}$ (top to

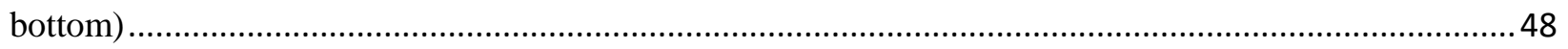

Figure 38: Comparing reverberation time measured, and simulated without living wall........................49

Figure 39: Location 2_Simulation and Measured: Reverberation Time ..............................................50

Figure 40: Sound Pressure Level distribution within Location 2 - at 250, 500, and $1000 \mathrm{~Hz}$ (top to

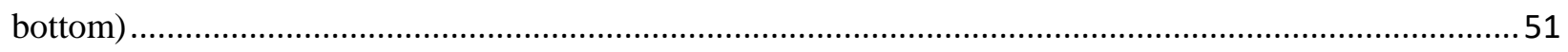

Figure 41: Comparing reverberation time measured, and simulated without living wall_Location2 .........52

Figure 42: Location 3_Simulation and Measured: Reverberation Time ................................................53 
Figure 43: Sound Pressure Level distribution within Location 3 - at 250, 500, and $1000 \mathrm{~Hz}$ (top to bottom)

Figure 44: Location 3- average measured, simulated RT with and Without Living Wall .......................55

Figure 45: Paul Cocker Gallery Entrance $\quad$ Figure 46: 3D Model of the Space (simplified) ...................56

Figure 47: Gallery Simulation and Measured: Reverberation Time ..................................................5

Figure 48: Gallery Model - First Run - application of living wall ..................................................58

Figure 49: Gallery Reverberation Time - Simulation 1 compared with measured and optimum ...............59

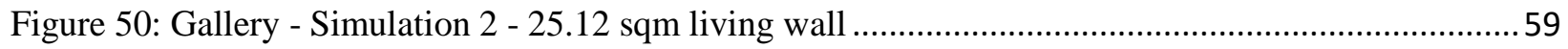

Figure 51: Gallery Reverberation time: simulation 1 and 2, measured and optimum ............................60

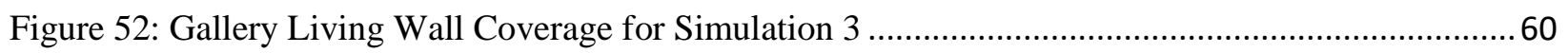

Figure 53: Gallery Reverberation time: simulation 1, 2 and 3, measured and optimum ..........................61

Figure 54: Final Simulation - Gallery Living Wall Application.......................................................61

Figure 56: Living Wall investigated in this research, images showing the geotextile modules and the density of the vegetation 
Table 1: Design Guidelines for Background Sound in Rooms by use..................................................16

Table 2: Optimum Reverberation Time determined by space Volume .................................................18

Table 3: Design Guidelines for Approximate Sound Distribution Levels by space and use .....................18

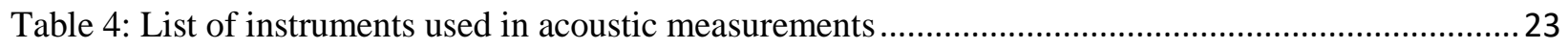

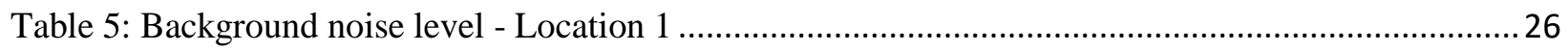

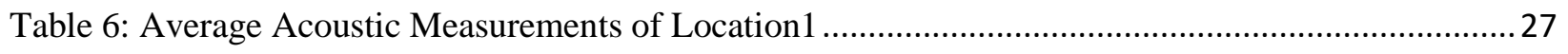

Table 7: Calibrated Absorption Coefficient of Living Wall .............................................................. 31

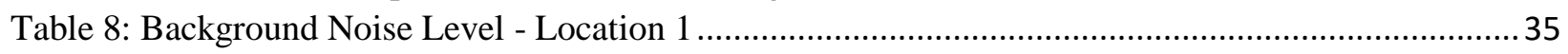

Table 9: Average of Acoustic Measurements - Location 2 .............................................................. 35

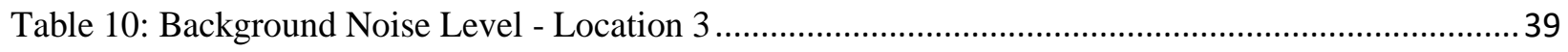

Table 11: Average of Acoustic Measurements - Location 3 ...............................................................39

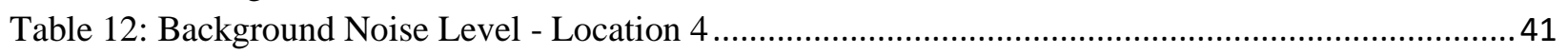

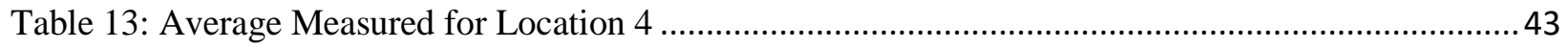

Table 14: Living Wall Absorption Coefficient Iteration 1 ................................................................46

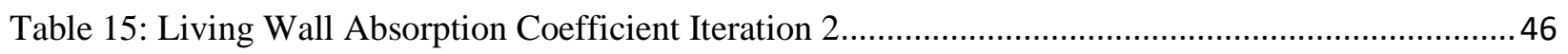

Table 16: Living Wall Absorption Coefficient Final Iteration ......................................................... 47

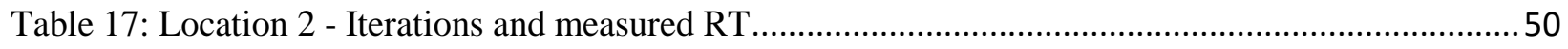

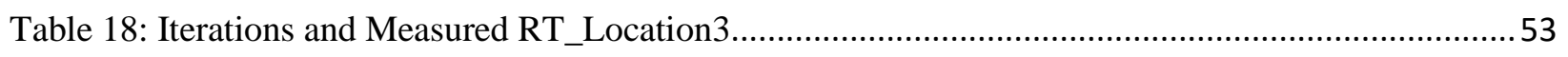

Table 19: Gallery acoustic measurements results ..........................................................................5 56

Table 20: Iterations and Measured RT_Gallery ............................................................................5

Table 21: Optimum Reverberation Time for Gallery ....................................................................5 58

Table 22: Gallery Reverberation Time Comparison: optimum, measured, simulated 1 ............................59 
Buildings are constructed essentially to provide an indoor environment entirely separated from the outdoor atmosphere, creating an enclosure that caters for the well-being of its occupants. Indoor enclosed spaces are a function of the construction assemblies and the enclosed volume within. The current 'green' and 'sustainable' industry incorporates factors that are an index to comfort of the occupants and users of the space. Therefore, the various aspects of building physics are integrated in the design of buildings that provide energy savings in their construction and occupation phases.

Previous studies evaluating the effect of indoor environment in terms of human comfort and their work performance demonstrated a significant reduction in work performance of the occupant due to their discomfort within the space [1].

Comfort for occupants of the space extends beyond thermal qualities. Where other aspects come into consideration, the indoor air quality (IAQ) extends to encompass a broader range of attributes of a space, attaining an overall indoor environment quality (IEQ).

The attributes of the indoor air quality (IAQ) constitute of the ambient temperature, relative humidity and levels of air pollutants within the enclosed space, where as the indoor environment quality (IEQ) incorporates factors in addition to temperature and humidity, such as indoor illuminance and noise levels. The required IEQ of a space is subject to its use, size, and the number of people within said space. Hence, to achieve high IEQ for occupants, a balance of the mentioned factors should be accomplished to attain the required milieu for the space.

A significant index of the indoor environment quality for occupant comfort and productivity levels is the acoustic performance of the space, as demonstrated from past research. The acoustics of a space is influenced by airborne sounds, as well as noise mitigating from outdoors and adjacent spaces. The requirement for noise control strategies is recognised in sustainable building design, in addition to the more common parameters of air quality and thermal control [2]. Green building standards, such as LEED have incorporated acoustic comfort for certification credits, however it is not a mandatory guideline yet [3].

The necessity of attaining well-defined acoustic qualities pertains to the tasks carried out within the space, to avoid disruption of concentration of users or the undesired transmission of conversation. Additionally, noise levels above a certain threshold could lead to discomfort, and with longer exposures and higher noise levels, a possible partial or total hearing loss [4].

Current practices incorporate living walls within internal spaces for their indoor air quality properties. Studies have shown that these living walls can be utilized for sound insulation, where they have the ability to absorb some of the noise within the space and reduce the overall sound levels.

Living walls are generally constructed as panels of geotextile felts with pre-cultivated plants, which are fixed to a vertical support or on the wall structure. A variation of this panel form integrates a module box with a substrate, structurally held onto the wall. 
Per the International Organization for Standardization (ISO 354:2003): "When a sound source operates in an enclosed space, the level to which reverberant sound builds up, and the subsequent decay of reverberant sound when the source is stopped, are governed by the sound-absorbing characteristics of the boundary surfaces, the air filling the space, and objects within the space."

Hence, the focus of this research is to evaluate the effectiveness of integration living walls within interior spaces to provide acoustic comfort for the occupants. This is carried out through in-situ acoustic measurements of spaces with installed living walls. The absorption coefficient of the measured living wall is calculated, and an evaluation is carried out to estimate the impact on the reverberation time within open spaces, such as atriums, churches, restaurants and public spaces. The results are used to quantify the acoustic comfort of mentioned spaces and evaluate the influence it has on the speech transmission index. Simulations are used to assess the potential of the application of living walls as a passive sound insulation mechanism, using the Paul Cocker Gallery as a case study application, to obtain a suitable acoustic environment. 


\section{LITERATURE REVIEW AND BACKGROUND}

Minimal experimentations and studies have been carried out on the acoustic performance of vertical greenery systems. Hence, there are no concluding values obtained for the absorption coefficient of living walls in-situ. Most studies associated with greenery systems for buildings include energy savings, biodiversity support, storm water control [5], and to that, this research aims to evaluate the benefits for noise attenuation.

The necessity of noise insulation in interior spaces is linked with occupant comfort within the space. Noise, that is above a certain threshold, has been shown to reduce people's efficiency in carrying out tasks, as well as affect the sense of balance, raise blood pressure and reduce blood flow volume, as verified by laboratory studies [4].

Vegetation can reduce sound levels through the reflection, scattering and absorption by plant elements, and the destructive interference of sound waves by the substrate [5].

Azkorra et al. [5] have found through experimentation that the sound absorption of living walls is dependent on both the soil (substrate) and the vegetation itself. The vegetation rooting and the presence of fibers leads to an acoustically very soft soil, due to the porosity created by the plant elements, hence, significantly influencing the absorption properties of the soil. With greater vegetation coverage, the absorption coefficient of the wall increases with increasing frequencies.

Therefore, it can be determined that the substrate (soil) performs well in low frequency by absorbing the acoustic energy, and the plants perform better in high frequencies through scattering the sound [6,7].

The study conducted by Azkorra et al. [5] evaluated a modular based living wall system, where measurements were carried out in a reverberant chamber and the sound absorption and sound reduction index were calculated accordingly. The measured sound reduction index obtained range from $9.7 \mathrm{~dB}$ to $17.1 \mathrm{~dB}$ across one-third octave frequencies $100 \mathrm{~Hz}$ to $5 \mathrm{k} \mathrm{Hz}$, and the calculated value of the weighted sound absorption coefficient was $\alpha=0.40$.

Experiments carried by Wong et al. [7] conclude that the sound absorption coefficients of living walls under investigation are higher than those of other building materials, therefore, representing an enhanced noise attenuation mechanisms.

Sound levels are evaluated across a range of frequencies from $30 \mathrm{~Hz}$ to $10,000 \mathrm{~Hz}$, and the living walls demonstrate a noise attenuation across the lower frequencies through the integration of the substrate, usually soil, and across the higher frequencies due to the plant itself [7].

In compatibility with Azkorra et al.'s results, Wong et al. have found that living wall sound attenuation can reach beyond $10 \mathrm{~dB}$. However, tests show that the presence of moisture within the substrate could significantly affect its absorption properties. In extreme cases, where the medium is fully saturated, it behaves similar to a rigid material.

Wong et al. conducted measurements to evaluate the insertion loss caused by a vertical greenery system within a reverberant chamber. Four varieties of the same system were utilized in the study, 
with an empty module structure, $43 \%, 71 \%$, and $100 \%$ greenery coverage densities. The sound absorption coefficient increases and the reverberation time decreases with increasing frequencies. Therefore, vertical greenery systems may be installed in internal spaces to enhance speech privacy [7].

Research carried out by Davis et al. [2], on living wall modules solely with substrate and densely planted with ferns developed at the Pontificia Universidad Catolica del Ecuador (PUCE), showed that the most prominent outcome found was the increase in sound absorption caused by ferns for frequencies higher than $400 \mathrm{~Hz}$. The weighted random incidence sound absorption coefficient of the modules densely planted with ferns equals 1.00 .

Perez et al. [8] evaluated the effect of sound insulation of two in-situ vertical greenery systems, a Green Wall and a Green Façade. The Green Wall was a pre-cultivated modular based system, while the Green Façade was made with a 2-mm wire mesh parallel to the cubicle façade wall, located $25 \mathrm{~cm}$ away by means of metallic supports anchored to the wall. Their results agreed with those obtained by Wong et al. [7] and Azkorra et al. [5]. The acoustic performance of the two VGS demonstrated different frequency spectrums, where the Green Façade exhibited a profile much more irregular than the Green Wall.

The results obtained from the work of Horoshenkov et al. [6] show that the absorption coefficient of plants is controlled predominantly by the leaf area density and angle of leaf orientation. However, a concluding absorption coefficient for the living wall was not determined.

Lacasta et al. [9] found the absorption coefficient of in-situ green walls to be measured at approximately 0.65 , using an experimental prototype. The intensity of vegetation density in the wall used was at an intermediate stage, and the noise absorption values demonstrated can be observed as average values.

Kang et al. [10] conducted a series of measurements in a reverberation chamber to examine random-incidence absorption coefficients and scattering coefficients of vegetation by considering soil depth, vegetation coverage and leaf size, and soil moisture content. Outcome attained solidifies findings by Azkorra et al. [5], Horoshenkov et al. [6], and Wong et al. [7], concerning the absorption of acoustic energy by the soil and the scattering by the plant, in addition to the increase in coverage of the vegetation and its impact on the overall absorption coefficient of the living wall across the frequency range.

Fernandez-Bregon et al. [11] assessed the effect on sound mitigation by measuring sound levels across a bare concrete wall and one with a living wall installed by fasteners onto the concrete block wall. The results demonstrate that the average decrease was around 2-8\% compared to a bare concrete block wall, providing acoustic benefits for the assembly.

Per ASHRAE standards for room acoustics, as surfaces within an internal space would absorb, reflect or transmit sounds, the lower the absorption of those surfaces results in higher sound pressure levels in the space, and longer reverberation time, affecting speech intelligibility and sound perception [12]. Hence, criteria have been set to create a guideline for architects and engineers to follow when designing spaces with acoustic performance considered. 


\section{SPECIFICATIONS FOR ACOUSTIC COMFORT WITHIN INTERNAL SPACES}

As the focus of this research is to evaluate the potential of the application of living walls for acoustic comfort within interior spaces, the criteria and guidelines are considered according to the typology of the spaces and the tasks carried out in them. Table 1 from Chapter 48, Noise and Vibration Control, from the ASHRAE 2015 Handbook [13] displays the design values to be achieved in different spaces, through the use of Noise Criteria, Room Criterion, and the weighted sound pressure levels in $\mathrm{dBA}$ and $\mathrm{dBC}$.

The four main acoustic matrices that are evaluated and assessed in this research are:

\subsection{NoISE CRITERIA/RoOM Criteria}

The Noise Criteria (NC) of an enclosed space is defined with contour lines that form the upper limit of the measured spectrum of sound pressure level across all frequencies. Design guidelines outline this upper limit, describing the maximum background noise acceptable within a space where a particular task is carried out [13].

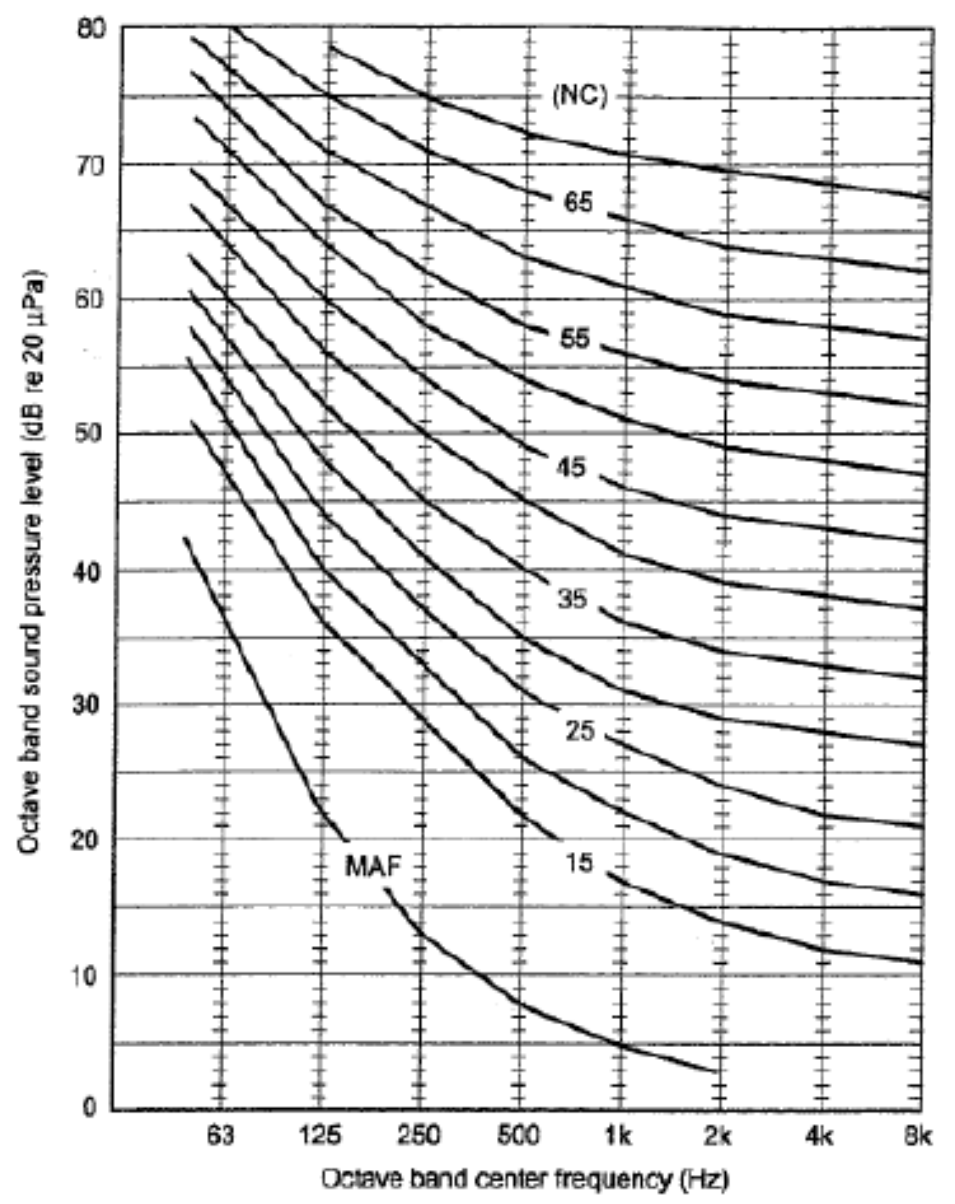

Figure 1: Noise Criteria Curves [Source: http://www.spectratechltd.com/images/NC\%20curves.jpg] 
The Room Criterion curve (RC), similar to NC curves, define the background noise level within a space using a single number, extracted through plotting the sound pressure levels across the frequency range. RC curves provide the character of the sound in addition to the RC number, defining the sound within a room as either rumbly or hissy, if they fall within the range shown on the RC graph [13].

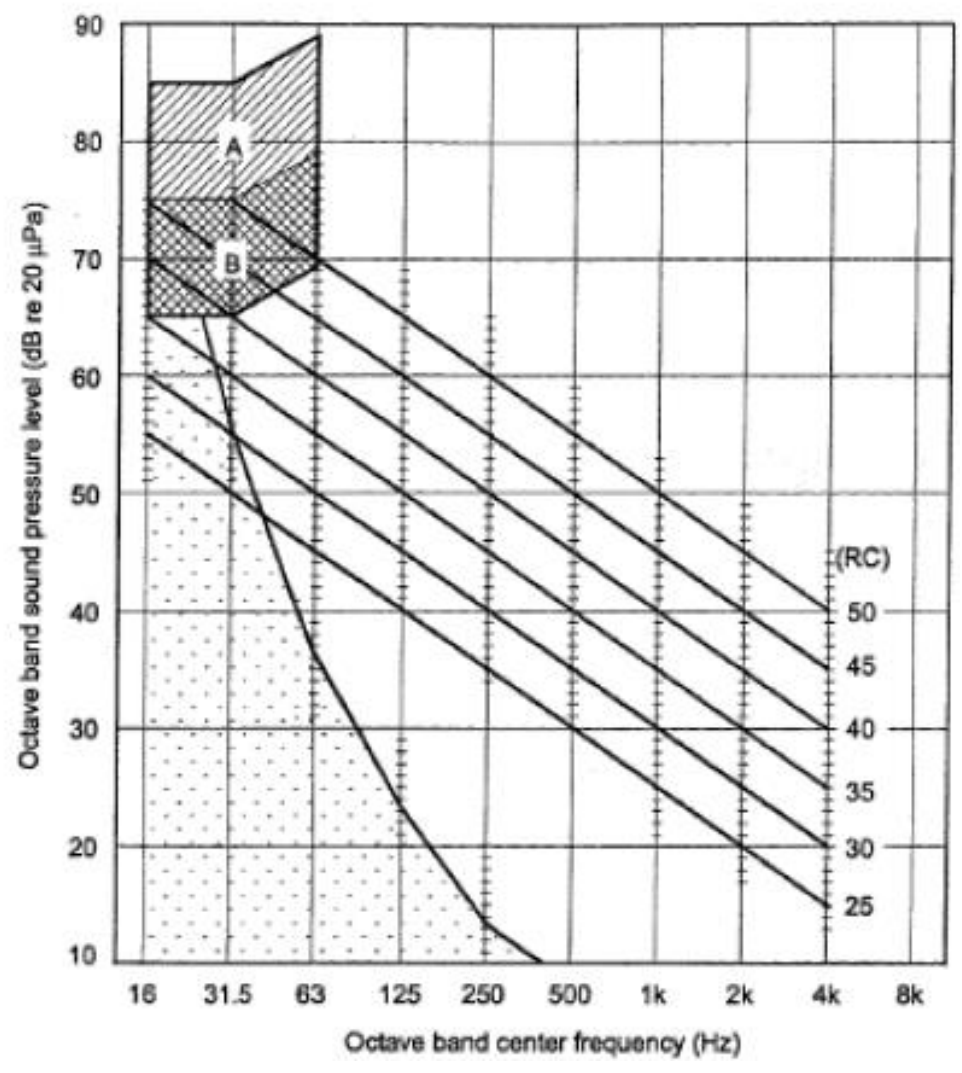

Figure 2: Room Criteria Curve

The following table is an extract of Table 1 from Chapter 48, Noise and Vibration Control, from the ASHRAE 2015 Handbook, demonstrating the spaces of concern in this research [13].

\begin{tabular}{cccc}
\hline Room Type & NC/RC & $\begin{array}{c}\text { Approximate Overall } \\
\text { Sound Pressure Level } \\
\text { (dBA) }\end{array}$ \\
\hline $\begin{array}{c}\text { Hospitals and Clinics } \\
\text { Churches, mosques, and } \\
\text { synagogues } \\
\text { Libraries }\end{array}$ & Corridors and lobbies & 40 & 45 \\
Restaurant & General areas & 25 & 30 \\
\hline
\end{tabular}

Table 1: Design Guidelines for Background Sound in Rooms by use 
The NC and RC curves permit the evaluation of the acoustic character of the room, and the respective noise levels using a single number that encompasses all the frequency ranges. Both curves are essential in assessing the sound and noise levels to provide the necessary acoustic comfort for the occupants. Furthermore, RC curves will be used in this research, as they provide additional characteristics of the noise level within the spaces under study, defining the characteristic of the noise/sound levels.

\subsection{REVERBERATION TIME}

Reverberation time of an enclosed space is the time that it takes the measured sound pressure level to decrease by $60 \mathrm{~dB}$. It defines the level of speech intelligibility within the space [13].

The reverberation time of the space is dependent on its volume and use, the figure below graphs these two factors to determine the optimum reverberation time at $500 \mathrm{~Hz}$.

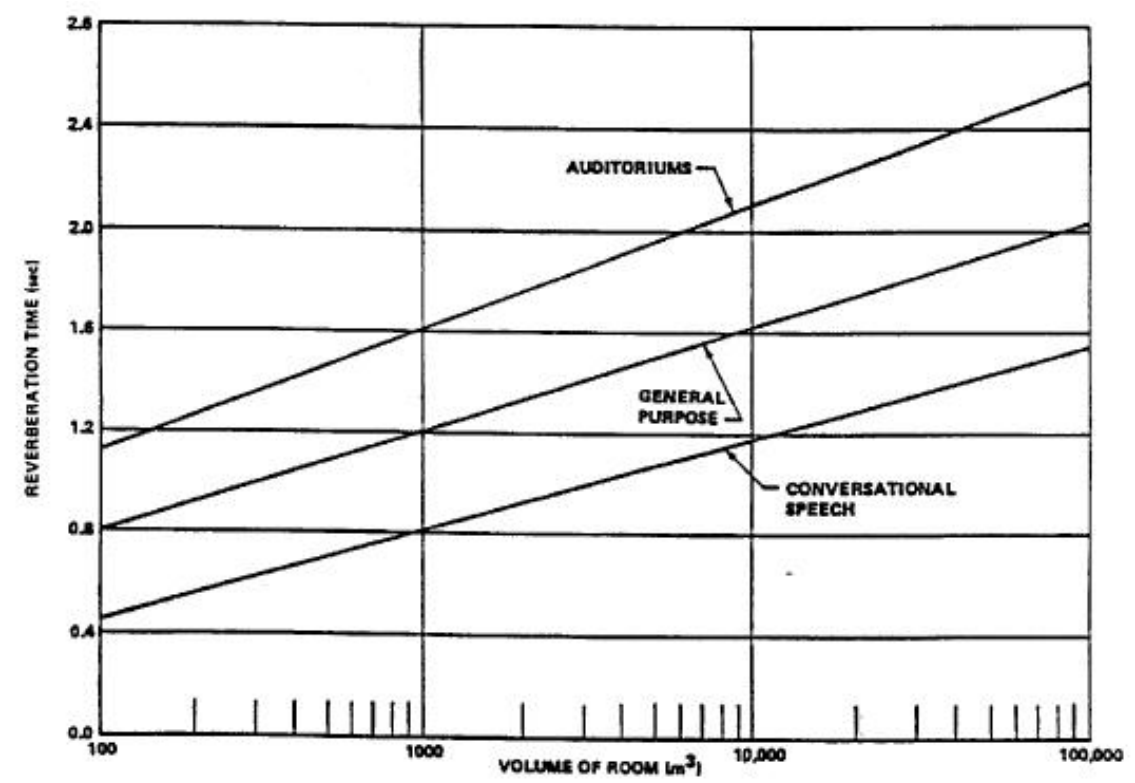

Figure 3: Range of acceptable reverberation time. [Source: https://msis.jsc.nasa.gov/images/Section05/Image169.gif]

Table 2 demonstrates the optimum reverberation time across the center frequencies, obtained from Figure 1 for $\mathrm{RT}_{500}$, using the following calculation method:

$$
\begin{aligned}
& \text { Optimum } \mathrm{RT}_{125}=1.3 * \text { Optimum } \mathrm{RT}_{500} \\
& \text { Optimum } \mathrm{RT}_{250}=1.15 * \text { Optimum } \mathrm{RT}_{500} \\
& \text { Optimum } \mathrm{RT}_{1000}=1.0 * \text { Optimum } \mathrm{RT}_{500} \\
& \text { Optimum } \mathrm{RT}_{2000}=1.0 * \text { Optimum } \mathrm{RT}_{500} \\
& \text { Optimum } \mathrm{RT}_{4000}=1.0 * \text { Optimum } \mathrm{RT}_{500}
\end{aligned}
$$

The volume of the spaces is plotted along the general purpose line for the library and health center, and along the conversational speech line for the church foyer and restaurant. The obtained point 
represents the optimum reverberation time at $500 \mathrm{~Hz}$, which is multiplied by the mentioned method to obtain the optimum reverberation time across the other center frequencies.

\begin{tabular}{|c|c|c|c|c|c|c|c|c|}
\hline \multirow{3}{*}{ Space Type } & \multirow{3}{*}{$\begin{array}{c}\text { Volume } \\
\left(\mathbf{m}^{3}\right)\end{array}$} & \multirow{3}{*}{$\begin{array}{c}\text { Speech } \\
\text { Requirement }\end{array}$} & \multicolumn{6}{|c|}{ RT (sec) } \\
\hline & & & \multicolumn{6}{|c|}{ Center Frequency $(\mathrm{Hz})$} \\
\hline & & & 125 & 250 & 500 & 1000 & 2000 & 4000 \\
\hline $\begin{array}{l}\text { Health Center } \\
\text { Lobby }\end{array}$ & 525 & $\begin{array}{l}\text { Low noise/high } \\
\text { speech privacy }\end{array}$ & 1.43 & 1.27 & 1.1 & 1.1 & 1.1 & 1.1 \\
\hline Church Foyer & 1400 & $\begin{array}{l}\text { High Speech } \\
\text { Intelligibility }\end{array}$ & 1.17 & 1.04 & 0.9 & 0.9 & 0.9 & 0.9 \\
\hline Library & 5275 & Low/no noise & 1.95 & 1.73 & 1.5 & 1.5 & 1.5 & 1.5 \\
\hline Restaurant & 570 & $\begin{array}{l}\text { Moderate speech } \\
\text { privacy/speech } \\
\text { intelligibility }\end{array}$ & 0.91 & 0.81 & 0.7 & 0.7 & 0.7 & 0.7 \\
\hline
\end{tabular}

Table 2: Optimum Reverberation Time determined by space Volume

The optimum reverberation time in Table 2 represent the model values for design guidelines of spaces with ideal speech intelligibility and acoustic comfort for the users and the task of the space. These ranges are dependent on the volume, and hence for spaces with similar tasks and different volumes, the RT of each would differ accordingly.

\subsection{OVERALl SOUNd Distribution Within THE SPACE}

The sound distribution within a space describes the overall ranges of sound pressure level across the room. Spaces with ideal acoustic performance demonstrate a range of $\pm 3 \mathrm{~dB}$ across the room, resulting in a balanced distribution from the source of the sound. Additionally, the sound distribution defines the NC and RC of the room, and therefore should not exceed the recommended values for the space, in order to maintain good acoustic performance. The following table illustrates the acceptable ranges from the values obtained in Table 1.

\begin{tabular}{cccc}
\hline Room Type & Corridors and lobbies & $\begin{array}{c}\text { Approximate Overall } \\
\text { Sound Pressure Level } \\
\text { (dBA) }\end{array}$ & $\begin{array}{c}\text { Acceptable Range of } \\
\text { Sound Pressure Level } \\
\text { (dBA) }\end{array}$ \\
\hline $\begin{array}{c}\text { Hospitals and Clinics } \\
\text { Churches, mosques, } \\
\text { and synagogues } \\
\text { Libraries }\end{array}$ & General areas & 45 & $42-48$ \\
Restaurant & - & 30 & $27-33$ \\
\hline
\end{tabular}

Table 3: Design Guidelines for Approximate Sound Distribution Levels by space and use 


\subsection{Clarity}

Clarity and Reverberation time have an inversely proportional relationship, where increasing reverberation time would lead to a lower clarity value, and to obtain a higher clarity, the reverberation time has to be decreased.

Clarity $\left(\mathrm{C}_{80}\right)$ could be defined as the difference between the sound energy received at a listener in the first 80 milliseconds and the reverberant energy in $\mathrm{dB}$.

$$
C_{80}=\text { Early Energy }_{0 \text { to } 80}-\text { Reverberant energy } y_{80 \text { to } \infty}(\mathrm{dB})
$$

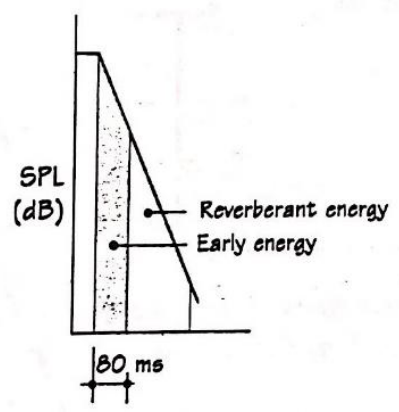

(a) Short RT - high clarity Early energy (indicated by the darker area) is a large fraction of the total energy, giving greater clarity.

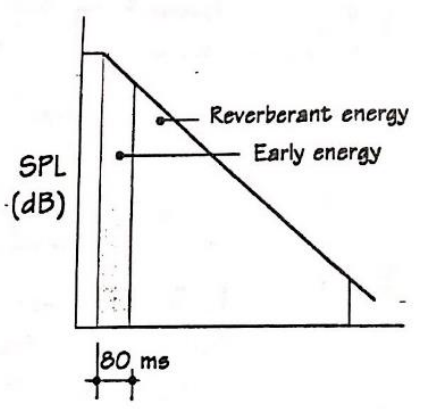

(b) Long RT - low clarity Early energy (indicated by the darker area) is a small fraction of the total energy, giving lower clarity.

Figure 4: Relationship between RT and Clarity [Source: Mehta et. al]

An acceptable range of value for clarity is between -5 to $+10 \mathrm{~dB}$, where increasing the reverberant energy could lead to a decrease in clarity (more negative value) and thus decreasing the definition of sound and obtaining a "muddy" sound.

It is essential to maintain the design RT values to ensure that the sound reaching the listener has a well-defined clarity.

Clarity $\left(\mathrm{C}_{80}\right)$ is assessed in all the acoustic measurements made, to evaluate the acoustic qualities of the space and the characteristic of the sound. 
With the objective of evaluating the absorption coefficient of living walls and applying it to a case study, this research is carried out in four (4) main phases.

\section{Phase One:}

Four locations with in-situ living walls are chosen: a church, restaurant, college library and community/health center. Each of the locations is subjected to a continuous flow of users throughout the day, and the noise levels within the space varies, depending on background noise, the number of occupants of the space, and speech levels.

The installed living wall in the four locations is measured, to determine the surface area that it occupies within the space. Architectural drawings are produced, including plans, and elevations of the interior spaces. Images are taken of the living wall and the spaces for further reference.

The background noise level is measured in 2 or more locations within the space, followed by the initial procedure in the acoustic measurements conducted in each location constitutes the use of a speaker system and microphone connected to an external sound card to a laptop computer. An impulse response is sent out using a room acoustics simulation software, and the decay of the impulse is measured across a range of frequencies from $63 \mathrm{~Hz}$ to $8000 \mathrm{~Hz}$.

The output extracted from each measurement focuses on the reverberation time across the frequency range (T15 and T30), the relative sound distribution (SPL), and the clarity (C80) of the space.

Where accessible, the living wall installed in one of the locations was partially covered using $1 / 4$ " MDF boards, of 2' $4^{\prime}$ ', and another impulse response measurement is conducted. This technique is done to calculate the absorption coefficient of the living wall, by using Equation (1), and demonstrating the difference in reverberation time values obtained from both measurements, due to the decrease in absorption from the wall. The MDF board acts as a hard element, exhibiting acoustic properties of a reflective panel.

$$
R T=\frac{0.16 \mathrm{~V}}{\Sigma A}
$$

where $\Sigma A$ is the sum of the surfaces within the room multiplied by the corresponding absorption coefficient of each surface, and $V$ is the volume of the enclosed space.

\section{Phase Two:}

Three-dimensional models of three of the spaces are created using Google Sketchup and are exported into a (.par) extension, using a Plugin installed in the software. The generated models are imported for simulation analysis. Each surface within the model is assigned a material, resembling the acoustic properties of the construction assembly of the space. A point source is added into the 
simulated room and a grid is defined at hearing level $(\sim 1.5 \mathrm{~m}$ from the ground) to obtain the acoustic performance of the room. The values gathered from the onsite measurements are referenced to validate the simulation values for higher accuracy results.

\section{Phase Three:}

The obtained absorption coefficient of the living wall is created in the simulation software database as a new material. Calculations are made to evaluate the noise reduction due to the presence of the living wall in the chosen locations, and results are drawn to evaluate if the presence of the living wall achieves requirements the acceptable noise levels (NC and RC) for the tasks carried out within the spaces.

\section{Phase Four:}

Further modelling and simulation of the Paul Cocker Gallery is carried out, integrating the living wall to obtain good acoustic performance of the space, for it to be suitable to be used as a critique space. 
Acoustic measurements were conducted in the four chosen locations with living walls installed. Each location was visited during hours with least or no occupants using the space, for the purpose of conducting measurements to evaluate the performance of the space without human interference.

Location 1 is a restaurant, where the living wall is installed in the dining room space. The floor area of the dining room is $176 \mathrm{~m}^{2}$, and the living walls integrated cover a total of $20 \mathrm{~m}^{2}$ of wall area. An interior waterfall is integrated between the two portions of the living wall.

Location 2, the church common area, has a floor area of $246 \mathrm{~m}^{2}$, in which the living wall installed in the space covers $21 \mathrm{~m}^{2}$. In this location, there living wall is not accompanied by a waterfall. The overall building strives towards sustainability in the built environment.

Location 3 is a hub for promoting healthy practices for the community. The living wall, of $14 \mathrm{~m}^{2}$, is located in the main lobby atrium of the center, which has a floor area of $150 \mathrm{~m}^{2}$ on the main level. The living wall has an adjacent waterfall.

Location 4 is the largest of all locations in floor area and total covered living wall area, with 740 $\mathrm{m}^{2}$ and $126 \mathrm{~m}^{2}$, respectively. The living wall is installed in the atrium of the college library. The living wall soars through four floors of the library.

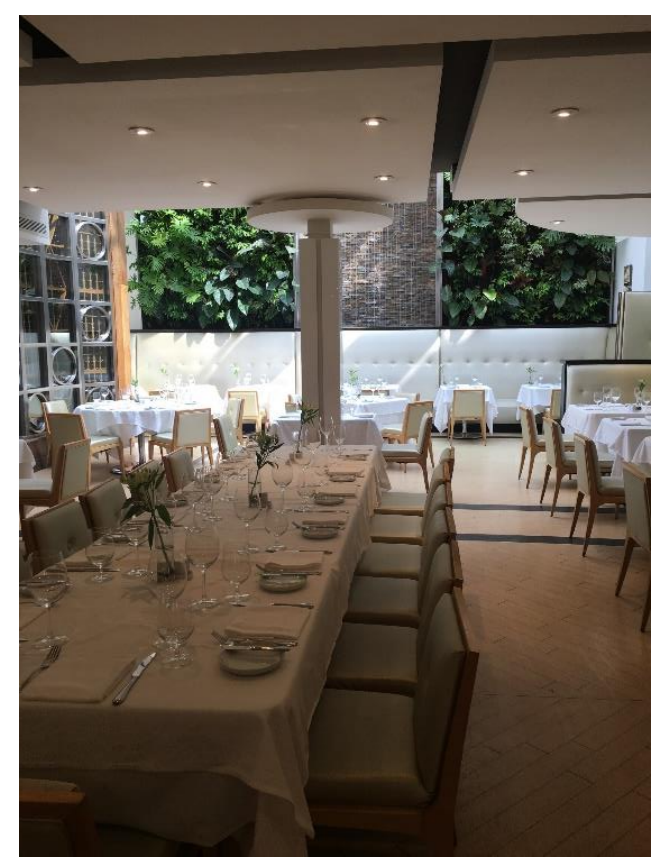

Figure 5: Location 1 - Restaurant Dining Room

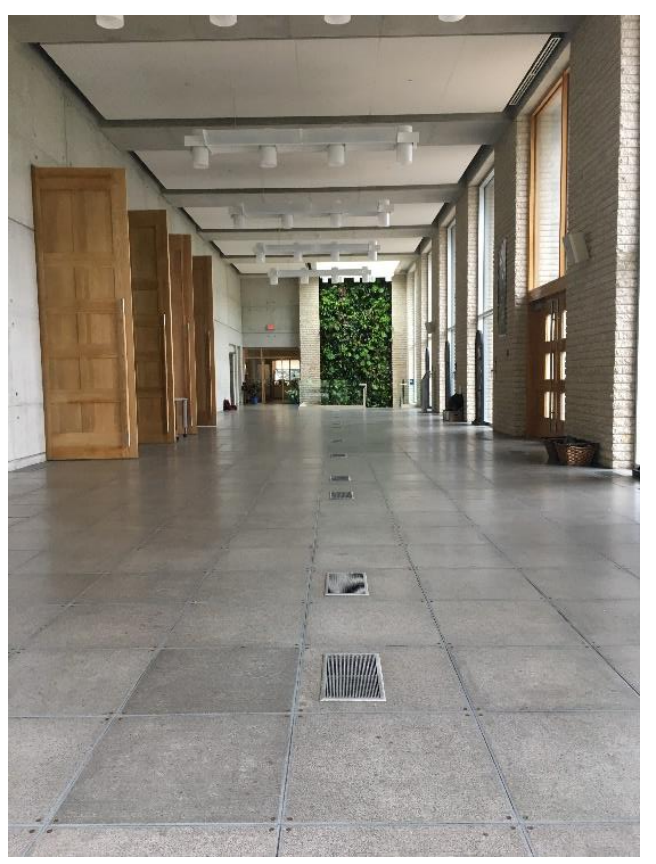

Figure 6: Location 2 - Church Common Area 


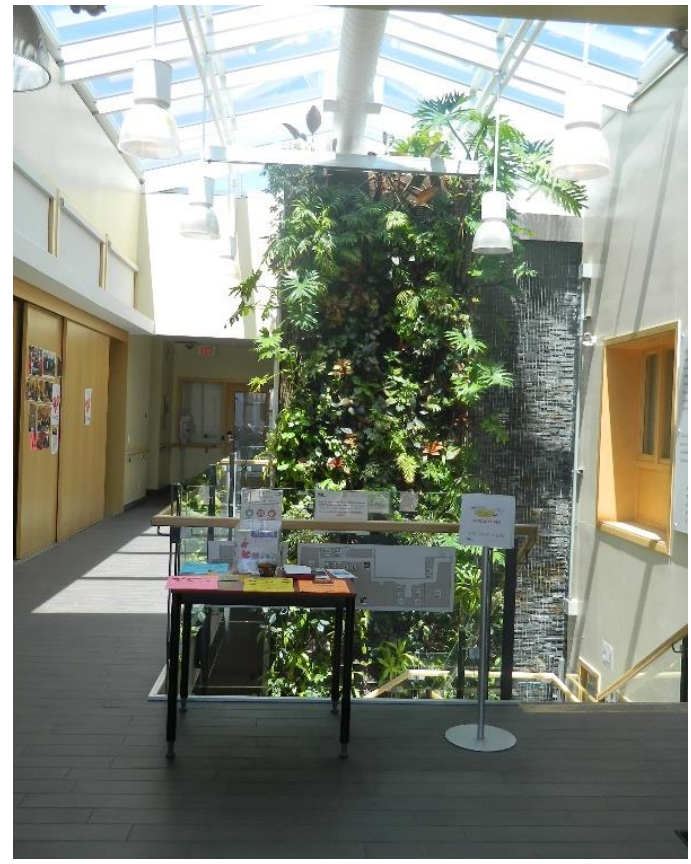

Figure 7: Location 3 - Community Center

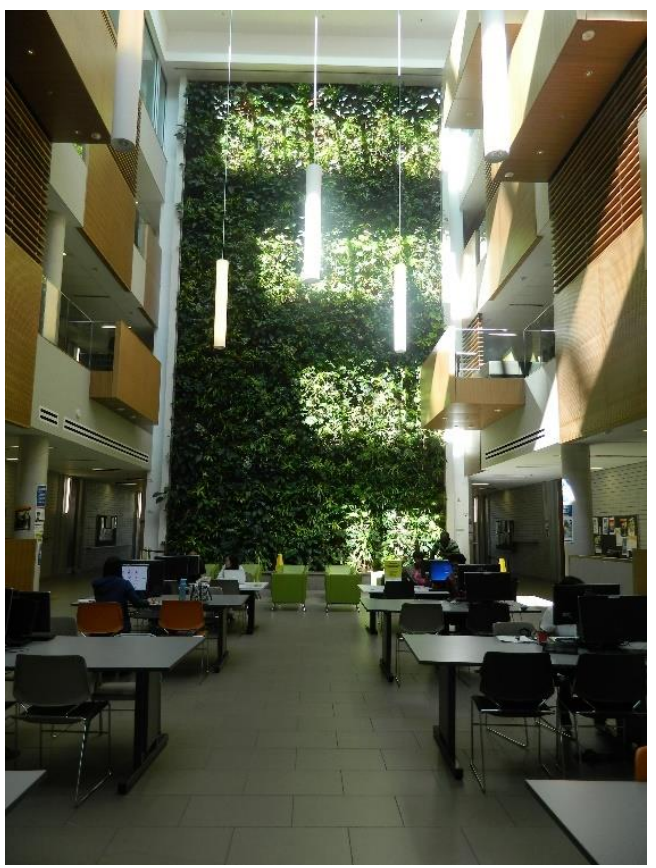

Figure 8: Location 4 - College Library

The acoustic measurements were carried out following the same process and using the same instruments, to maintain higher accuracy when comparing the results obtained from each measurement. The instruments used in the procedure are listed in Table 3 below.

\begin{tabular}{|c|c|c|}
\hline & Make & Connection \\
\hline Sound Level meter & CESVA [SC160] & - \\
\hline Speaker/Amplifier & Brüel \& Kjaer Type 4241 & $\begin{array}{c}\text { Connected to sound card output port/electrical } \\
\text { plug }\end{array}$ \\
\hline Microphone & MA221 & Connected to sound card input port \\
\hline External Sound card & MC3022 & $\begin{array}{l}\text { Connected to laptop USB port, input port to } \\
\text { microphone, output port to speaker/amplifier }\end{array}$ \\
\hline Odeon Software & $\begin{array}{l}\text { ODEON } 13.00 \\
\text { Auditorium }\end{array}$ & 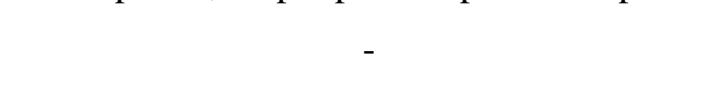 \\
\hline Rocky6 smart dongle & USB drive & Laptop USB port - to operate Odeon \\
\hline Laptop & $\begin{array}{l}\text { DELL 64bit operating } \\
\text { system - Windows } 10\end{array}$ & All connections to USB ports \\
\hline
\end{tabular}

Table 4: List of instruments used in acoustic measurements

The measurement procedure is as follows:

An initial background noise level measurement using the sound level meter is conducted at two points within the space, obtaining the noise level across the frequency range ( $31 \mathrm{~Hz}$ to $8000 \mathrm{~Hz})$ and a weighted average value in $\mathrm{dBA}$. 
All the connections are setup and associated to the laptop as stated in Table 1. An initial trial run is done to ensure the setup is running properly. The first impulse response is sent out and the decay time is measured at the first point. The speaker/amplifier system remains in place and the microphone is moved to the second point for the second set of measurements, sending out the impulse response and measuring the decay, similar to the first set. The measurement is carried out twice at each point, resulting in an overall four sets of measurements for each location. The output from each measurement is saved and exported into a spreadsheet to be analyzed.

For obtaining more accurate and comparable results, the living walls chosen for this research have similar construction and installation techniques. The living wall is composed of a structure that is mounted onto the constructed wall, in which layers of felt are attached onto. The plants are inserted into the growth medium, constituted of the felt with a hydroponic mechanism. A water pipe system runs behind the wall and a basin positioned at the bottom collects and recirculates the water for a continuous flow to water the plants.

The plants used are composed of mainly the large leaf type, and a mixture of different species is utilized to resemble a naturally organic ensemble. 


\subsection{LOCATION ONE:}

Two living walls are installed in this location, side by side, and separated by a decorative interior water fall, creating a soothing ambiance for the space. The integration of the walls within the main dining room area narrates a connection with the name of the restaurant.

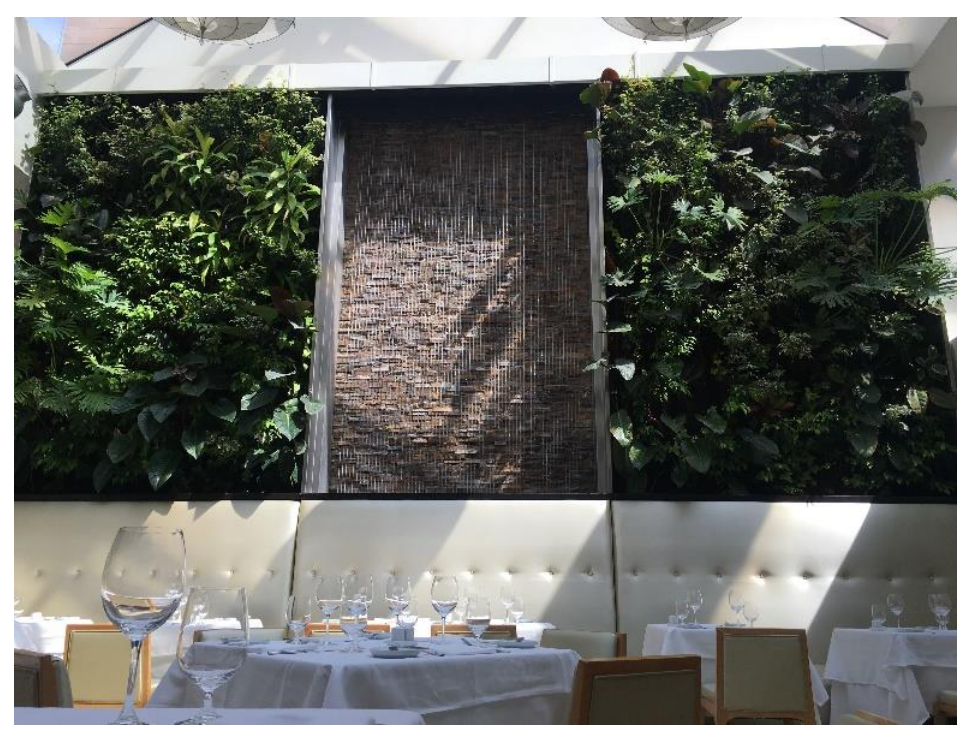

Figure 9: Living Wall with Waterfall - Location 1

Each of the walls covers an area of $10 \mathrm{~m}^{2}[2.5 \mathrm{~m} \mathrm{x} 4 \mathrm{~m}]$ and are situated at the end wall of the space, with a floor area of $176 \mathrm{~m}^{2}$. The background noise level was measured at two points, and the values are shown in the Table 4 . The presence of the water fall influenced the background noise level measured.

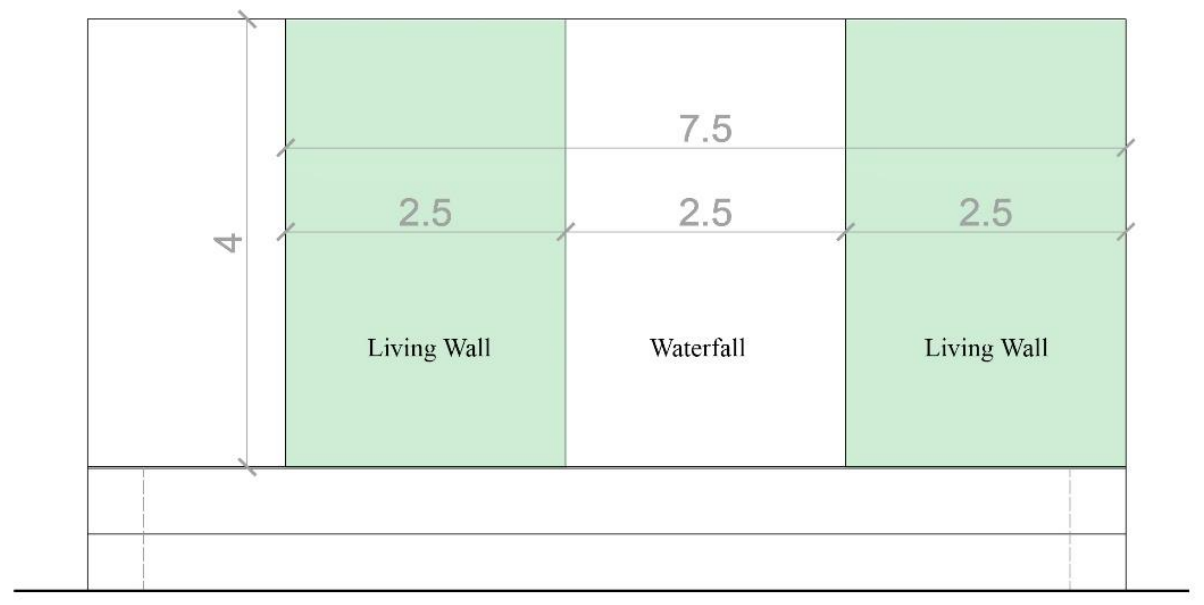

Figure 10: Location 1- Diagrammatic Elevation 


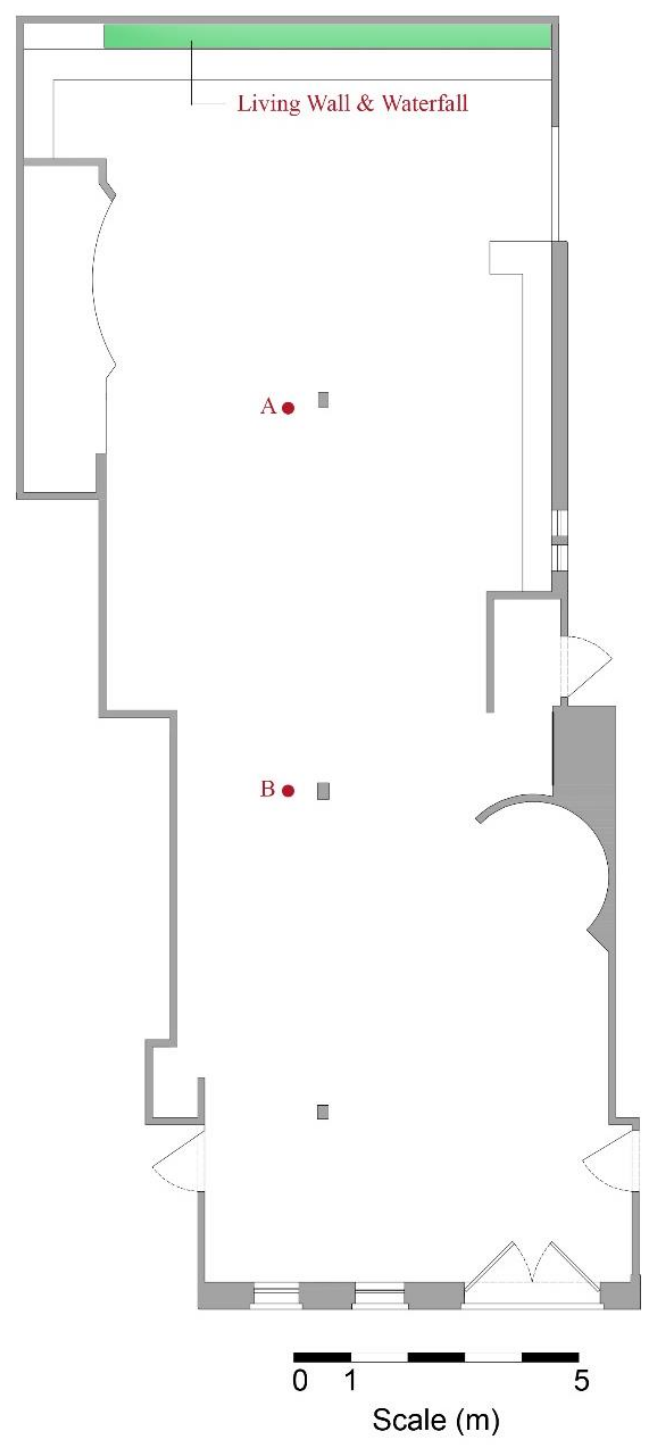

Figure 11: Location 1 - Floor Plan

\subsubsection{Measurement Results for Location One}

The A-weighted average for the measured background noise level in the space at Point $\mathbf{A}$ is 53.7 $\mathrm{dBA}$ and Point B is $46.4 \mathrm{dBA}$.

\begin{tabular}{c|cccccccc}
\hline $\begin{array}{c}\text { Location 1_Measured } \\
\text { Background Noise Level } \\
(\text { dB) }\end{array}$ & \multicolumn{8}{|c}{ Center Frequency } \\
\cline { 2 - 9 } & $\mathbf{6 3}$ & $\mathbf{1 2 5}$ & $\mathbf{2 5 0}$ & $\mathbf{5 0 0}$ & $\mathbf{1 0 0 0}$ & $\mathbf{2 0 0 0}$ & $\mathbf{4 0 0 0}$ & $\mathbf{8 0 0 0}$ \\
\hline Point A & 65.7 & 58.2 & 52.3 & 48.9 & 48.4 & 46.6 & 43.3 & 38.3 \\
Point B & 57.0 & 54.0 & 43.5 & 42.6 & 42.0 & 38.2 & 33.6 & 29.1 \\
\hline
\end{tabular}

Table 5: Background noise level - Location 1 
The impulse response test measurements were carried out with the microphone at Point A and Point B. Two sets of measurements were done for each point location. The results found for the reverberation time (T15 and T30), the sound pressure level (SPL), and clarity (C80) are averaged follows in Table 6.

\begin{tabular}{cc|cccccccc}
\hline \multirow{2}{*}{\multicolumn{2}{c|}{ Location 1_Average }} & \multicolumn{8}{c}{ Center Frequency } \\
\cline { 3 - 9 } & & $\mathbf{6 3}$ & $\mathbf{1 2 5}$ & $\mathbf{2 5 0}$ & $\mathbf{5 0 0}$ & $\mathbf{1 0 0 0}$ & $\mathbf{2 0 0 0}$ & $\mathbf{4 0 0 0}$ & $\mathbf{8 0 0 0}$ \\
\hline $\begin{array}{c}\text { Reverberation Time } \\
\text { Relative Sound } \\
\text { Distribution } \\
\text { Clarity }\end{array}$ & seconds & 0.39 & 0.49 & 0.67 & 0.72 & 0.80 & 0.81 & 0.79 & 0.66 \\
& decibel & 37.9 & 34.2 & 23.7 & 21.4 & 20.9 & 13.7 & 10.9 & 14.9 \\
& decibel & 10.9 & 11.6 & 11.3 & 10.2 & 9.0 & 9.2 & 9.1 & 10.7 \\
\hline
\end{tabular}

Table 6: Average Acoustic Measurements of Location1

The noise from the waterfall further affected the reverberation time measurements conducted for the lower frequency ranges. However, excluding the lower frequency values, the reverberation time obtained from the measurements have close values to the recommended design values for the volume of the restaurant space.

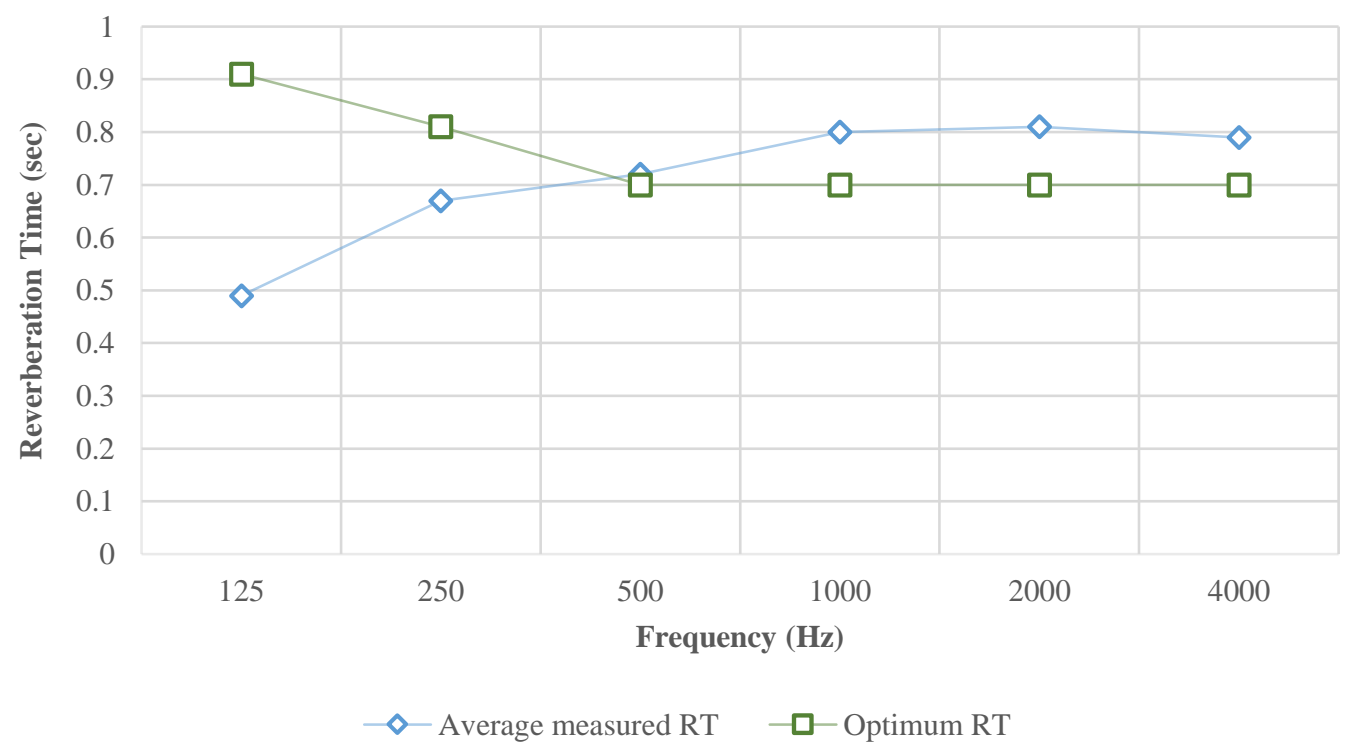

Figure 12: Comparing measured RT to Optimum RT for Location 1

The obtained measurements of the clarity index (C80) show values that reach the extreme end of the acceptable range $(-5$ to $+10 \mathrm{~dB})$, where the values are 9.0 to $11.6 \mathrm{~dB}$. This indicates that the quality of clarity of the sound reaching the listener is slightly "muddy". 
The relative sound distribution measured at Point A and Point B demonstrate an average range of $\pm 5 \mathrm{~dB}$ across the frequencies, slightly exceed the ideal $\pm 3 \mathrm{~dB}$ value.

\subsubsection{Room Criteria Curves for Location One}

The background noise levels across the octave band center frequencies measured in Location One are averaged and plotted to define the RC number of the space. The Room Criteria rating for Location one is RC-49 and is defined by choosing the highest value on the curves, as shown plotted in the figure below. This rating is higher than the recommended RC-40 for a restaurant dining room space indicated in Table 3. As mentioned earlier, the background noise level at this location was highly influenced with the presence of the waterfall running adjacent to the living wall installed. The mechanical system maintaining the filter of the living wall (fan and pump) had additionally affected the measurements carried out, and the respective $\mathrm{RC}$ rating.
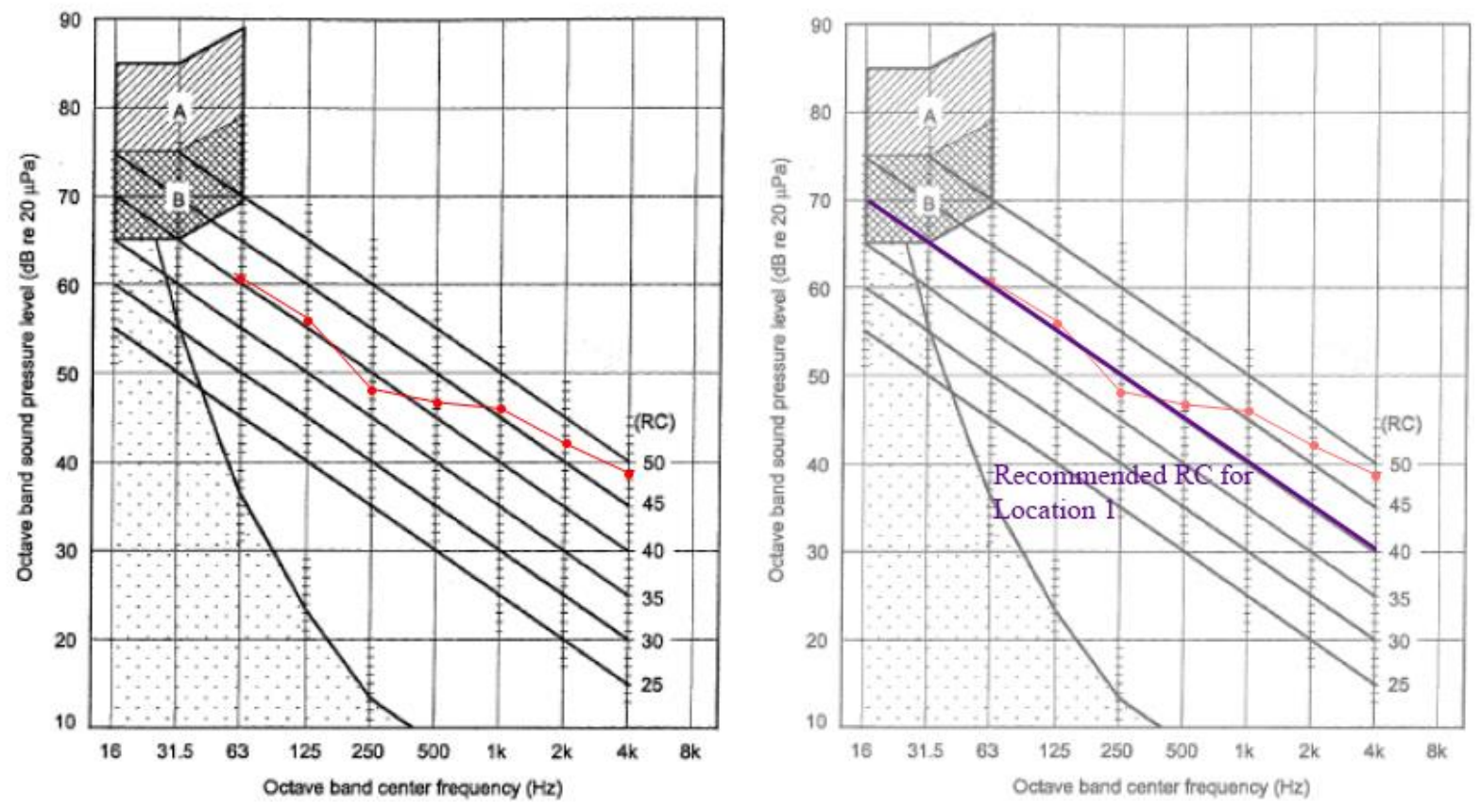

Figure 13: RC rating for Location 1 


\subsubsection{Calculating the absorption coefficient of the living wall}

The absorption coefficient of the living wall is calculated using the results obtained from the testing carried out in this location. Using the Sabine equation, the reverberation time is given through the measurements, the surface areas of the materials within the space and their respective absorption coefficients are inserted into the calculation to obtain the overall absorption of the room, with the only unknown being the absorption coefficient of the living wall.

$$
R T=\frac{0.16 V}{S \alpha_{1}+S \alpha_{2}+\cdots+S \alpha_{L I V I N G ~ W A L L}}
$$

Rearranging the equation to solve for the absorption coefficient of the living wall, it becomes:

$$
\alpha_{\text {LIVING WALL }}=\frac{\left[\left[\frac{0.16 V}{R T}\right]-\left[S \alpha_{1}+S \alpha_{2}+\cdots S \alpha_{n}\right]\right]}{S_{L I V I N G} W A L L}
$$

Figure 15 illustrates the 3D model of the space, labelling the main surfaces.

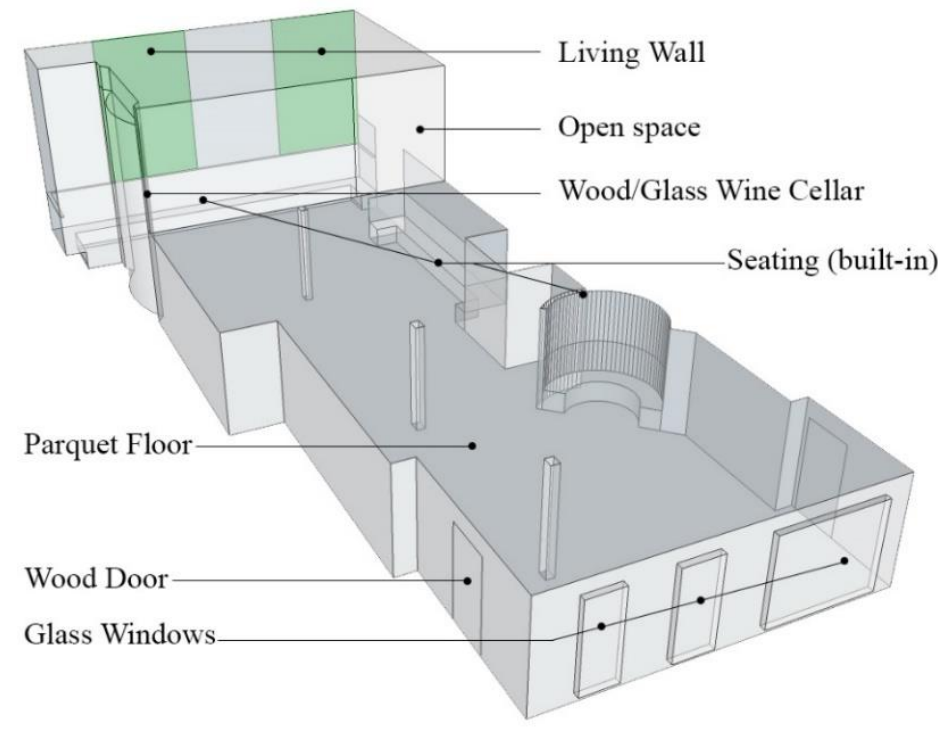

Figure 14: Restaurant 3D model with material surfaces

As acoustics are a function of frequency, Table 7 demonstrates the calculations for the absorption coefficient of the living wall per Equation 2, across the frequency ranges from $125 \mathrm{~Hz}$ to $4000 \mathrm{~Hz}$. The absorption coefficient of each surface is multiplied by its area, and are summed to obtain $\mathrm{A}_{0}$, which excludes the living wall. 


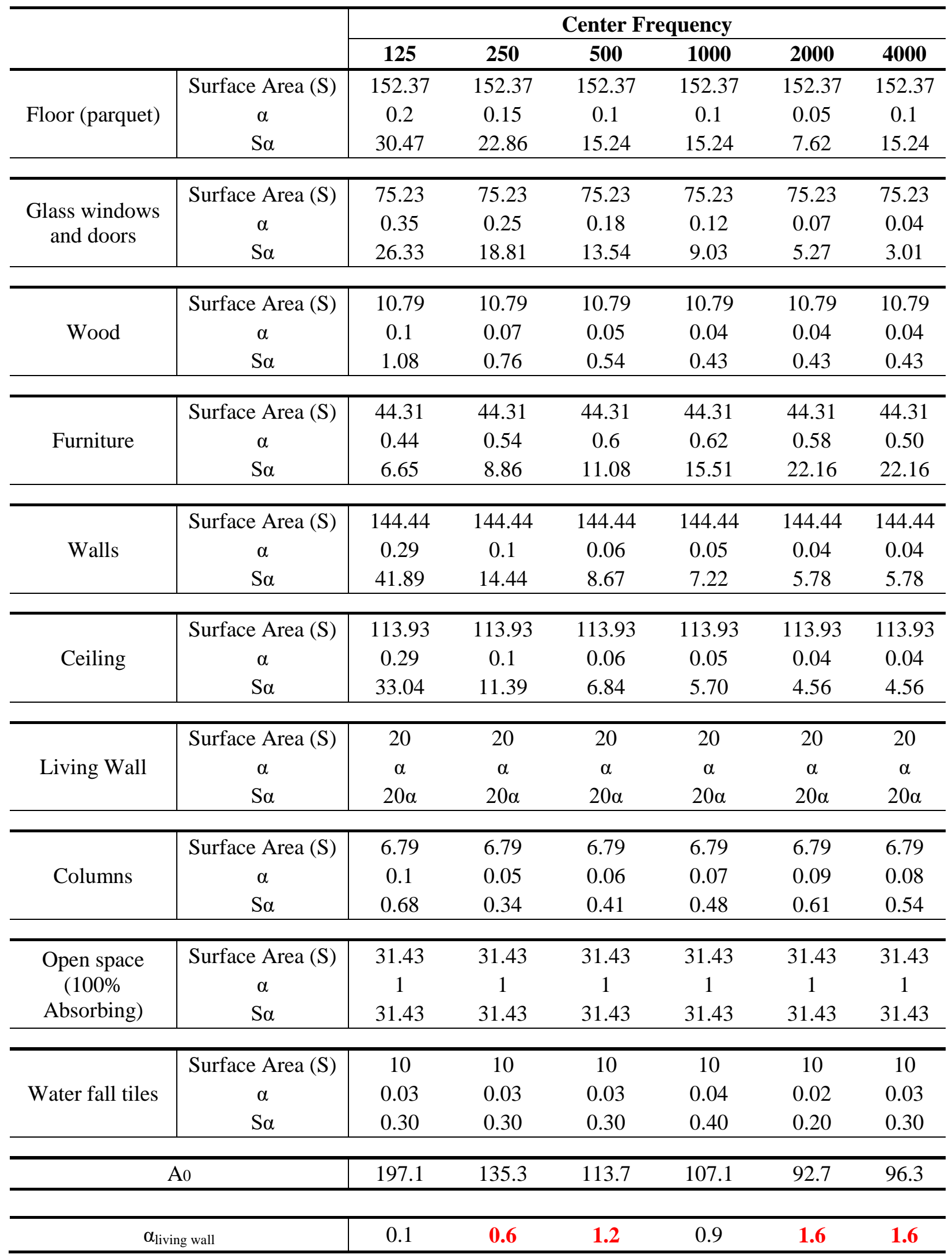

Table 6: Sabine Calculation Method for Absorption Coefficient of Living Wall 
The obtained values for the absorption coefficient of the wall are comparable to those found by Thomazelli et al. [18] in their experimentation for frequencies of $125 \mathrm{~Hz}$ and $1000 \mathrm{~Hz}$. However, the absorption coefficient at 250 and $500 \mathrm{~Hz}$ demonstrated a higher calculated value. This is justified by the high background noise due to the waterfall running, in addition to the equipment running the living wall (fan and pump installed behind the wall). Additionally, the absorption at $2000 \mathrm{~Hz}$ and $4000 \mathrm{~Hz}$ were higher than 1.00, which would be ultimately reduced to 1.00 as the absorption coefficient ranges from 0 to 1.00 .

The comparison is possible as living wall researched by Thomazelli et al. has a modular system with felt holding in a substrate and the plants inserted into it, which has a similar assembly as that of the installed living walls researched in this study.

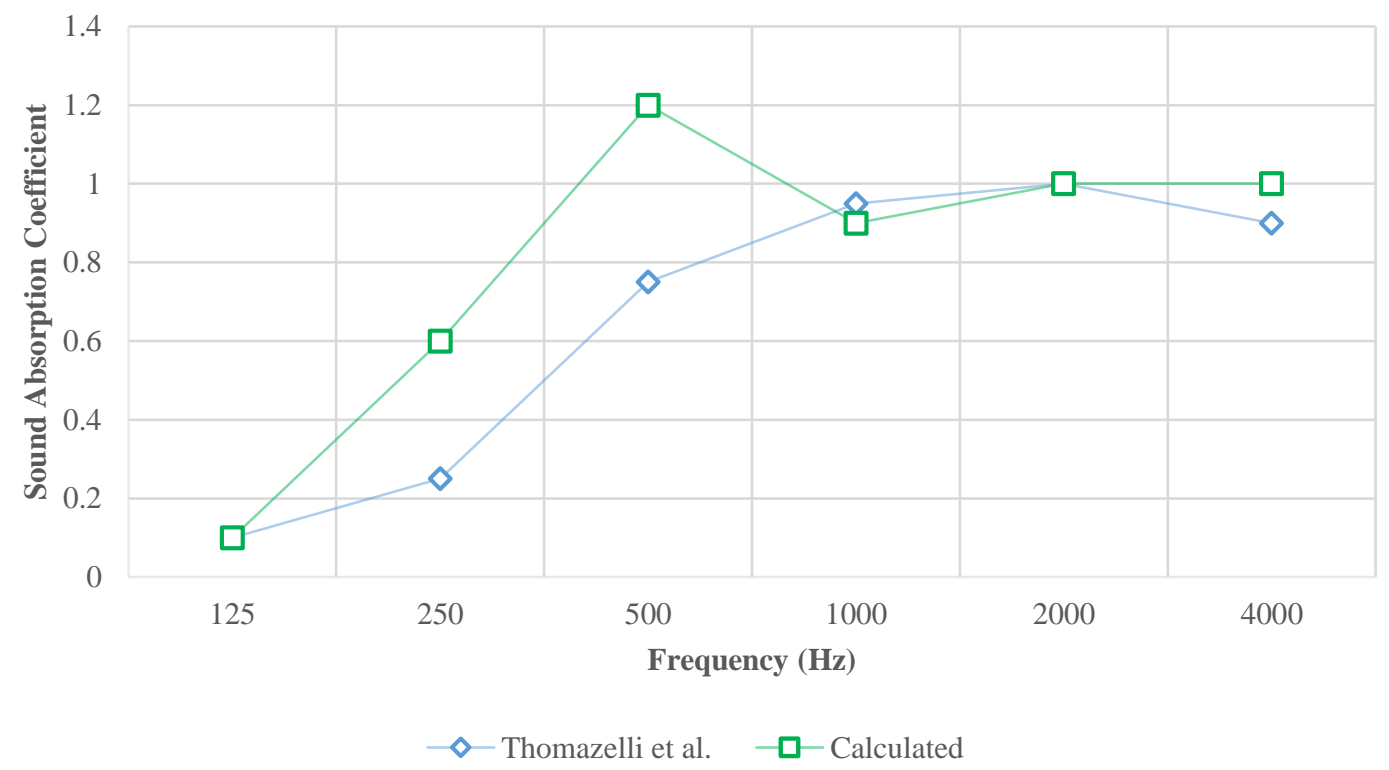

Figure 15: Comparing the calculated absorption coefficient of the living wall from the measurements done at location 1, with that found in the literature review from Thomazelli et al [18]

Hence, the absorption coefficient of the living wall could be deduced as in Table 8 , and these values are further used in this research in the acoustic simulation and modelling.

\begin{tabular}{l|cccccc}
\hline \multirow{2}{*}{} & \multicolumn{6}{|c}{ Center Frequency } \\
\cline { 2 - 6 } & $\mathbf{1 2 5}$ & $\mathbf{2 5 0}$ & $\mathbf{5 0 0}$ & $\mathbf{1 0 0 0}$ & $\mathbf{2 0 0 0}$ & $\mathbf{4 0 0 0}$ \\
\hline Living Wall Absorption coefficient & 0.1 & $\mathbf{0 . 2 5}$ & $\mathbf{0 . 7 0}$ & 0.9 & 1.00 & 1.00 \\
\hline
\end{tabular}

Table 7: Calibrated Absorption Coefficient of Living Wall 
The deduction is calibrated with the values from Thomazelli et al., eliminating the possible errors that might have resulted in the measurements made, and therefore aligning the values.

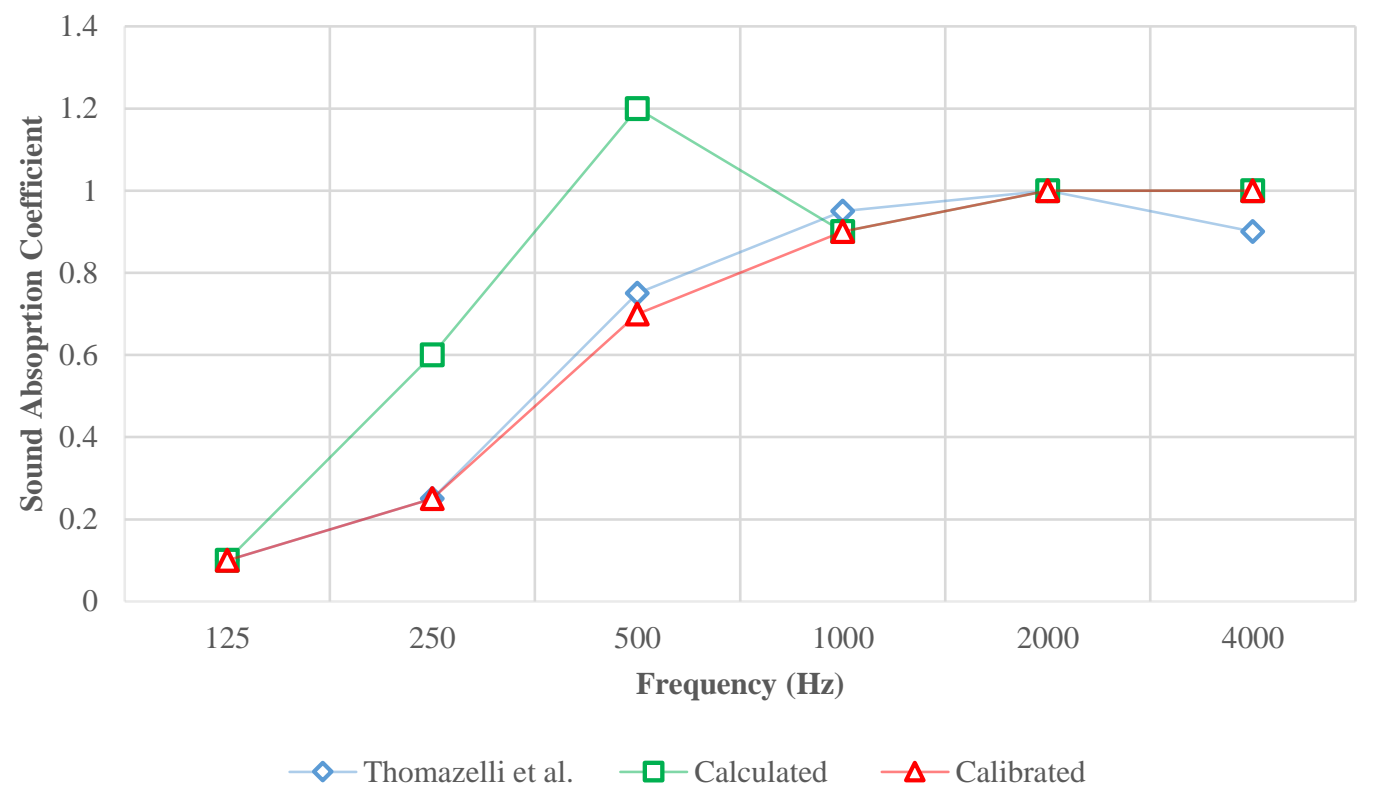

Figure 16: Calibrated Absorption Coefficient of the Living Wall 


\subsection{LOCATION TWO:}

Constructed in 2006, the building holds a Gold LEED $^{\odot}$ certification and is designed with the initiative to value the sacredness of the Earth. The living wall installed in the main lobby outside the chapel space responds to the vision set by the architect and building consultants.

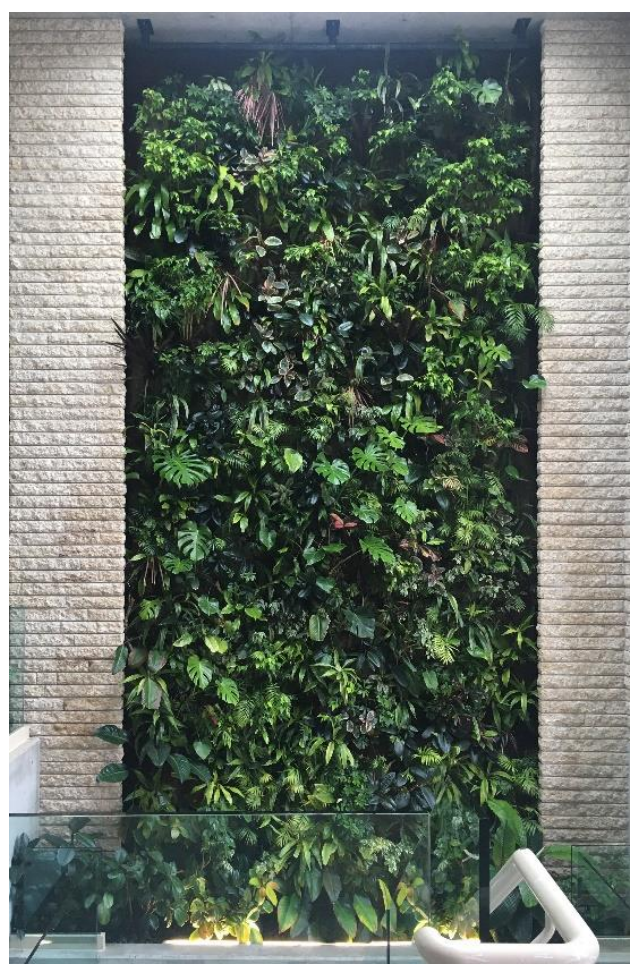

Figure 17: Living Wall - Location 1

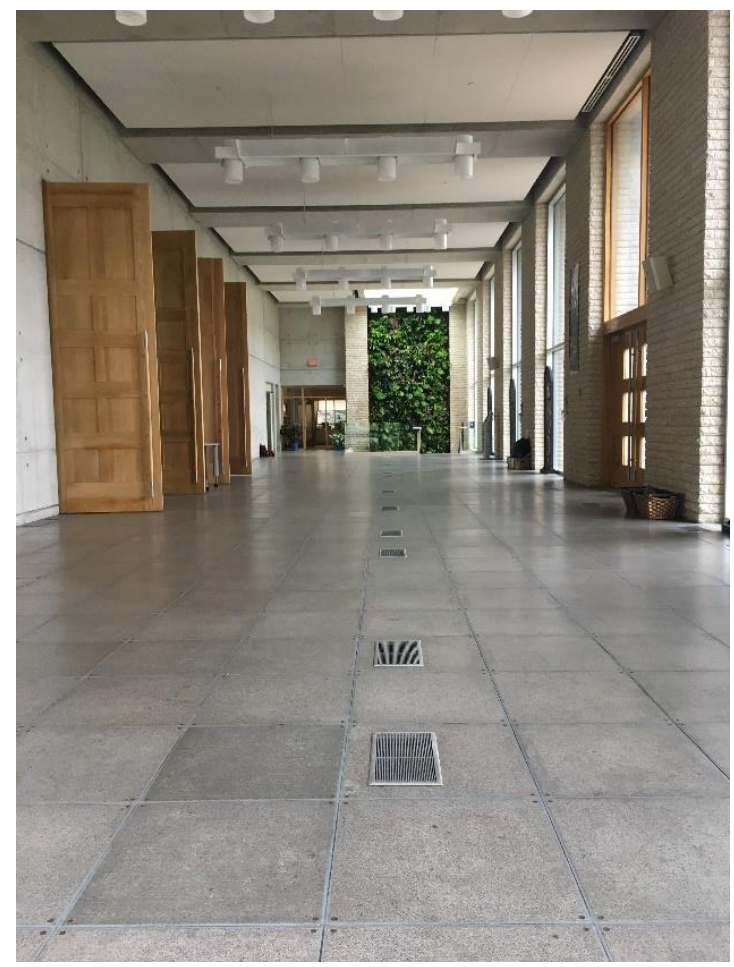

Figure 18: Main Lobby with Living Wall - Location 1

The area of the living wall is $21 \mathrm{~m}^{2}$ [3m x 7m] and the floor area of the entire space is $246 \mathrm{~m}^{2}$ [31.5m x $7.8 \mathrm{~m}$ ] with a height of $5.7 \mathrm{~m}$, resulting in a volume of $1400 \mathrm{~m}^{3}$. The living wall is situated at the landing of the staircase between the main floor and the lower floor.

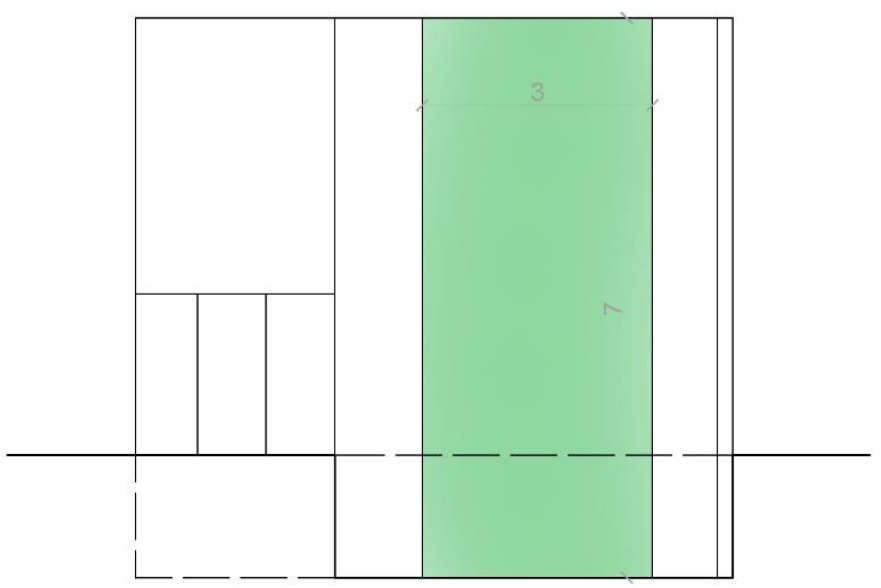

Figure 19: Location 2 - Diagrammatic Elevation 


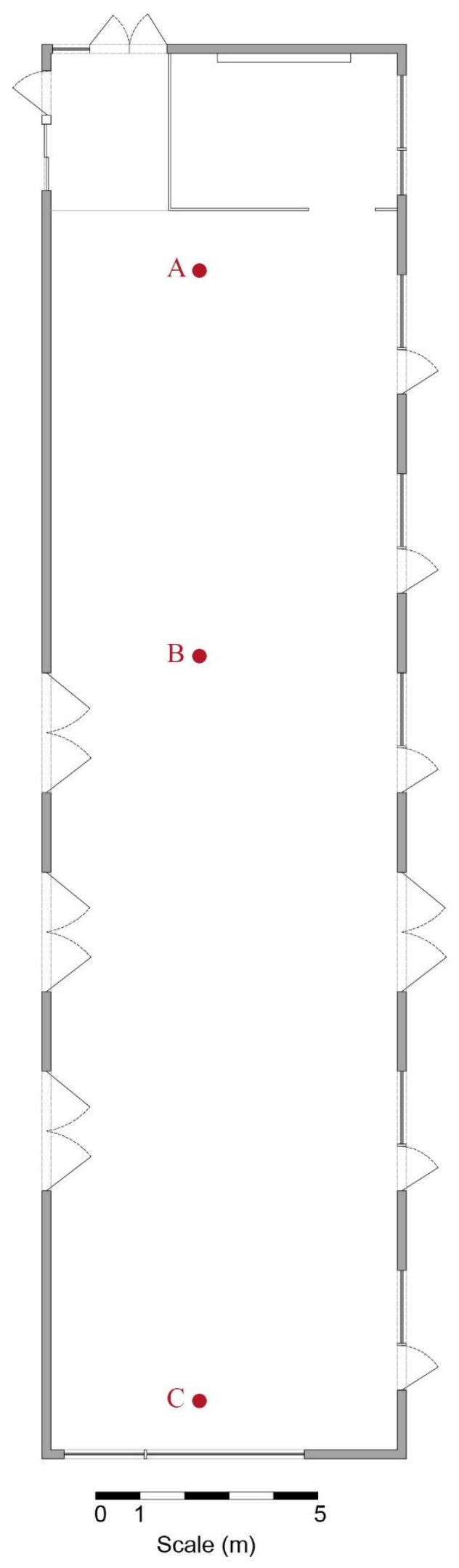

Figure 20: Location 2 - Floor Plan 


\subsubsection{Measurement Results for Location Two}

The background noise level was measured at 3 points within the space, as shown in Figure 12, and the table below demonstrates the values obtained across the center frequencies. The A-weighted average for Point A is $46.4 \mathrm{dBA}$, Point B is $45.4 \mathrm{dBA}$, and Point $\mathbf{C}$ is $45.6 \mathrm{dBA}$.

\begin{tabular}{c|cccccccc}
\hline $\begin{array}{c}\text { Location 2_Measured } \\
\text { Background Noise Level } \\
(\mathbf{d B})\end{array}$ & $\mathbf{8}$ Center Frequency \\
\cline { 2 - 9 } & $\mathbf{6 3}$ & $\mathbf{1 2 5}$ & $\mathbf{2 5 0}$ & $\mathbf{5 0 0}$ & $\mathbf{1 0 0 0}$ & $\mathbf{2 0 0 0}$ & $\mathbf{4 0 0 0}$ & $\mathbf{8 0 0 0}$ \\
\hline Point A & 54.9 & 52.9 & 47.6 & 43.1 & 40 & 38.7 & 33.9 & 29.5 \\
Point B & 55.5 & 51.4 & 45.8 & 42 & 39.5 & 38.1 & 32.6 & 28 \\
Point C & 56.1 & 51.2 & 48 & 43.8 & 39.7 & 36.2 & 30 & 24.2 \\
\hline
\end{tabular}

Table 8: Background Noise Level - Location 1

The impulse response test measurements were carried out with the microphone at Point A and Point B. Two sets of measurements were done for each point location. The results found for the reverberation time (T15 and T30), the sound pressure level (SPL), and clarity (C80) are as follows in Table 10.

\begin{tabular}{cc|cccccccc}
\hline \multirow{2}{*}{\multicolumn{1}{c|}{ Location 2_Average }} & \multicolumn{8}{c}{ Center Frequency } \\
\cline { 3 - 9 } & $\mathbf{6 3}$ & $\mathbf{1 2 5}$ & $\mathbf{2 5 0}$ & $\mathbf{5 0 0}$ & $\mathbf{1 0 0 0}$ & $\mathbf{2 0 0 0}$ & $\mathbf{4 0 0 0}$ & $\mathbf{8 0 0 0}$ \\
\hline $\begin{array}{c}\text { Reverberation Time } \\
\text { Relative Sound } \\
\text { Distribution } \\
\text { Clarity }\end{array}$ & seconds & $*$ & 1.35 & 1.40 & 1.47 & 1.45 & 1.46 & 1.23 & 0.95 \\
& decibel & 41.0 & 37.2 & 26.6 & 24.8 & 24.8 & 19.0 & 16.5 & 20.7 \\
\hline
\end{tabular}

Table 9: Average of Acoustic Measurements - Location 2

While the measured reverberation time and sound pressure level of the space is higher than the optimum values for the volume and use identified for the space, the clarity of sound lies within the ideal range of -5 to $+10 \mathrm{~dB}$, verifying good speech intelligibility between the listener and the sound source.

As the living wall in this location was accessible for covering, two additional sets of impulse response testing were executed, to obtain values that facilitate the calculation of the absorption coefficient of the living wall. Quarter-inch MDF boards were used to cover $3.70 \mathrm{~m}^{2}$ portion, more than $15 \%$ of the living wall's total area. 
An increase in the reverberation time of the space is observed when covering a small portion of the living wall, justifying its effective acoustic absorption. Hence, it can be predicted that covering the entire wall or replacing its surface area would ultimately affect the acoustic performance of the space, further increasing the reverberation time and reducing the sound absorption. It is further observed that the average measured reverberation time of the space is higher than the optimum guideline reverberation time.

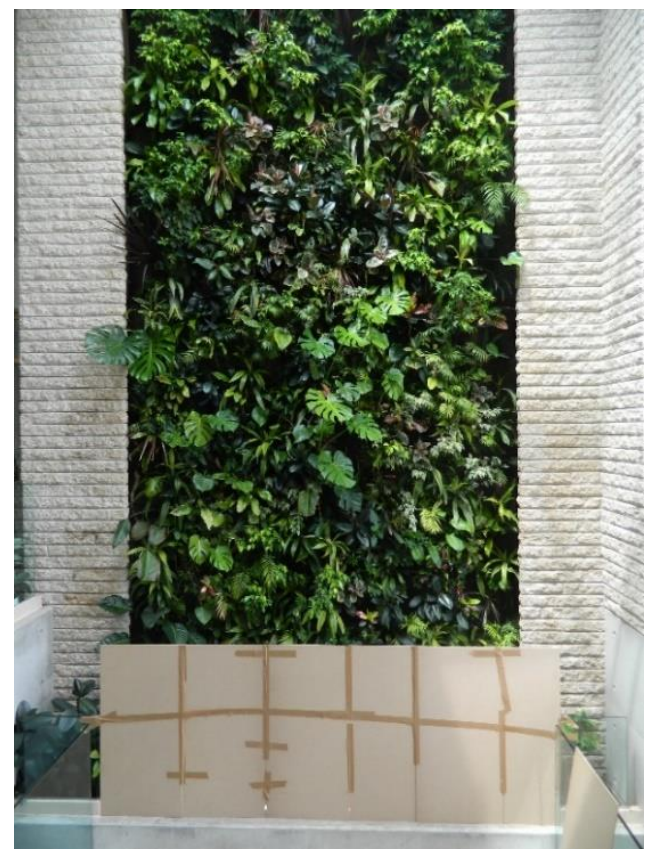

Figure 21: Testing with covered portion Location 2

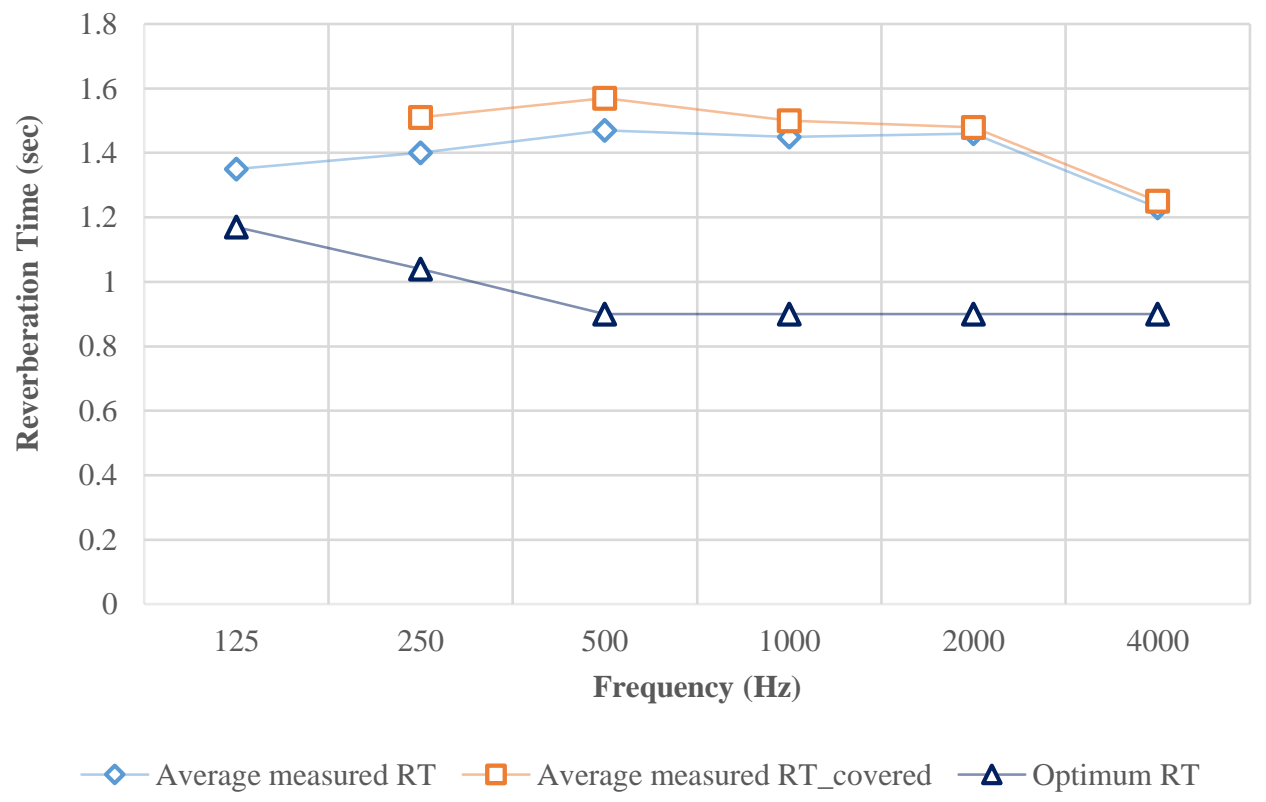

Figure 22: Comparing average measured RT, covered and uncovered, with Optimum RT for Location 2 


\subsubsection{Room Criteria Curves for Location Two}

The Room Criteria rating for the church common area is identified as RC-42, through the plotted graph shown below. It is observed much higher than the recommended RC-25 for this location. This is justified by the presence of construction materials identified as 'hard' or sound 'reflective' surfaces, such as the concrete, glass, brick and floor tiles, which cause the reverberation within the space to be higher. The installed living wall area is not as significant when compared to the other surface areas, having a minor effect on the acoustic properties of the space.
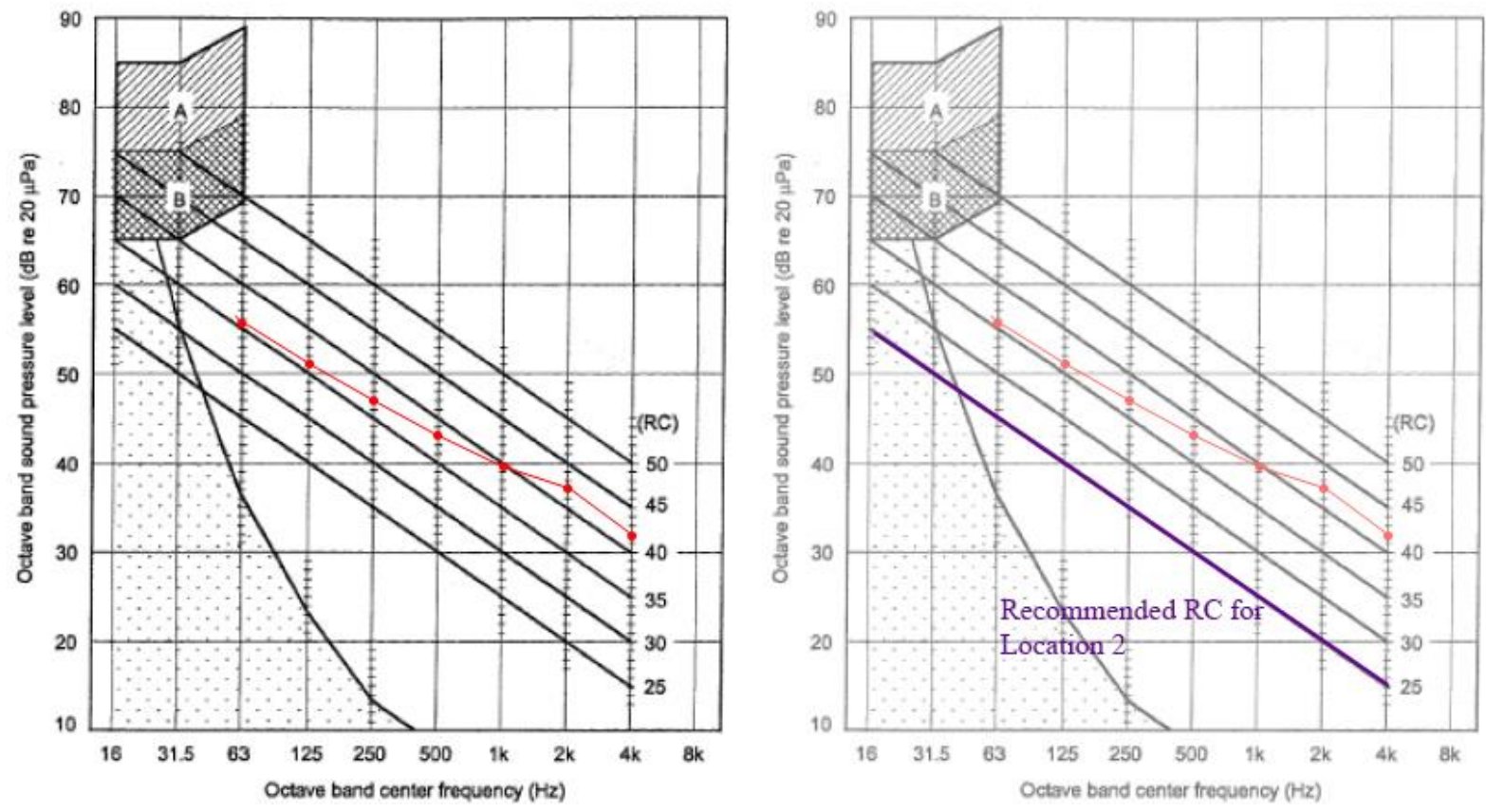

Figure 23: RC rating for Location 2

While this location does not have a waterfall running along side the living wall, the mechanical systems of the wall had an effect on the obtained results, in addition to the significant surface areas of hard, reflective materials. 


\subsection{LOCATION THREE:}

Installed in 2013, the living wall at the community center is integrated as part of the driving initiative of the building: encouraging a healthy community space. The greenery of the wall and the adjacent water fall add an organic life to the interior of the space, inviting the users of the space, as it is located at the entrance of the building.

The living wall covers an area of $14 \mathrm{~m}^{2}$ [ $\left.2 \mathrm{~m} \times 7 \mathrm{~m}\right]$, and spans two storeys with its position in the staircase atrium. However, the lower portion of the wall is obstructed with glass railing of the stairs, which ultimately could cause a discrepancy in the acoustic measurements carried out.

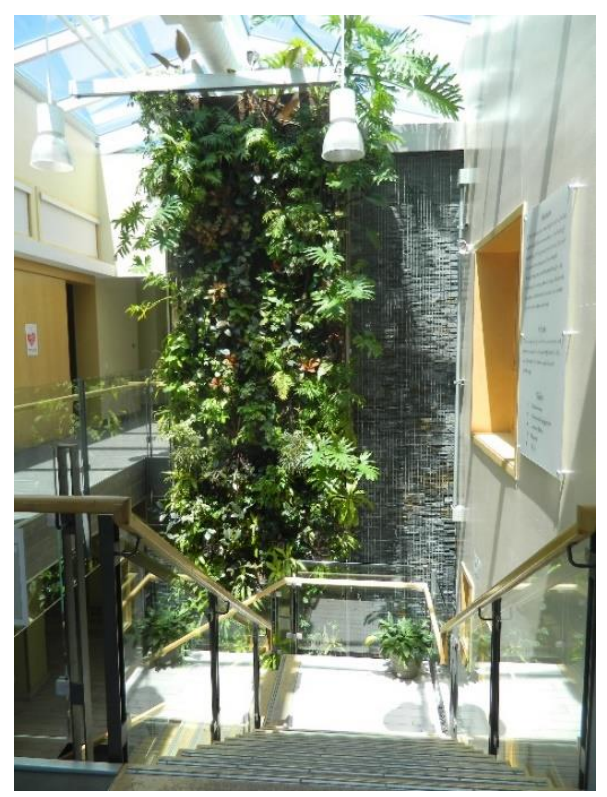

Figure 24: Living Wall - Location 3

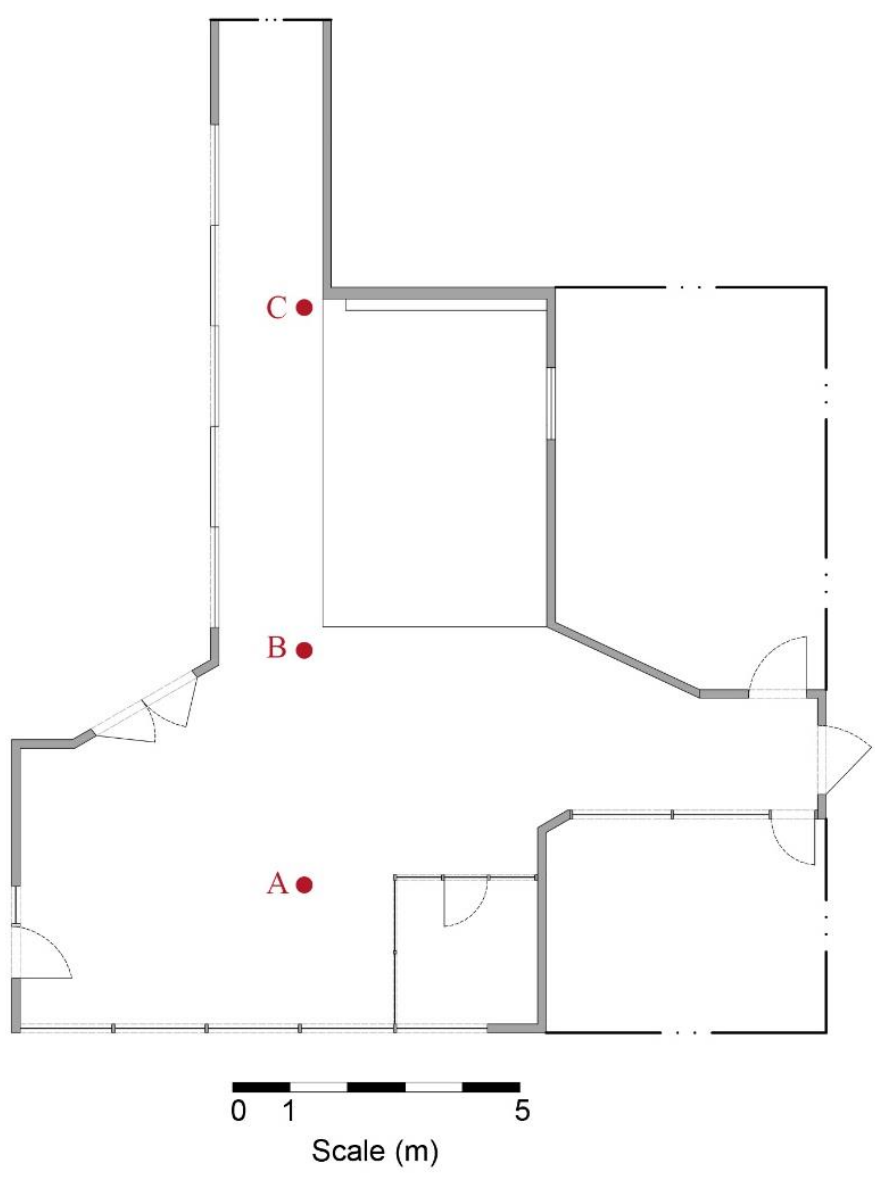

Figure 25: Location 3 - Floor Plan 


\subsubsection{Measurement Results for Location Three}

The background noise level was measured at 3 points on the main floor level, as shown in Figure 16, and the table below illustrate the results across the center frequencies. The A-weighted average for Point A is $56.1 \mathrm{dBA}$, Point B is $59.0 \mathrm{dBA}$, and Point $\mathbf{C}$ is $56.3 \mathrm{dBA}$.

\begin{tabular}{c|cccccccc}
\hline $\begin{array}{c}\text { Location 3_Measured } \\
\text { Background Noise Level } \\
(\mathbf{d B})\end{array}$ & \multicolumn{8}{|c}{ Center Frequency } \\
\cline { 2 - 9 } & $\mathbf{6 3}$ & $\mathbf{1 2 5}$ & $\mathbf{2 5 0}$ & $\mathbf{5 0 0}$ & $\mathbf{1 0 0 0}$ & $\mathbf{2 0 0 0}$ & $\mathbf{4 0 0 0}$ & $\mathbf{8 0 0 0}$ \\
\hline Point A & 61.0 & 63.7 & 55.4 & 50.1 & 47.3 & 48.0 & 48.6 & 47.7 \\
Point B & 65.5 & 70.0 & 59.0 & 50.7 & 48.5 & 49.6 & 50.7 & 50.2 \\
Point C & 59.6 & 61.7 & 56.2 & 50.3 & 48.4 & 48.4 & 48.9 & 47.4 \\
\hline
\end{tabular}

Table 10: Background Noise Level - Location 3

The impulse response measurements were conducted at Point B and Point C. Two sets of measurements were done for each point location. The results of the measurements are as follows in Table 14.

\begin{tabular}{|c|c|c|c|c|c|c|c|c|c|}
\hline \multirow{2}{*}{\multicolumn{2}{|c|}{ Location 3_Average }} & \multicolumn{8}{|c|}{ Center Frequency } \\
\hline & & \multirow{2}{*}{$\frac{\mathbf{6 3}}{*}$} & \multirow{2}{*}{$\frac{125}{*}$} & \multirow{2}{*}{$\frac{250}{1.15}$} & \multirow{2}{*}{$\frac{\mathbf{5 0 0}}{1.30}$} & \multirow{2}{*}{$\frac{1000}{1.38}$} & \multirow{2}{*}{$\frac{2000}{1.28}$} & \multirow{2}{*}{$\frac{4000}{1.22}$} & \multirow{2}{*}{$\frac{8000}{1.05}$} \\
\hline Reverberation Time & seconds & & & & & & & & \\
\hline $\begin{array}{l}\text { Relative Sound } \\
\text { Distribution }\end{array}$ & decibel & $*$ & 33.1 & 21.8 & 17.8 & 16.7 & 10.4 & 6.8 & 12.2 \\
\hline Clarity & decibel & $*$ & 7.9 & 5.3 & 1.5 & -11.4 & -35.0 & 37.4 & -34.4 \\
\hline
\end{tabular}

Table 11: Average of Acoustic Measurements - Location 3

As observed from the results of the acoustic measurements, the presence of the waterfall in this location lead to an increased background noise level, affecting the measurements in the lower frequency range. Additionally, it lead to an increased reverberation time and overall sound pressure level, in comparison with the optimum values for the space.

The clarity of sound within the space measured for the lower frequency ranges $125-500 \mathrm{~Hz}$, demonstrate acceptable values, while the values in the higher frequency ranges of $2000-8000 \mathrm{~Hz}$ exceed the ideal values significantly, causing the sound reaching the listener to be highly 'muddy' with minor intelligibility. 


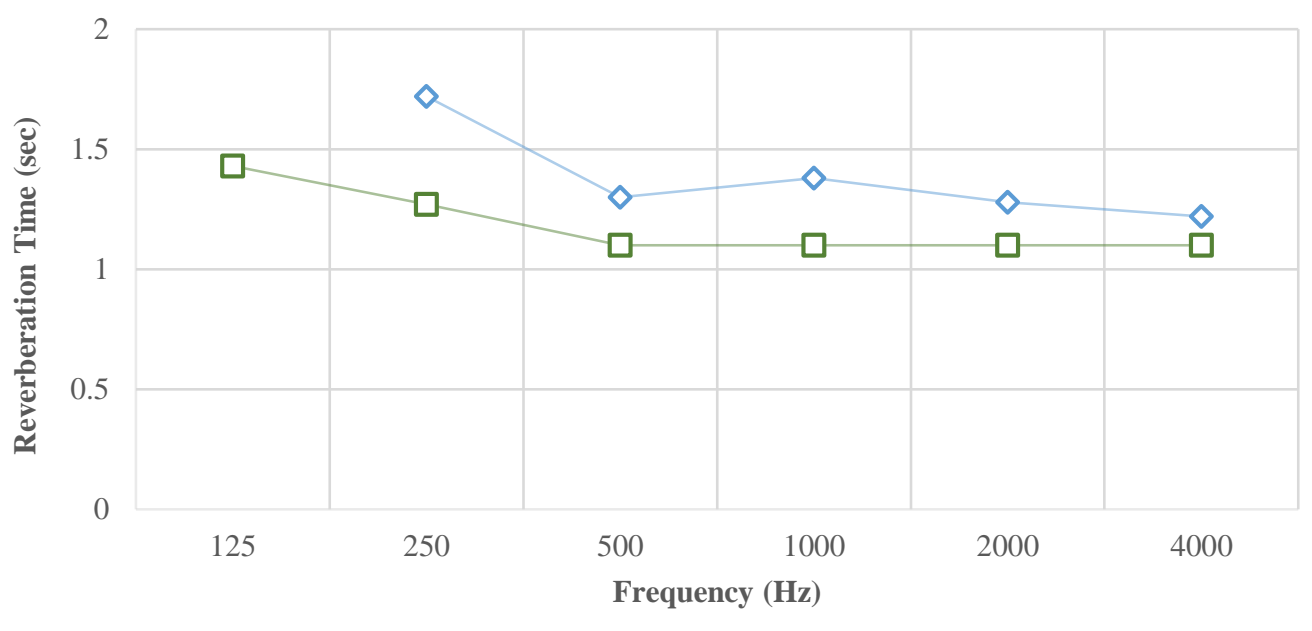

$\diamond$ Average measured RT $\quad-\quad$ Optimum RT

Figure 26: Comparing measured and optimum reverberation time for Location 3

\subsubsection{Room Criteria Curves for Location Three}

The Room Criteria is evaluated as RC-54 for this location, which is higher than the recommended RC-40. In this case, the effect of the waterfall had a significant impact on the results of the conducted measurements, raising the sound pressure level in the lower and higher frequency ranges much higher than the ideal values.
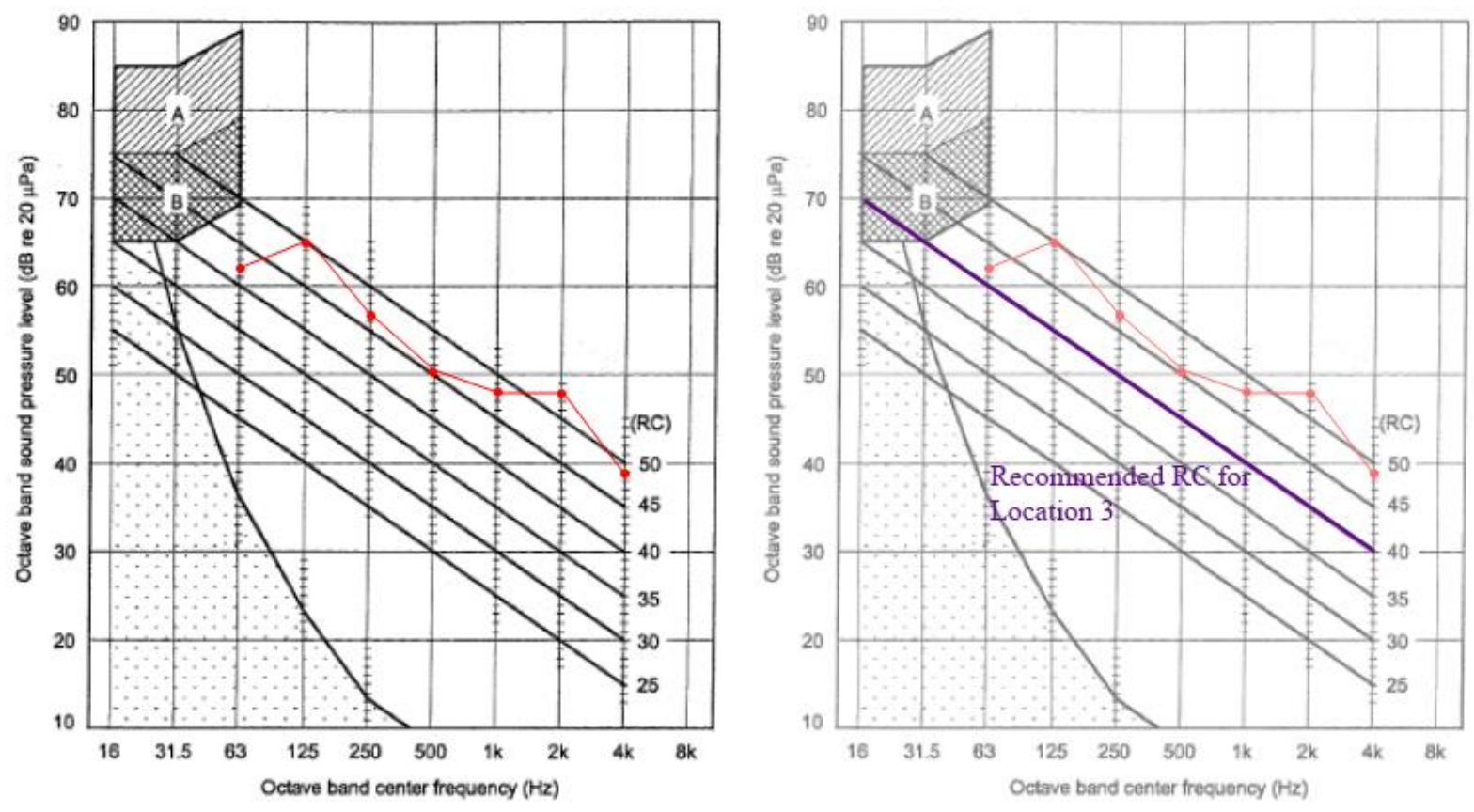

Figure 27: RC rating for Location 3 


\subsection{LOCATION FOUR:}

Installed in 2016, the living wall in the library is positioned in the vast atrium that opens into the four floors of the building. The ground floor is a main common space used by all the students and faculty. The space is flanked on both sides with closed classrooms on the main, first, second and third floors. The living wall covers an area of $126 \mathrm{~m}^{2}$ [8.4 m x $15 \mathrm{~m}$ ], within the open ground floor area of $740 \mathrm{~m}^{2}$. The wall in this location covers the largest area, compared to the other three locations in this research. However, the difference in area is justified with the greater volume of the space.

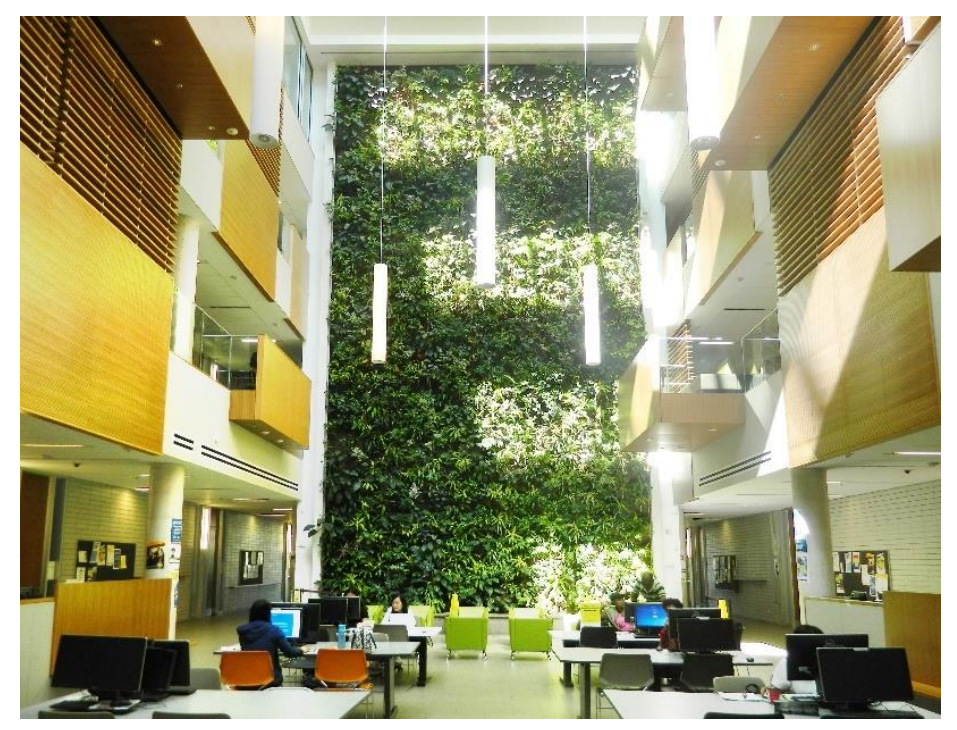

Figure 28: Living Wall - Location 4

The acoustic measurements were carried out after operation hours of the building, to ensure highest accuracy and less disruption due to the presence of occupants within the space.

\subsubsection{Measurement Results for Location Four}

The background noise level was measured at 3 points within the ground floor area, as shown in Figure 19, and the table below demonstrates the values obtained across the center frequencies.

\begin{tabular}{c|cccccccc}
\hline $\begin{array}{c}\text { Location 4_Measured } \\
\text { Background Noise Level } \\
(\text { dB) }\end{array}$ & \multicolumn{8}{|c}{ Center Frequency } \\
\cline { 2 - 9 } & $\mathbf{6 3}$ & $\mathbf{1 2 5}$ & $\mathbf{2 5 0}$ & $\mathbf{5 0 0}$ & $\mathbf{1 0 0 0}$ & $\mathbf{2 0 0 0}$ & $\mathbf{4 0 0 0}$ & $\mathbf{8 0 0 0}$ \\
\hline Point A & 51.8 & 46.1 & 43.9 & 45.5 & 43.4 & 39.9 & 35.7 & 32.3 \\
Point B & 54.8 & 48.2 & 45.1 & 43.6 & 39.6 & 36.0 & 33.0 & 29.5 \\
Point C & 56.4 & 49.8 & 48.8 & 46.0 & 40.2 & 36.9 & 33.9 & 28.5 \\
\hline
\end{tabular}

Table 12: Background Noise Level - Location 4 


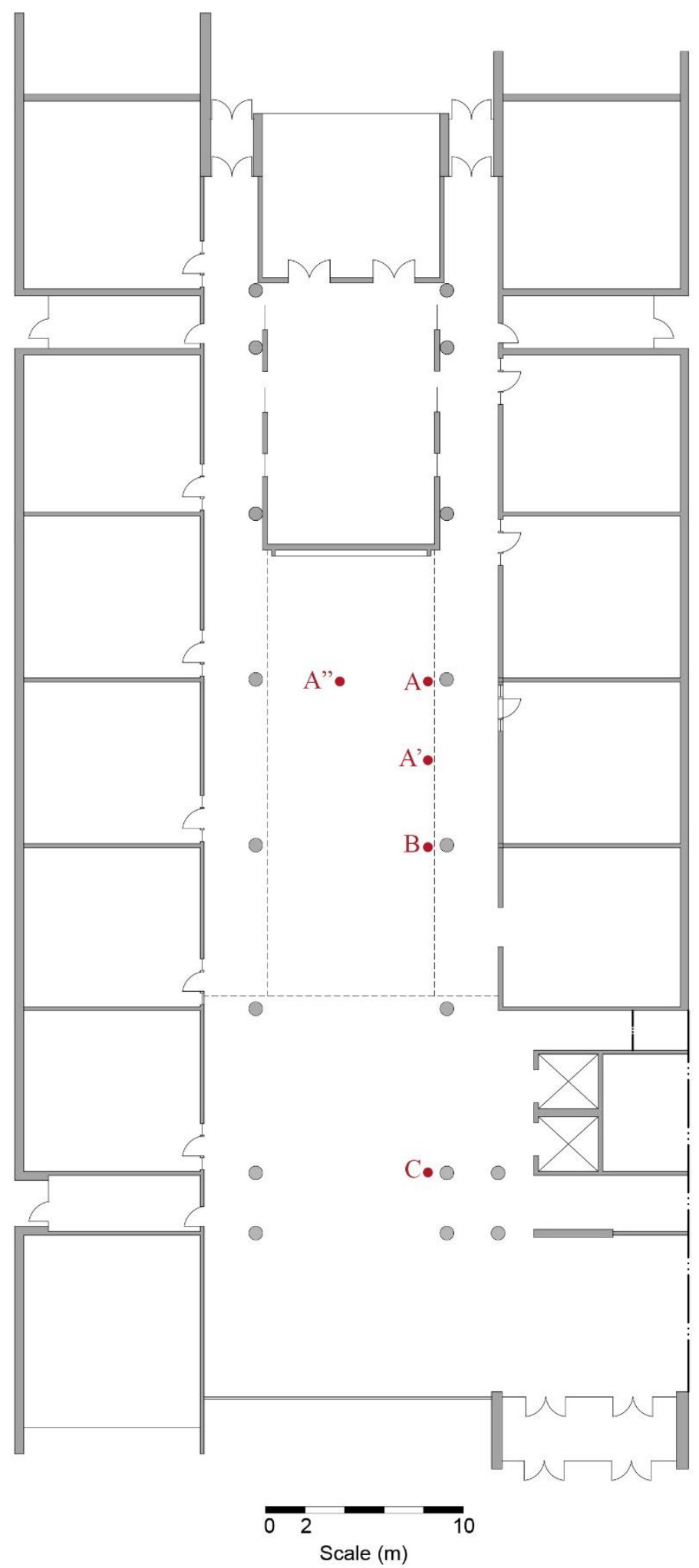

Figure 29: Location 4 - Floor Plan 
The impulse response test measurements were carried out with the microphone at Point A, Point A' and Point A". Two sets of measurements were done for each point location. The results of the measurements are as follows in Table 18.

\begin{tabular}{cc|cccccccc}
\hline \multirow{2}{*}{\multicolumn{1}{c|}{ Location 4_Average }} & \multicolumn{7}{|c}{ Center Frequency } \\
\cline { 2 - 9 } & $\mathbf{6 3}$ & $\mathbf{1 2 5}$ & $\mathbf{2 5 0}$ & $\mathbf{5 0 0}$ & $\mathbf{1 0 0 0}$ & $\mathbf{2 0 0 0}$ & $\mathbf{4 0 0 0}$ & $\mathbf{8 0 0 0}$ \\
\hline $\begin{array}{c}\text { Reverberation Time } \\
\text { Relative Sound } \\
\begin{array}{c}\text { Distribution } \\
\text { Clarity }\end{array}\end{array}$ & seconds & 1.01 & 0.9 & 0.98 & 1.07 & 1.12 & 1.04 & 0.96 & 0.77 \\
& decibel & 38.4 & 35.7 & 27.3 & 24.9 & 24.7 & 17.2 & 13.6 & 18.5 \\
\hline
\end{tabular}

Table 13: Average Measured for Location 4

The sound pressure level and the clarity values demonstrate higher values than the ideal design recommendation, although the average measured RT is lower than the optimum RT. As previously mentioned, having a lower reverberation time will lead to an increase in the clarity of the sound, however that is applicable to a certain degree. The ideal values of RT ensure that the sound reaching the listener has a well-defined clarity.

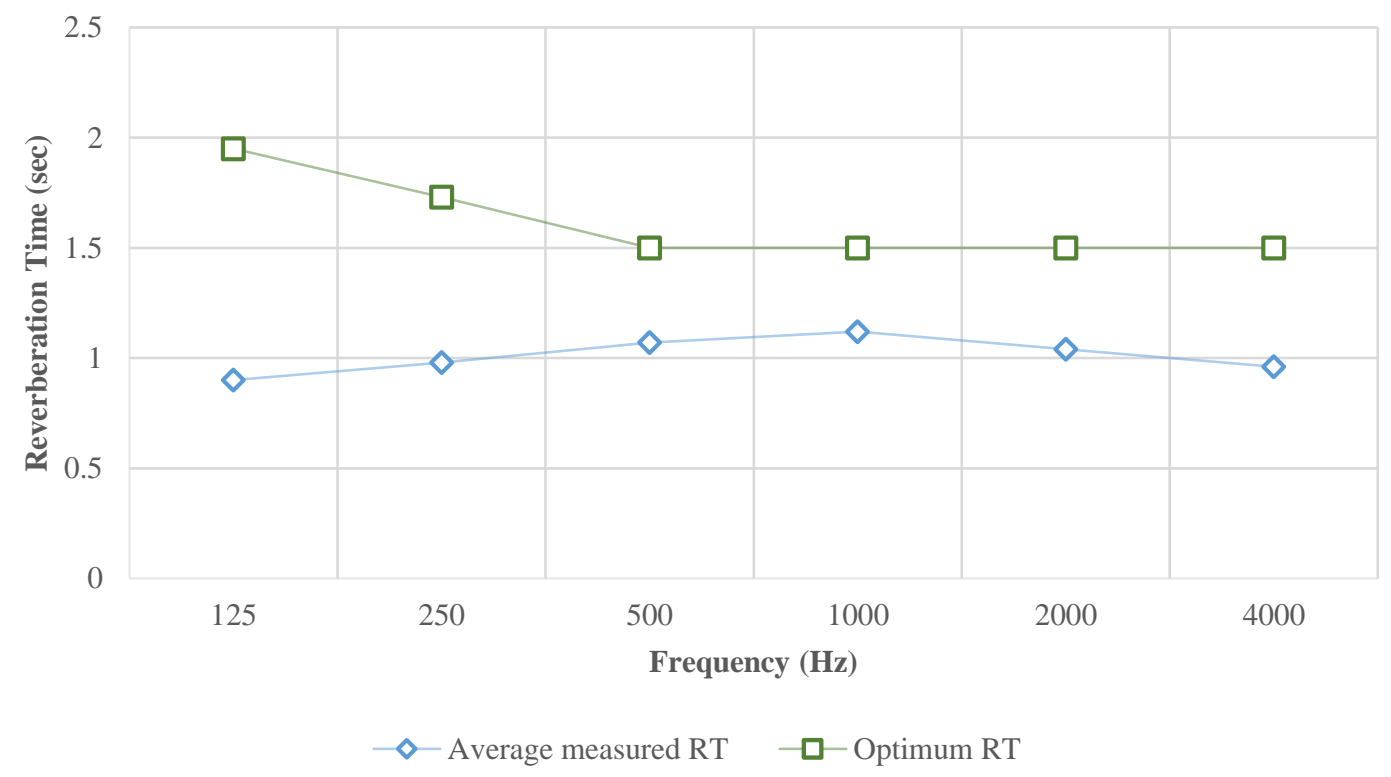

Figure 30: Reverberation Time, average measured and optimum, Location 4 


\subsubsection{Room Criteria Curves for Location Four}

Similar to the previous locations, the evaluated Room Criteria at RC-41 is higher than the recommended value for the space at RC-30. The same trend observed in location 2 , where the majority of the surface area of construction material are hard surfaces, or tile, concrete and glass, have a more significance impact on the overall acoustics of the space, when compared to the effect of the living wall. While the living wall in this location covers a total of $126 \mathrm{~m}^{2}$ and its mechanical system causes an increase in the background noise, this leads to higher sound levels that need to be absorbed across the $740 \mathrm{~m}^{2}$ floor area.
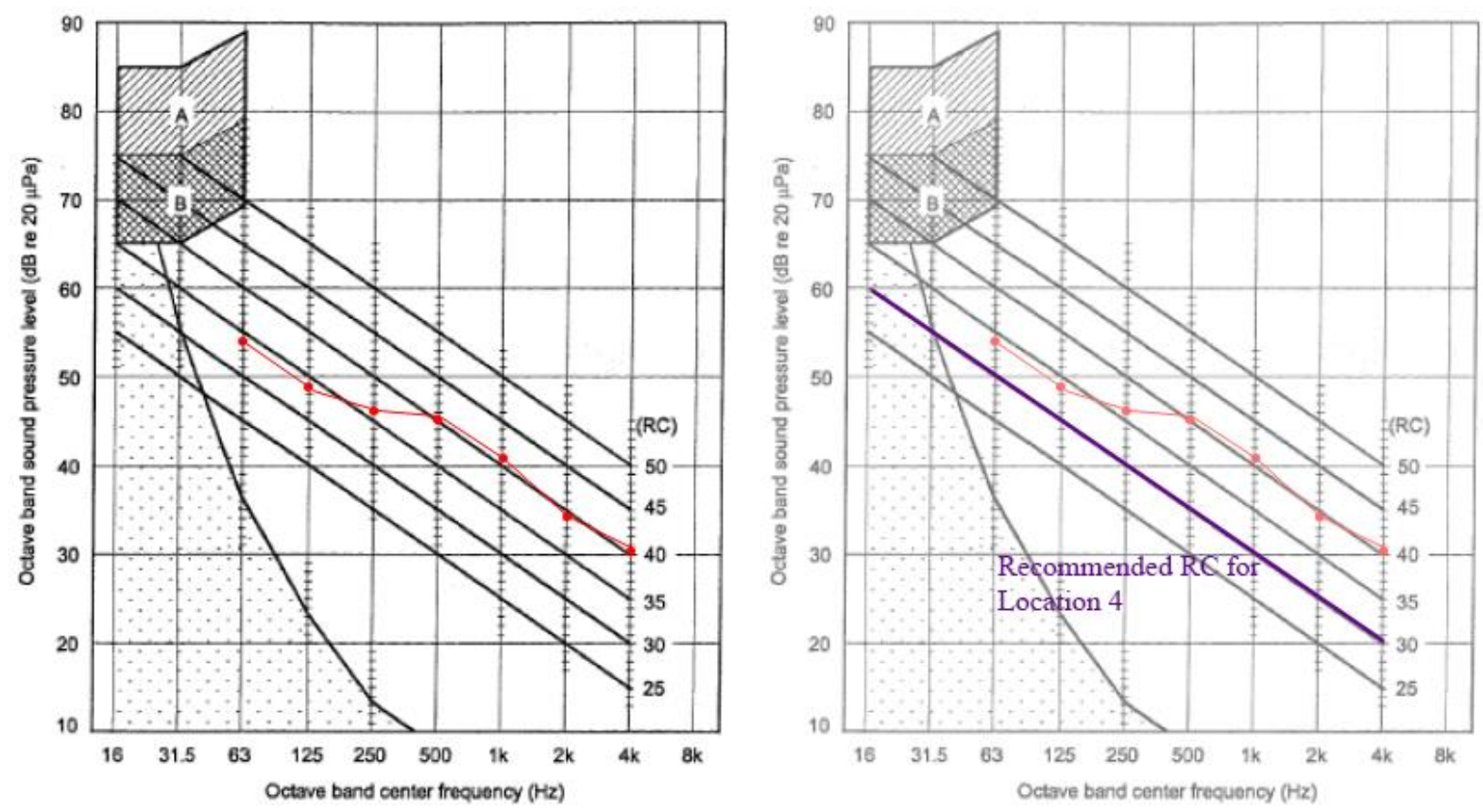

Figure 31: $R C$ rating for Location 4 


\section{ACOustic Modelling}

Covering phases two and three of this research, the acoustic modelling is carried out as a method to obtain simulation results that are as close to reality as possible, and is done through the validation with the results obtained from the acoustic measurements carried out in each of the spaces mentioned in the earlier sections of this report.

Three-dimensional models are created for each of the three locations: the restaurant, the church and the health center. The 3D models are then imported into the simulation software. The various construction and finishing surfaces are grouped into layers of the same material to facilitate the ease of acoustic modelling, and assigned their respective absorption coefficient. All the models are simplified for the purpose of eliminating malfunctions in the simulation, such as furniture and any minor architectural and/or construction details. A new material layer is created in the software database for the living wall, and the calculated absorption coefficients for the frequency ranges (from section 4.1.2) are input. Iterations on the calculated absorption coefficient is made, to evaluate final values that align with measured values.

The following sections demonstrate the simulation for each of the locations, evaluating of each of the spaces, in terms of achieving guidelines for design Noise Criteria and Room Criteria, as well as the required Reverberation Time.

\subsection{Location ONE Simulation}

The initial simulation run showed a higher reverberation time at Point $\mathrm{A}$, corresponding with the point location used for the acoustic measurements, in the frequency range of 500-2000 Hz, and a lower reverberation time in $125-250 \mathrm{~Hz}$ and in $4000 \mathrm{~Hz}$.

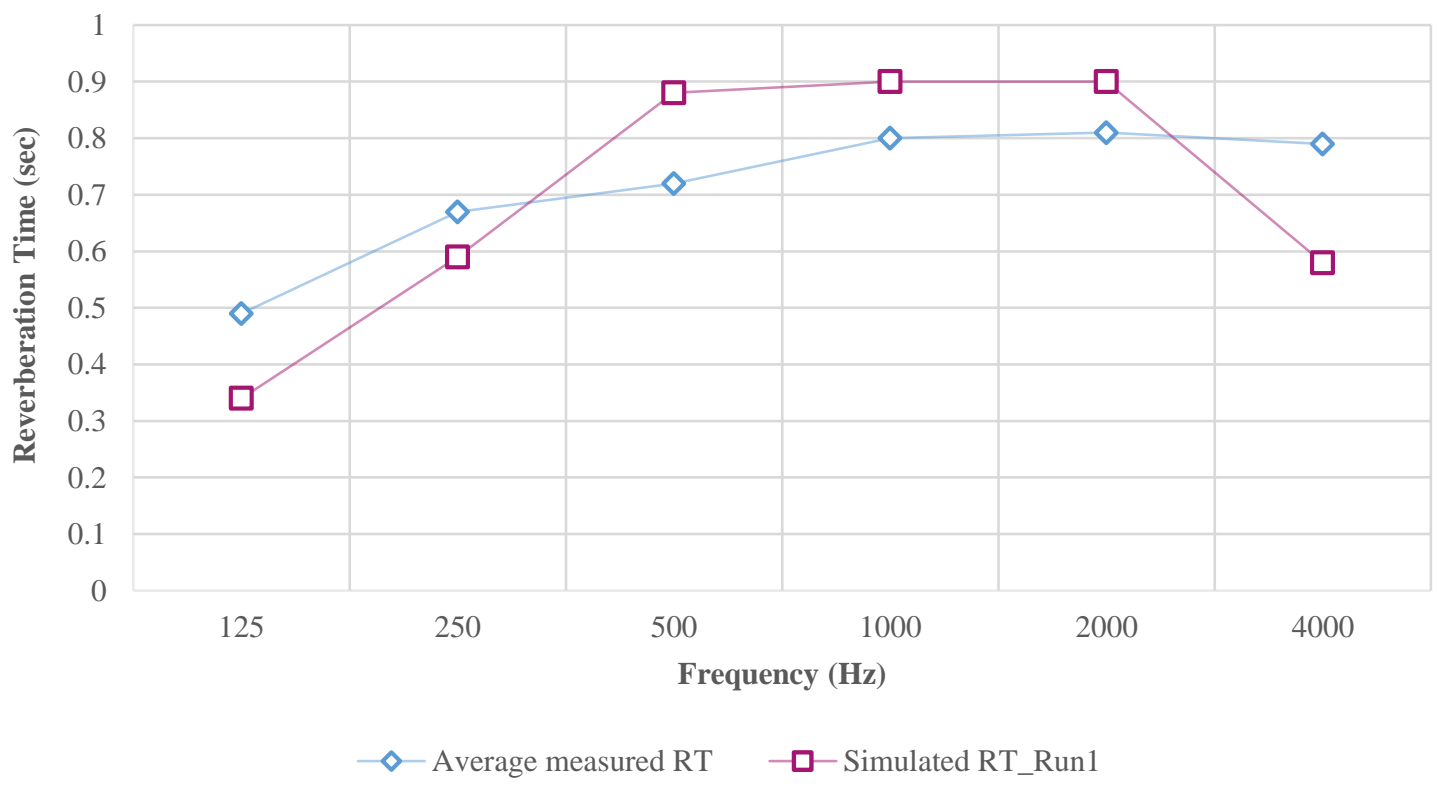

Figure 32: Location 1_Simulation Run 1: Reverberation Time 
Iterations are carried out on the model, from Run 1 to Run 2 to obtain values closer to the measured reverberation time. In simulation Run 2, slight adjustments were made to the absorption coefficient of the living wall, Table XX. The results show a closer value to the measured RT in $250 \mathrm{~Hz}$ and $4000 \mathrm{~Hz}$.

\begin{tabular}{c|cccccc}
\hline \multirow{2}{*}{ Living Wall Absorption Coefficient } & \multicolumn{7}{|c}{ Center Frequency } \\
\cline { 2 - 7 } & $\mathbf{1 2 5}$ & $\mathbf{2 5 0}$ & $\mathbf{5 0 0}$ & $\mathbf{1 0 0 0}$ & $\mathbf{2 0 0 0}$ & $\mathbf{4 0 0 0}$ \\
\hline Calculated from Location 1 & 0.1 & 0.25 & 0.70 & 0.9 & 1.00 & 1.00 \\
\hline Iteration 1_Simulation Run2 & 0.1 & 0.1 & 0.70 & 1.00 & 1.00 & 0.80 \\
\hline
\end{tabular}

Table 14: Living Wall Absorption Coefficient Iteration 1

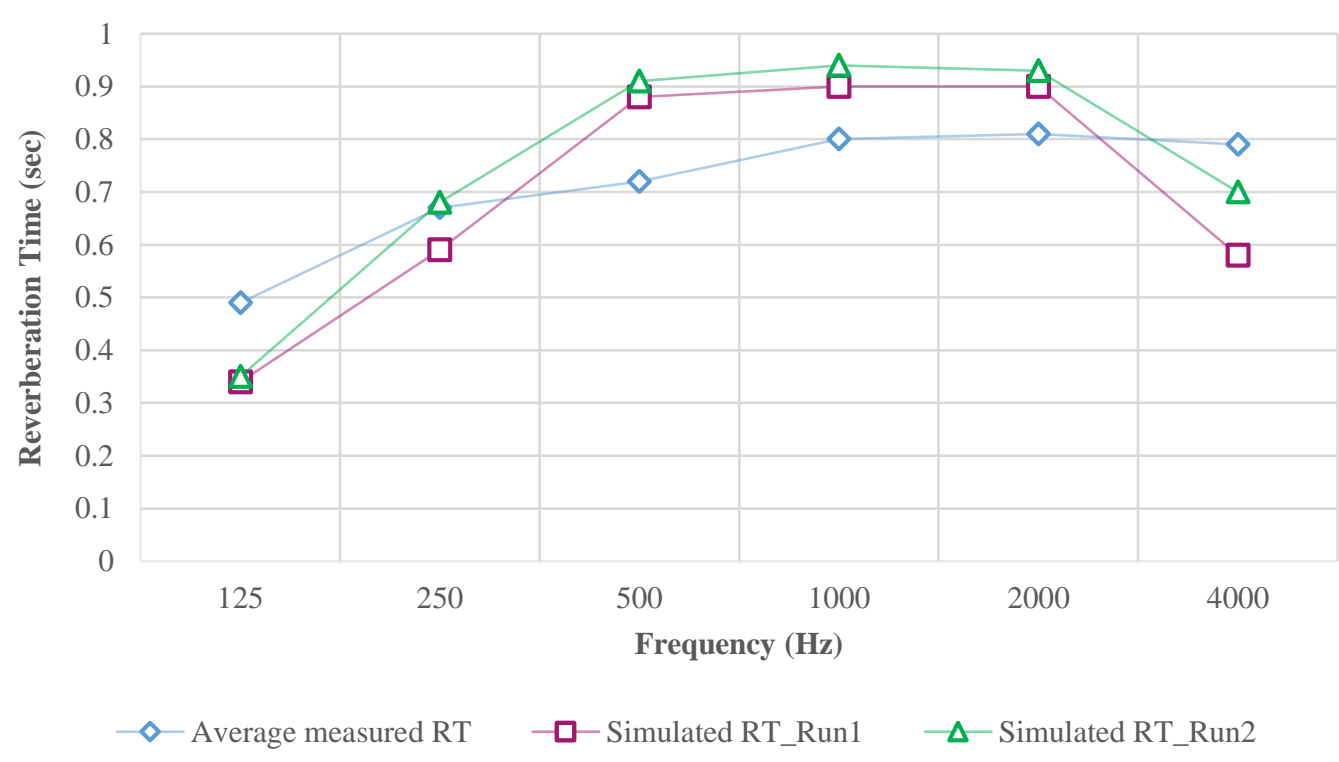

Figure 33: Location 1_Simulation Run 2: Reverberation Time

As the relation between reverberation time and sound absorption of the space is inversely proportional, hence in the second iteration a decrease in the absorption coefficient in 125 and 4000 $\mathrm{Hz}$ and an increase in $500 \mathrm{~Hz}$, while maintaining the values in other frequencies, is carried out.

\begin{tabular}{c|cccccc}
\hline \multirow{2}{*}{ Living Wall Absorption Coefficient } & \multicolumn{7}{|c}{ Center Frequency } \\
\cline { 2 - 7 } & $\mathbf{1 2 5}$ & $\mathbf{2 5 0}$ & $\mathbf{5 0 0}$ & $\mathbf{1 0 0 0}$ & $\mathbf{2 0 0 0}$ & $\mathbf{4 0 0 0}$ \\
\hline Calculated from Location 1 & 0.1 & 0.25 & 0.70 & 0.95 & 1.00 & 1.00 \\
\hline Iteration 1_Simulation Run2 & 0.1 & 0.1 & 0.70 & 1.00 & 1.00 & 0.80 \\
\hline Iteration 2_Simulation Run3 & 0.05 & 0.1 & 0.80 & 1.00 & 1.00 & 0.75 \\
\hline
\end{tabular}




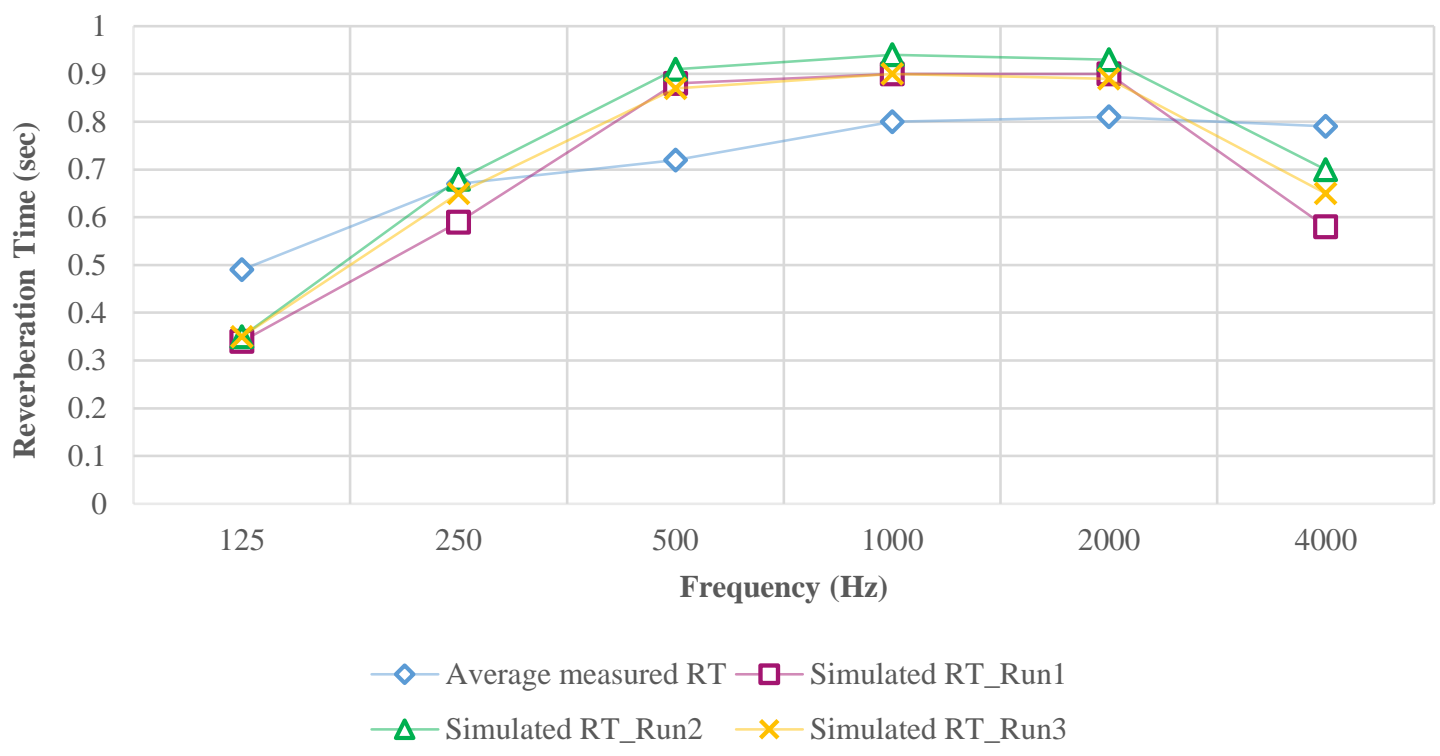

Figure 34: Location 1_Simulation Run 3: Reverberation Time

Several other iterations were carried out to obtain the most accurate simulation reverberation time to measured reverberation time. The final iteration results are as follows:

\begin{tabular}{c|cccccc}
\hline \multirow{2}{*}{ Living Wall Absorption Coefficient } & \multicolumn{7}{|c}{ Center Frequency } \\
\cline { 2 - 7 } & $\mathbf{1 2 5}$ & $\mathbf{2 5 0}$ & $\mathbf{5 0 0}$ & $\mathbf{1 0 0 0}$ & $\mathbf{2 0 0 0}$ & $\mathbf{4 0 0 0}$ \\
\hline Calculated from Location 1 & 0.1 & 0.25 & 0.70 & 0.9 & 1.00 & 1.00 \\
\hline Final Iteration & 0.1 & 0.1 & 0.8 & 0.9 & 0.9 & 0.9 \\
\hline
\end{tabular}

Table 16: Living Wall Absorption Coefficient Final Iteration

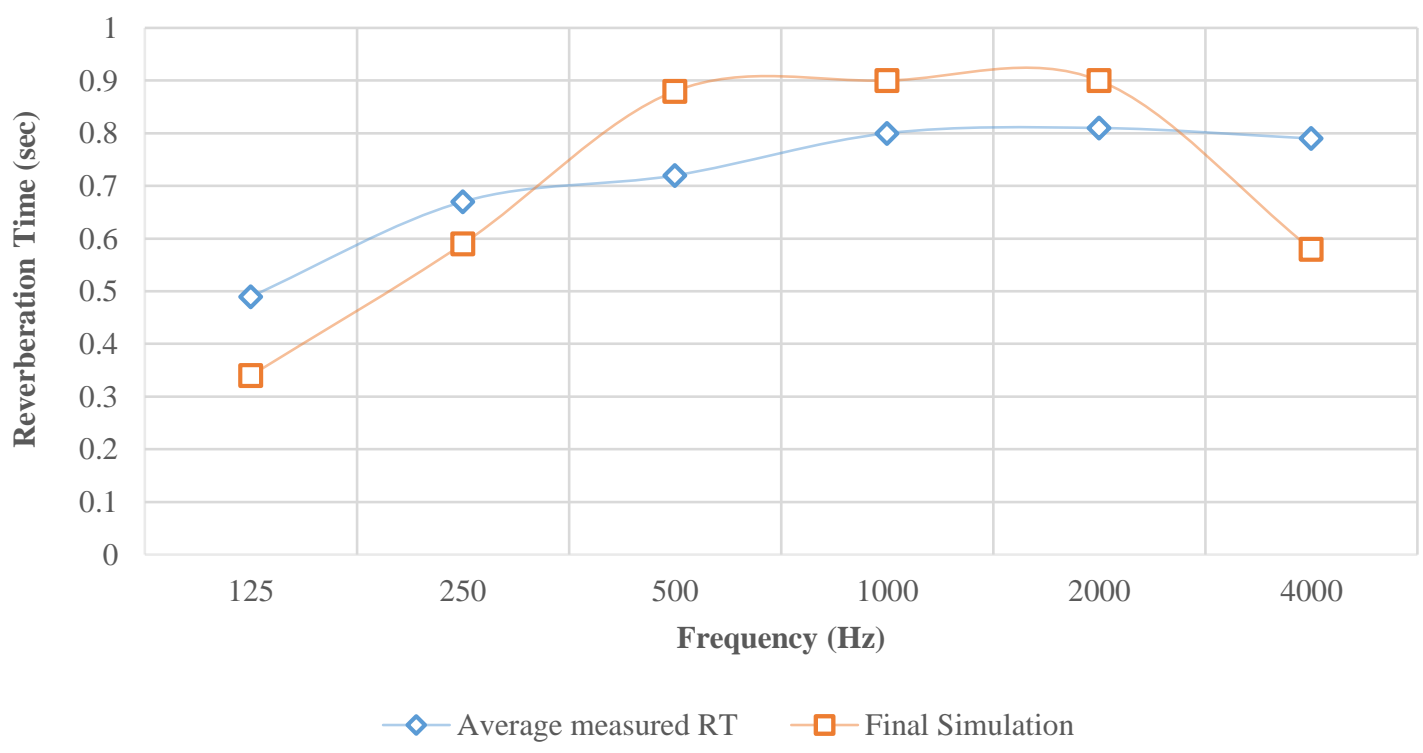

Figure 35: Location 1_Final Iteration Reverberation Time 
The final iteration showed results within a range of error less than $20 \%$. The overall reverberation time pattern from the simulation results mirrors the pattern from the measured values. The sound distribution levels within the room, from the final simulation and iteration, are within a $7 \mathrm{~dB}$ range. As this space is used as a dining room at a restaurant, the speech clarity within the space is not of high priority, as the conversation occurs between occupants seated within a small distance from each other.

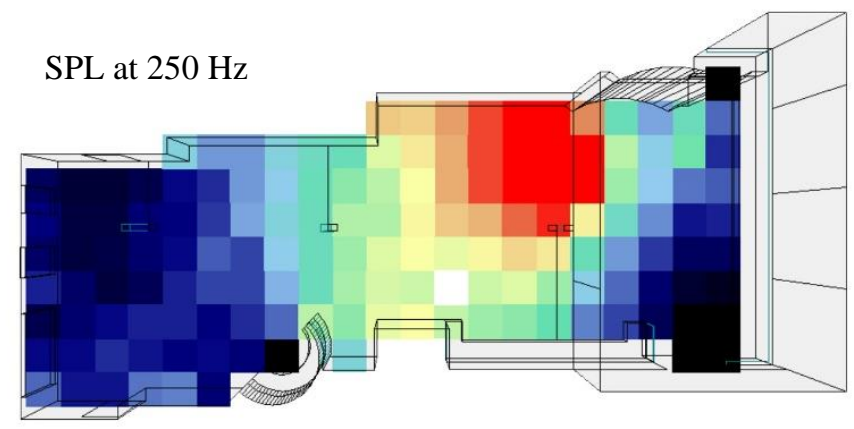

SPL $(\mathrm{dB})$
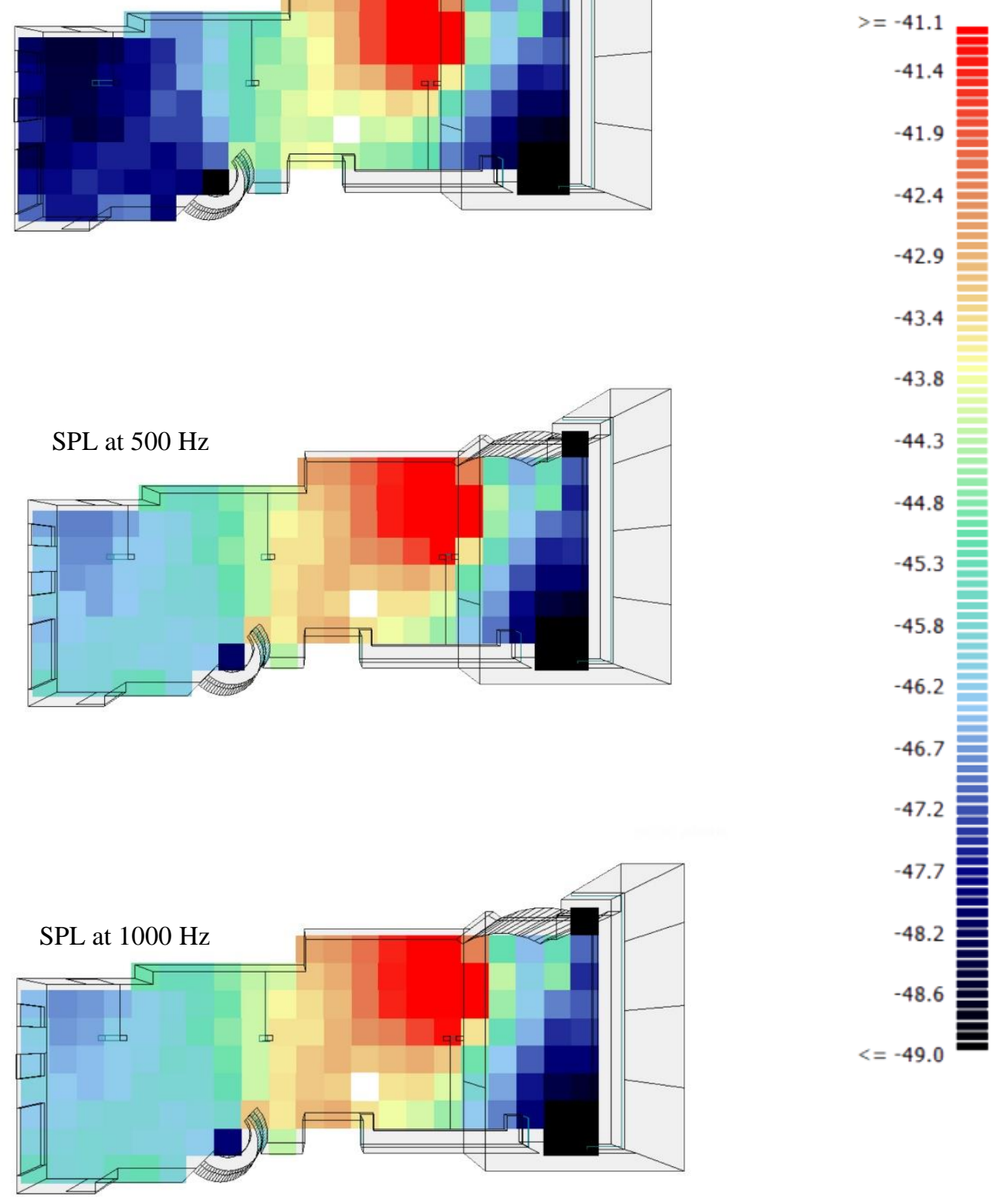

Figure 36: Sound Pressure Level distribution within Location 1 - at 250, 500, and $1000 \mathrm{~Hz}$ (top to bottom) 
Evaluating the Noise Criteria for the dining room, it achieves an NC-46 rating, which is slightly higher than the design recommended guideline (refer to Table 1), however, the average Aweighted sound distribution across the room remains within the acceptable range of 42-52 dBA.

To assess the effectiveness of integrating the living wall within the space, it is replaced in the simulation modelling with wall material in the space. The resultant output demonstrated an increase in the reverberation time within the space, further validating the definite sound absorption of the living wall installed.

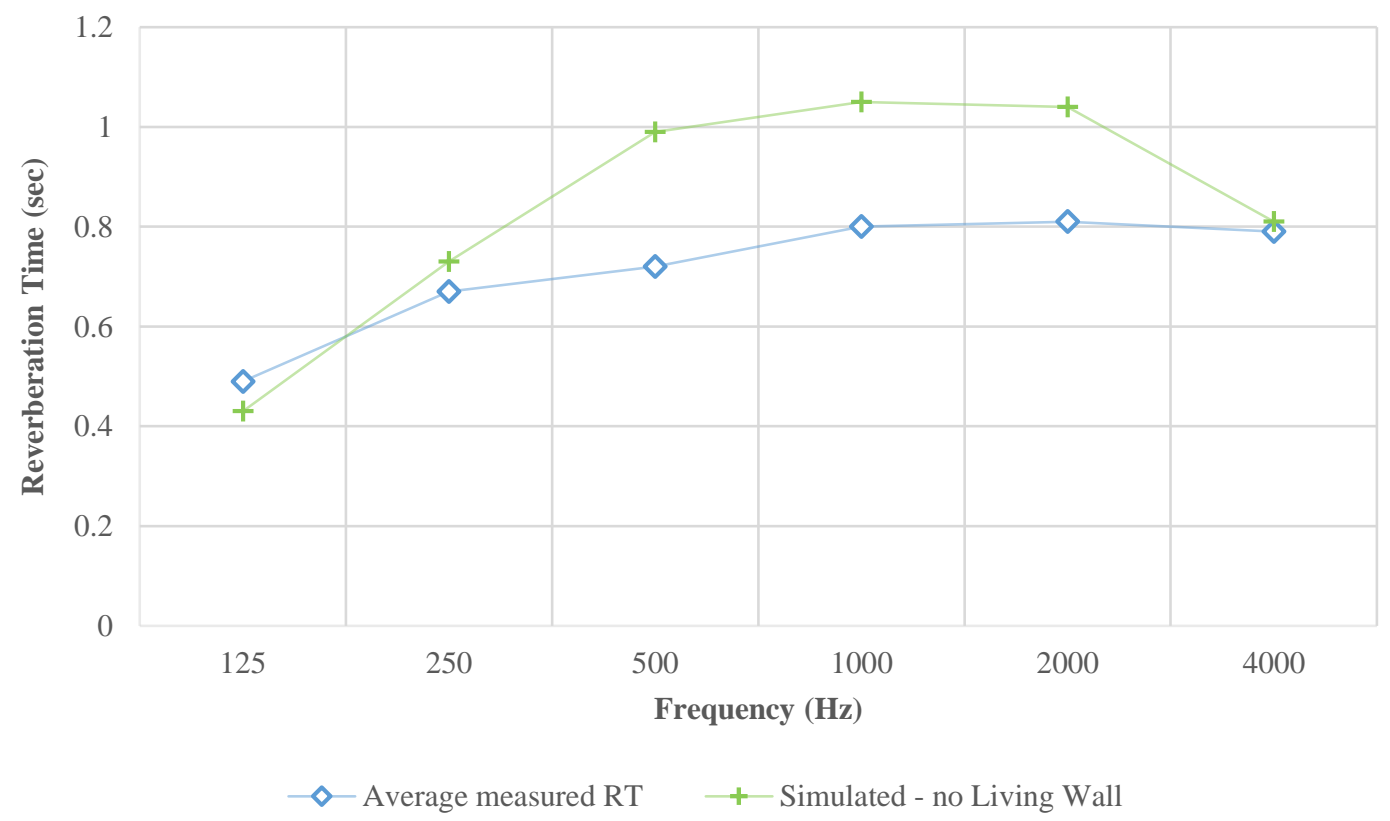

Figure 37: Comparing reverberation time measured, and simulated without living wall 


\subsection{LOCATION TWo Simulation}

Carrying out the same procedure conducted in the simulations of location one, the simulations of location two were ran. The aim of running the simulations in comparison with the average measured reverberation time and the simulated reverberation time is to permit a realistic evaluation of all other acoustic factors.

The first two simulation runs were done using two varieties of brick material from the software database, in order to assess which of the options resembles the actual brick used within the space. Several other runs were carried out to evaluate the correct version of the construction material, reaching the final simulation run, with the closest values to the average measured. The final iteration of the living wall material performed in the simulation for location one, was used.

\begin{tabular}{c|cccccc}
\hline \multirow{2}{*}{ Reverberation Time } & \multicolumn{7}{c}{ Center Frequency } \\
\cline { 2 - 7 } & $\mathbf{1 2 5}$ & $\mathbf{2 5 0}$ & $\mathbf{5 0 0}$ & $\mathbf{1 0 0 0}$ & $\mathbf{2 0 0 0}$ & $\mathbf{4 0 0 0}$ \\
\hline Average Measured & 1.35 & 1.40 & 1.47 & $\mathbf{1 . 4 5}$ & 1.46 & 1.23 \\
\hline Iteration 1_Simulation Run1 & 1.51 & 2.10 & 2.17 & 1.95 & 1.88 & 1.49 \\
\hline Iteration 2_Simulation Run2 & 1.50 & 2.04 & 2.05 & 1.75 & 1.70 & 1.47 \\
\hline Final Simulation Run & 1.45 & 1.77 & 1.73 & $\mathbf{1 . 4 5}$ & 1.54 & 1.27 \\
\hline
\end{tabular}

Table 17: Location 2 - Iterations and measured RT

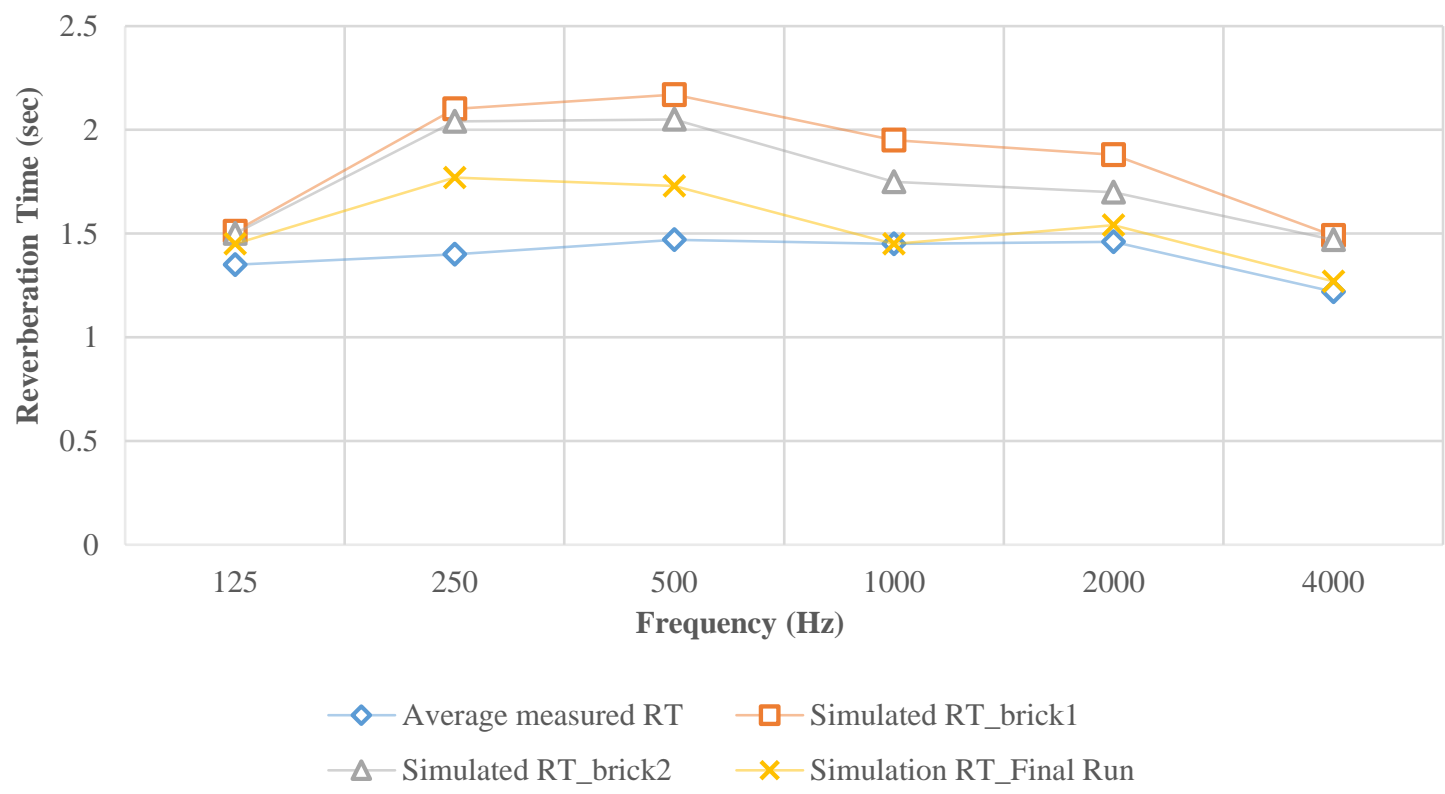

Figure 38: Location 2_Simulation and Measured: Reverberation Time 
The sound distribution levels of the space lie in a range of $8 \mathrm{~dB}$, across the entire room, which spans $28 \mathrm{~m}$ in length. Within a 10 - $\mathrm{m}$ radius of the room, the range of sound distribution level is \pm 5 $\mathrm{dB}$. This demonstrates good sound transmission and intelligibility within the space.

SPL at $250 \mathrm{~Hz}$

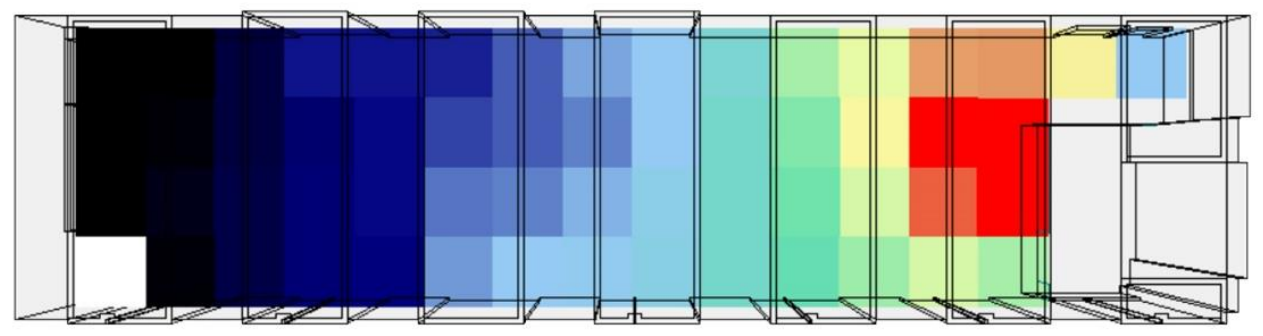

SPL $(d B)$

SPL at $500 \mathrm{~Hz}$

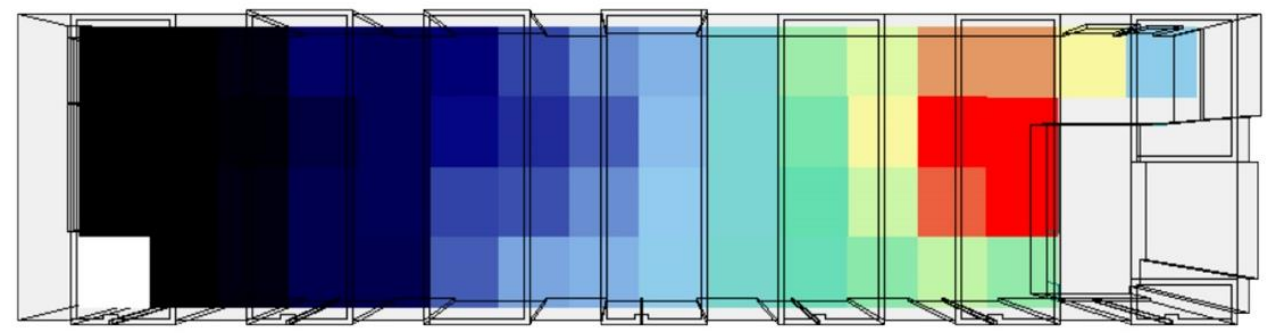

SPL at $1000 \mathrm{~Hz}$
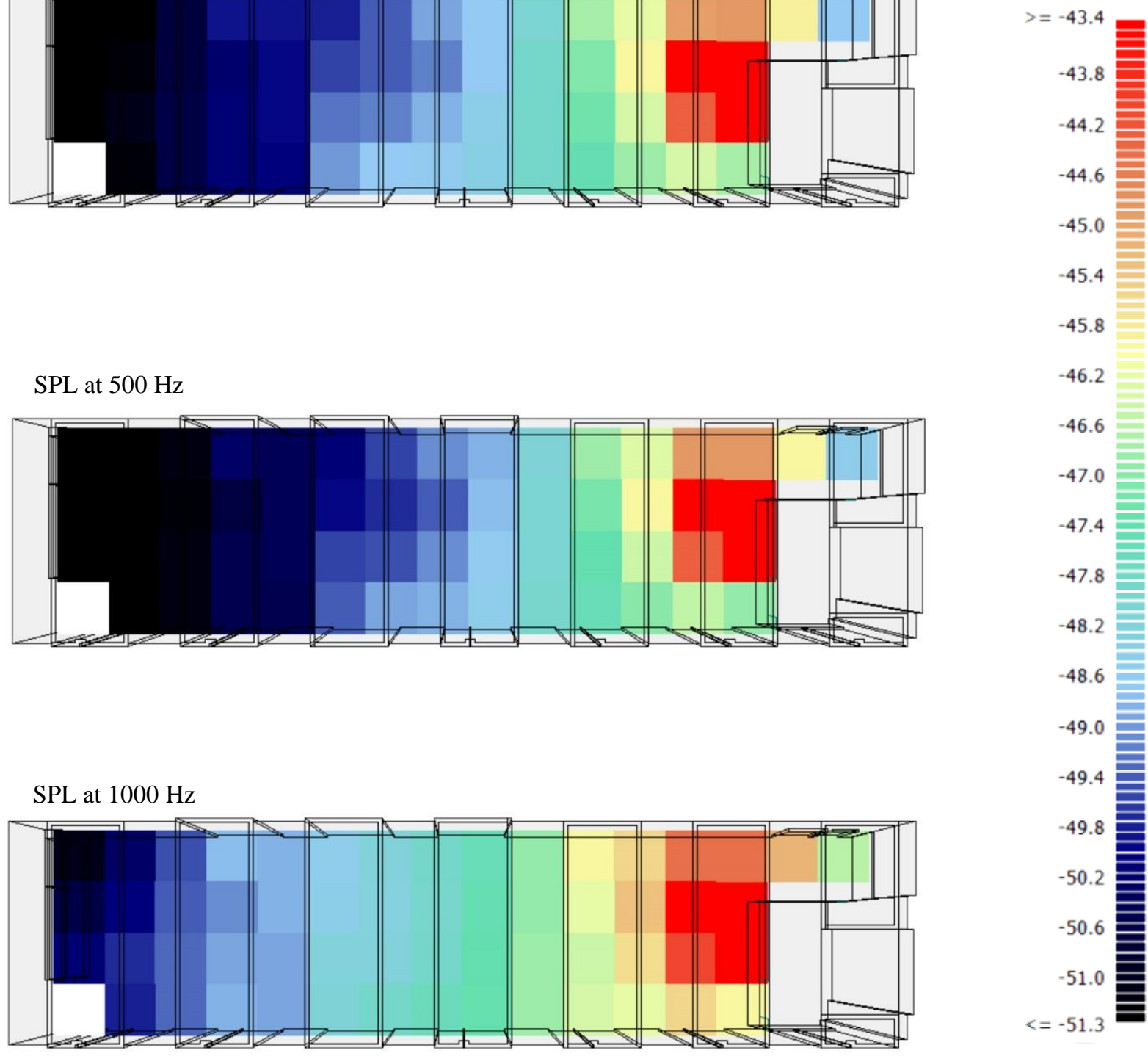

Figure 39: Sound Pressure Level distribution within Location 2 - at 250, 500, and $1000 \mathrm{~Hz}$ (top to bottom) 
The surface covered by the living wall is replaced with concrete in the simulation model. The output illustrates an increase in reverberation time of the space. However, the overall difference is not significant, and is justified by the comparatively small surface area of the living wall compared to the total volume of the space.

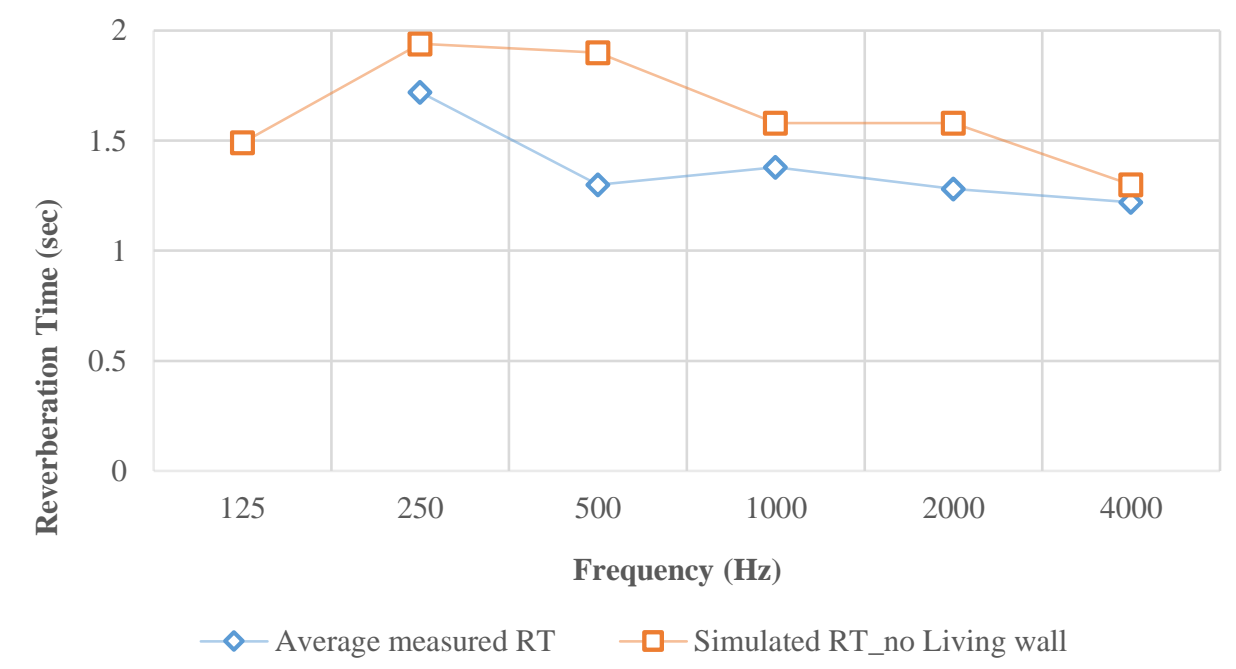

Figure 40: Comparing reverberation time measured, and simulated without living wall_Location2 


\subsection{LOCATION THREE SimUlation}

The acoustic measurements carried out in location three were significantly affected by the high background noise level produced by the waterfall running. The simulation validation in the frequency range $125-250 \mathrm{~Hz}$ and $4000 \mathrm{~Hz}$ for this location show an increased discrepancy, as a result. However, within the range of $500-2000 \mathrm{~Hz}$, the values in the simulation and measured were almost aligned.

\begin{tabular}{c|cccccc}
\hline \multirow{2}{*}{ Reverberation Time } & \multicolumn{7}{c}{ Center Frequency } \\
\cline { 2 - 7 } & $\mathbf{1 2 5}$ & $\mathbf{2 5 0}$ & $\mathbf{5 0 0}$ & $\mathbf{1 0 0 0}$ & $\mathbf{2 0 0 0}$ & $\mathbf{4 0 0 0}$ \\
\hline Average Measured & $*$ & 1.72 & $\mathbf{1 . 3}$ & $\mathbf{1 . 3 8}$ & $\mathbf{1 . 2 8}$ & 1.22 \\
\hline Iteration 1_Simulation Run1 & 0.56 & 1.03 & 1.26 & 1.51 & 1.15 & 0.94 \\
\hline Iteration 2_Simulation Run2 & 0.59 & 0.99 & 1.06 & 0.85 & 0.97 & 0.98 \\
\hline Final Simulation Run & 0.83 & 1.01 & $\mathbf{1 . 2 9}$ & $\mathbf{1 . 4 3}$ & $\mathbf{1 . 2 8}$ & 1.03
\end{tabular}

Table 18: Iterations and Measured RT_Location3

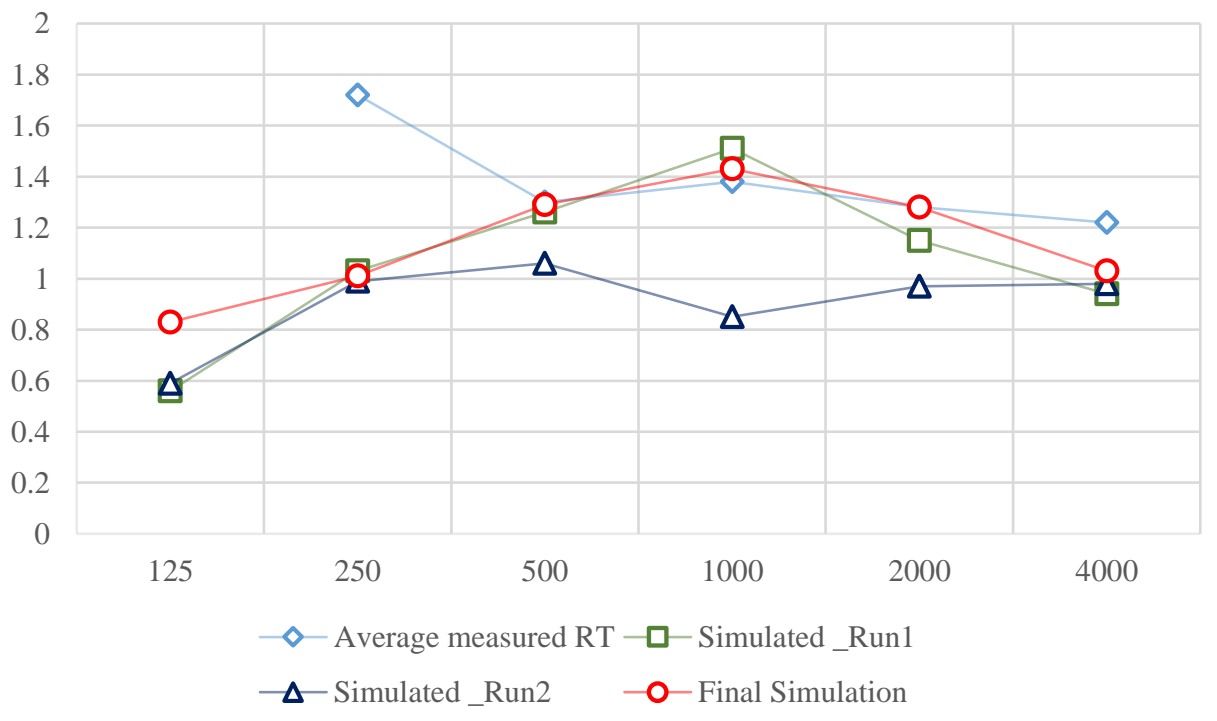

Figure 41: Location 3_Simulation and Measured: Reverberation Time 
The overall sound distribution levels within the space remain homogeneous across the range of frequencies.

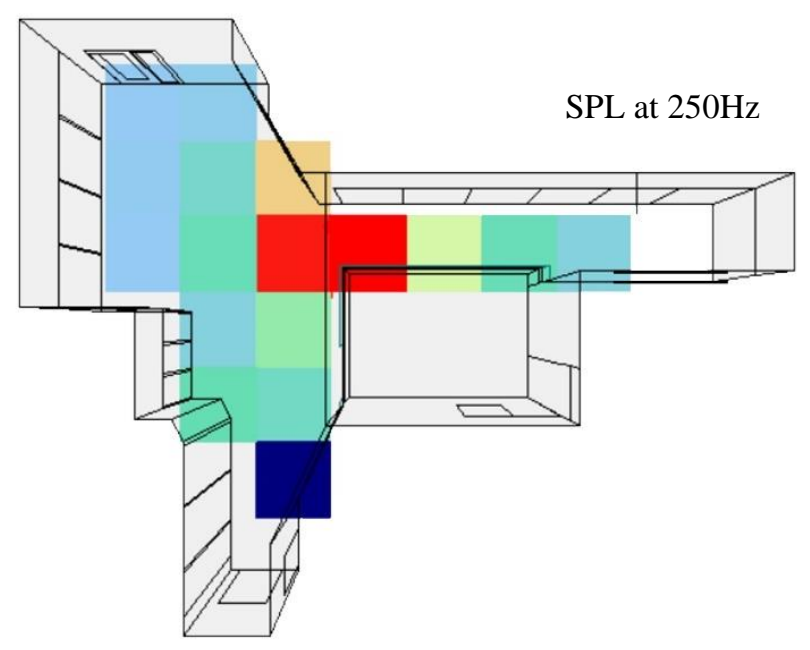

SPL $(\mathrm{dB})$

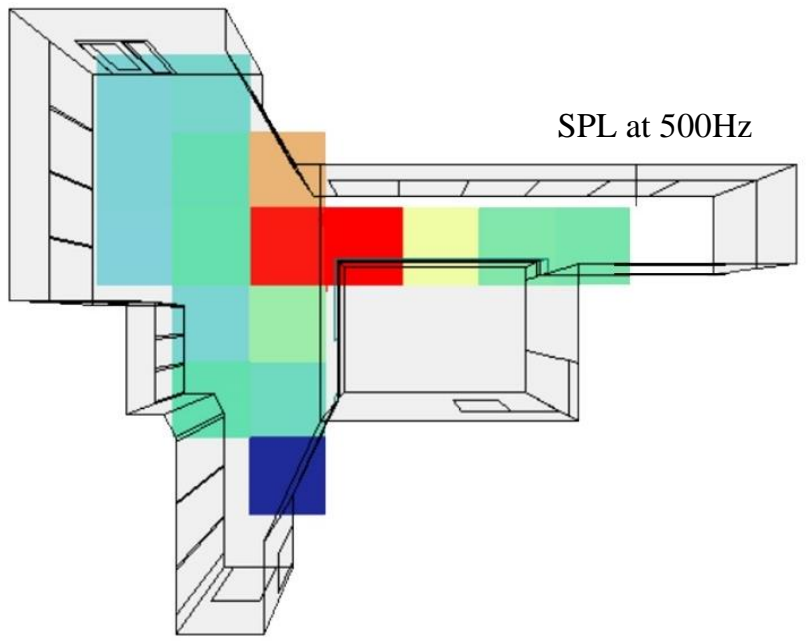

$-42.6$

$>=-40.3$

$-40.6$

$-41.1$

$-41.6$

$-42.1$

$-43.0$

$-43.5$

$-44.0$

$-44.5$

$-45.0$

$-45.4$

$-45.9$

$-46.4$

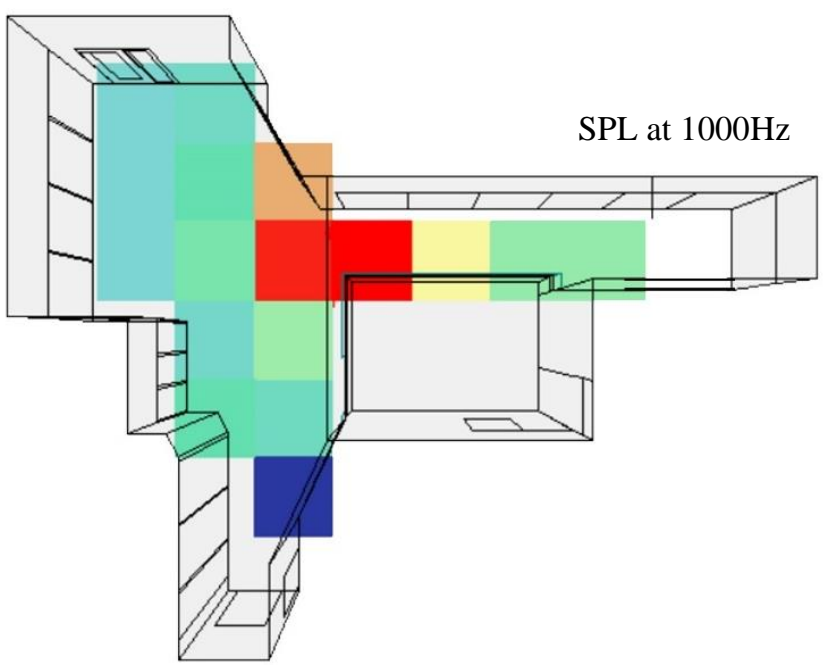

$-46.9$

$-47.4$

$-47.8$

Figure 42: Sound Pressure Level distribution within Location 3 - at 250, 500, and $1000 \mathrm{~Hz}$ (top to bottom) 
The NC rating of the space is evaluated at NC-46, which is slightly higher than the guideline of NC-40. The overall A-weighted sound pressure level within the space is $43.5 \mathrm{dBA}$, achieving the acceptable guideline range for the clinic.

Further evaluating the acoustic performance of the space, the living wall is removed and replaced by the conventional wall material used for the rest of the model. The NC and Reverberation Time are readdressed and the simulation result demonstrates a rating of NC-47. The slight change in the room noise criteria verifies that the living wall within this space has a minute effect on the acoustics of the space, which was observed earlier from the significant effect that the background noise had on the acoustics.

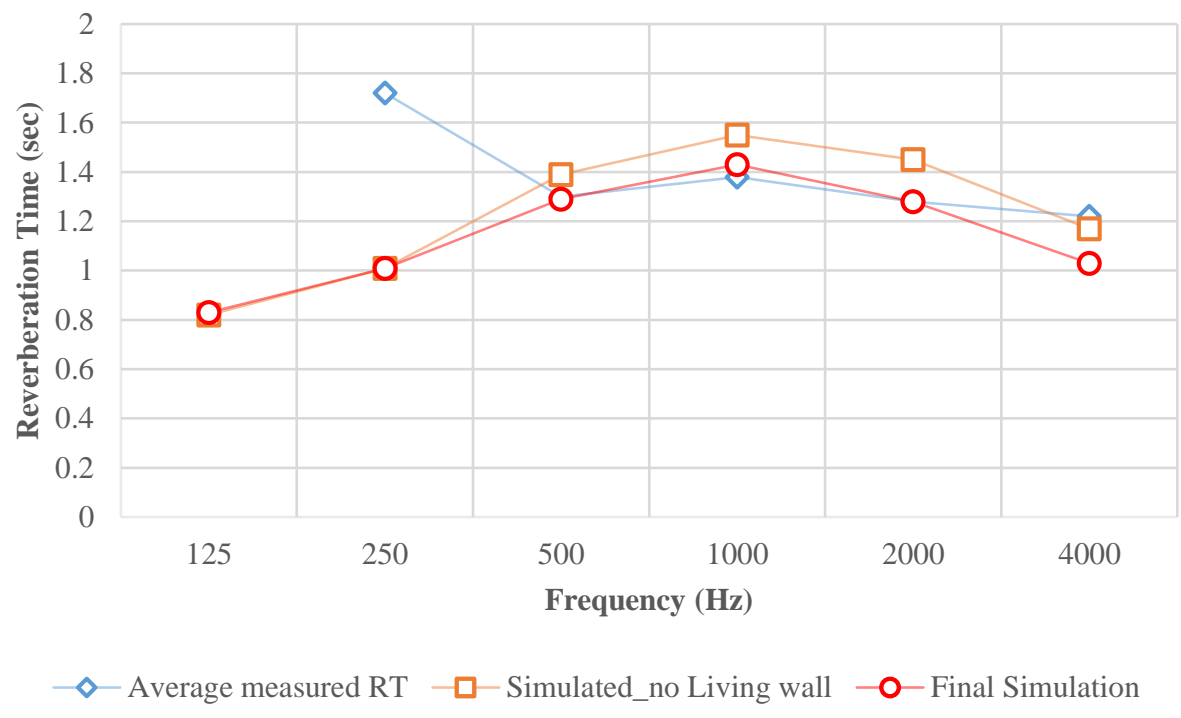

Figure 43: Location 3-average measured, simulated RT with and Without Living Wall 
The Paul Crocker Gallery is a multi-purpose space, situated on the entry level of Ryerson University's Department of Architectural Sciences. The space is constructed as dynamic plan with semi-circular walls towards the end of the room, with three glass rotating doors that allow the users to flow into the space; hence allowing the flexible use of the space for student exhibitions and critique sessions.

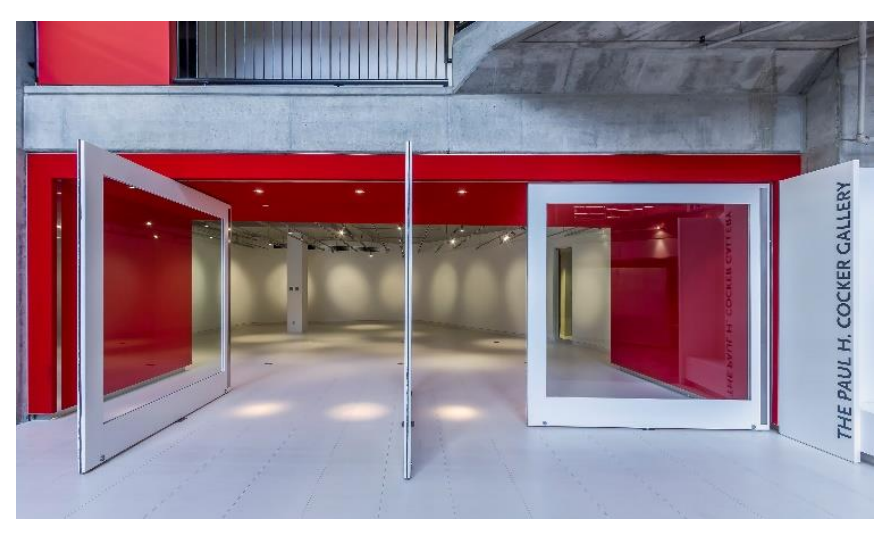

Figure 44: Paul Cocker Gallery Entrance

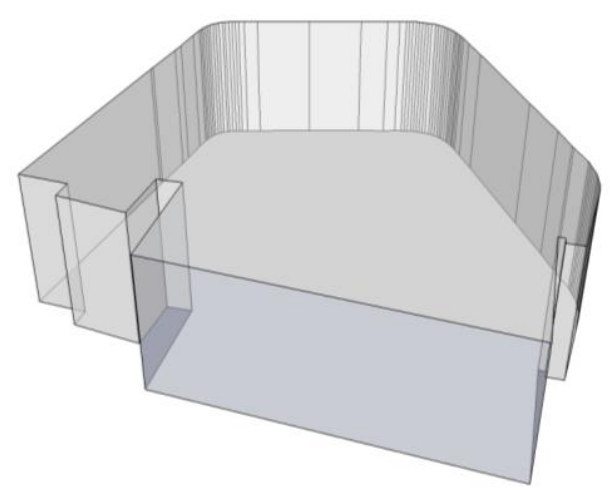

Figure 45: 3D Model of the Space (simplified)

The Gallery is used as the application case study, to evaluate the acoustic performance of the space to be used a critique space, where speech intelligibility becomes a significant acoustic parameter to be achieved. The Gallery is constructed with concrete ceilings, gypsum partition walls with felt covers at the entrance, floor tiles, and three glass doors. The acoustics of the gallery varies with the density of occupants in the space, as the presence of people affect the performance of the room as well.

The objective of the acoustic simulation of the gallery is to increase the overall sound absorption of the space, ultimately reducing the reverberation time, achieving the guideline $\mathrm{NC}$ rating within the range of NC-30 to NC-40 [23].

Results of the impulse response measurement carried out in the gallery space are demonstrated in Table 24.

\begin{tabular}{|c|c|c|c|c|c|c|c|c|}
\hline \multirow{2}{*}{\multicolumn{2}{|c|}{ PHC Gallery }} & \multicolumn{7}{|c|}{ Center Frequency } \\
\hline & & 125 & 250 & 500 & 1000 & 2000 & 4000 & 8000 \\
\hline Reverberation Time & seconds & 1.65 & 2.22 & 2.12 & 2.01 & 1.34 & 0.91 & 0.58 \\
\hline $\begin{array}{c}\text { Relative Sound } \\
\text { Distribution }\end{array}$ & decibel & 32 & 21.8 & 18.4 & 19.0 & 14.2 & 11.8 & 15.8 \\
\hline Clarity & decibel & 1.9 & 3.2 & 3.4 & 4.7 & 6.1 & 8.9 & 13.7 \\
\hline
\end{tabular}




\subsection{VALIDATING SIMULATION}

The gallery is modelled in 3D and imported into the room acoustics software, applying the same procedure carried out for the previous simulation modelling. The construction materials of the gallery are of internal walls, floors and ceiling, hence the assemblies vary from those used for external walls.

The first run of simulation was conducted by assigning the materials to their respective surfaces. The felt surfaces were applied as "velour curtains" as it represents a similar material to that of the felt. Further adjustments were made to the material in the database to obtain a closer validation output result to the measured average.

Several other simulation runs were done to obtain the most accurate absorption coefficient for the wall assembly within the space. Some of the main results are shown below. The process followed entails choosing the most accurate building material or construction assembly from the database of the software, and then slightly altering the absorption coefficient, by increasing it to obtain a lower reverberation time, or decreasing the coefficient to increase the reverberation time. This is repeated to attain the closest values when comparing the simulation to the measured RT.

\begin{tabular}{c|cccccc}
\hline \multirow{2}{*}{ Reverberation Time } & \multicolumn{7}{|c}{ Center Frequency } \\
\cline { 2 - 7 } & $\mathbf{1 2 5}$ & $\mathbf{2 5 0}$ & $\mathbf{5 0 0}$ & $\mathbf{1 0 0 0}$ & $\mathbf{2 0 0 0}$ & $\mathbf{4 0 0 0}$ \\
\hline Average Measured & 1.65 & $\mathbf{2 . 2 2}$ & $\mathbf{2 . 1 2}$ & $\mathbf{2 . 0 1}$ & $\mathbf{1 . 3 4}$ & 0.91 \\
\hline Iteration 1_Simulation Run1 & 0.74 & 1.85 & 2.96 & 3.32 & 2.13 & 1.45 \\
\hline Iteration 2_Simulation Run2 & 0.94 & 1.64 & 2.28 & 2.4 & 1.99 & 1.42 \\
\hline Final Simulation Run & 1.33 & $\mathbf{2 . 2 6}$ & $\mathbf{2 . 1 3}$ & $\mathbf{1 . 9 5}$ & $\mathbf{1 . 3 6}$ & 1.08 \\
\hline
\end{tabular}

Table 20: Iterations and Measured RT_Gallery

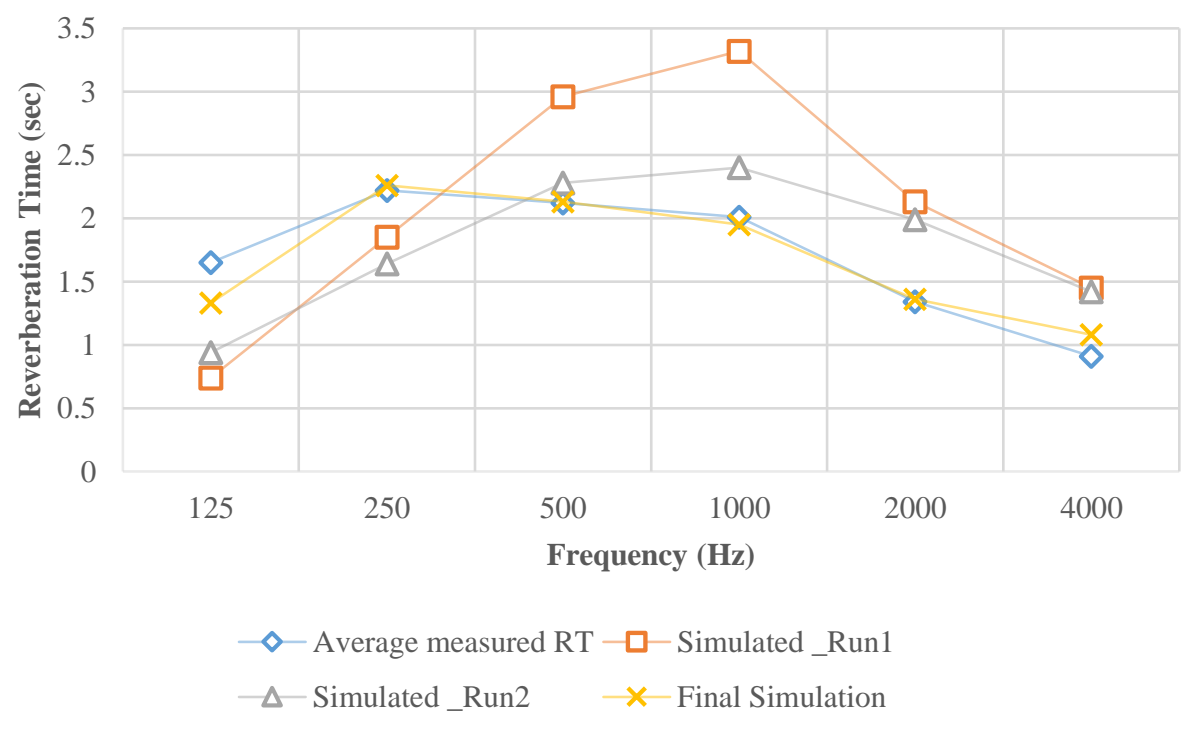

Figure 46: Gallery Simulation and Measured: Reverberation Time 


\subsection{Evaluating Acoustic Parameters in Gallery}

The measured sound distribution within the gallery results in an NC-19 rating, which is a significantly lower value than the design guideline NC-30 to NC-40 for the space type and use. This parallels the high measured reverberation time, causing the speech intelligibility to be lower, as the sound emitted by the speaker does not decay fast enough before the second sound is uttered, causing the speech to be muffled when reaching the listener.

The optimum reverberation time for the gallery space with a volume of $350 \mathrm{~m}^{3}$, and requirements for high speech intelligibility would be 0.5 seconds at $500 \mathrm{~Hz}$.

\begin{tabular}{c|cccccc}
\hline \multirow{2}{*}{ Reverberation Time } & \multicolumn{7}{|c}{ Center Frequency } \\
\cline { 2 - 7 } & $\mathbf{1 2 5}$ & $\mathbf{2 5 0}$ & $\mathbf{5 0 0}$ & $\mathbf{1 0 0 0}$ & $\mathbf{2 0 0 0}$ & $\mathbf{4 0 0 0}$ \\
\hline Optimum for gallery & 0.65 & 0.58 & 0.5 & 0.5 & 0.5 & 0.5 \\
\hline
\end{tabular}

Table 21: Optimum Reverberation Time for Gallery

\subsection{APPLiCATION OF LiVING WALL IN GALLERY}

The living wall is simulated within the model of the gallery to evaluate the installation area necessary to assess the prospect of using it as a passive sound insulation mechanism within an interior space, such as that of the gallery, to provide the required acoustic performance for occupant use.

The first simulation is conducted by covering the back wall, facing the glass door entrance with the material absorption of the living wall.

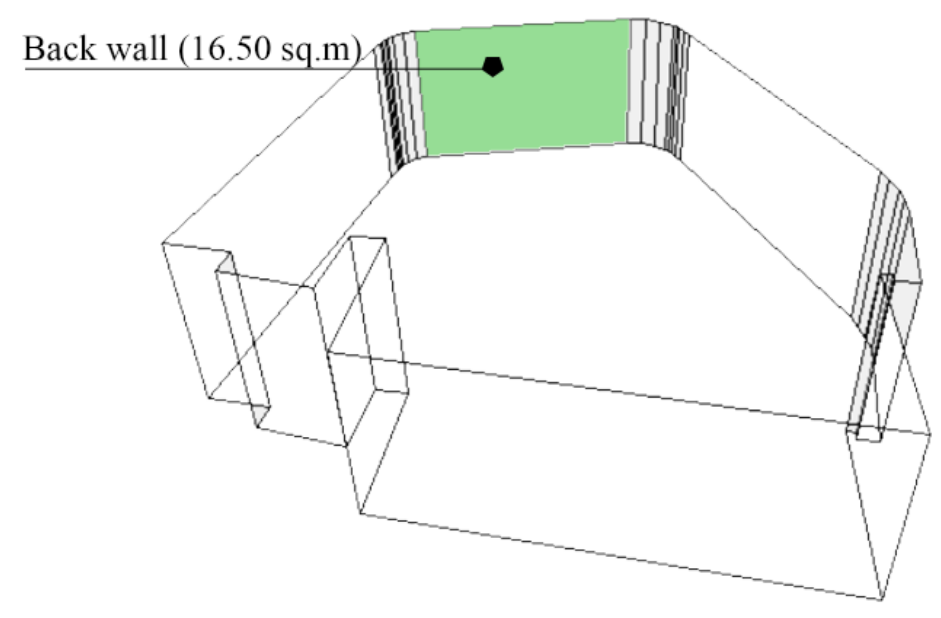

Figure 47: Gallery Model - First Run - application of living wall 
The outcome of the first simulation demonstrated a decrease in the reverberation time across all frequencies, however the optimum RT was not attained with only $16.50 \mathrm{~m}^{2}$ coverage.

\begin{tabular}{c|cccccc}
\hline \multirow{2}{*}{ Reverberation Time } & \multicolumn{7}{|c}{ Center Frequency } \\
\cline { 2 - 7 } & $\mathbf{1 2 5}$ & $\mathbf{2 5 0}$ & $\mathbf{5 0 0}$ & $\mathbf{1 0 0 0}$ & $\mathbf{2 0 0 0}$ & $\mathbf{4 0 0 0}$ \\
\hline Optimum for gallery & 0.65 & 0.58 & 0.5 & 0.5 & 0.5 & 0.5 \\
\hline Average Measured & 1.65 & 2.22 & 2.12 & 2.01 & 1.34 & 0.91 \\
\hline 16.5 sqm living wall simulated & 1.29 & 2.20 & 1.62 & 1.55 & 1.16 & 0.93 \\
\hline
\end{tabular}

Table 22: Gallery Reverberation Time Comparison: optimum, measured, simulated1

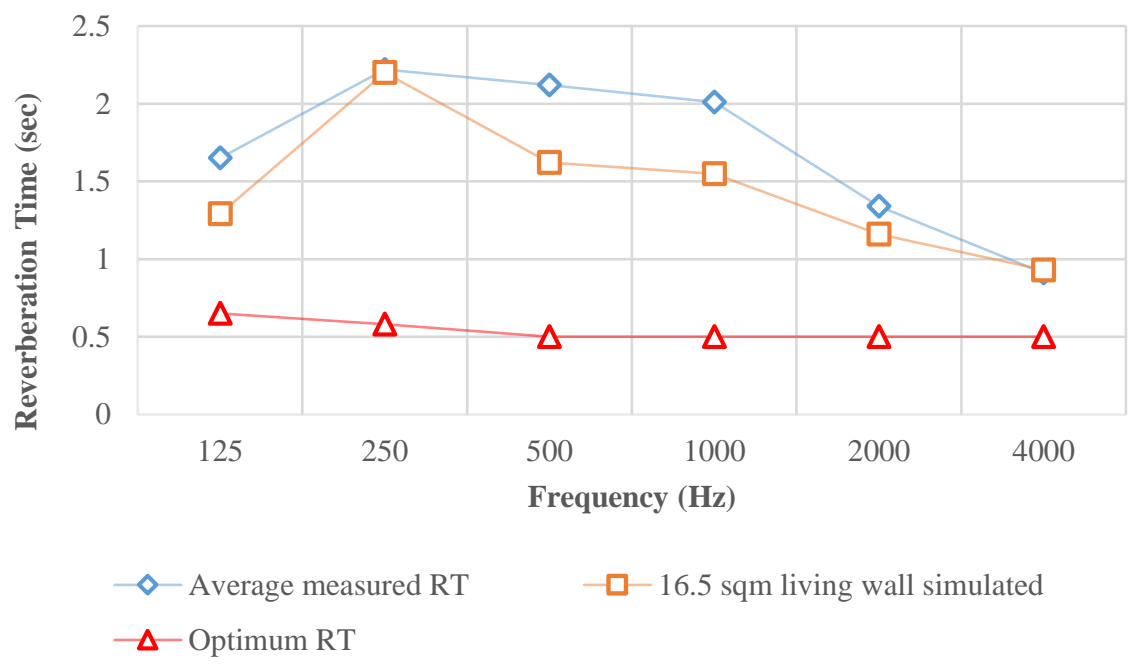

Figure 48: Gallery Reverberation Time - Simulation 1 compared with measured and optimum

The surface area of the simulated living wall is increased to $25.12 \mathrm{~m}^{2}$, and positioned on the western wall from the glass door entrance, as shown below.

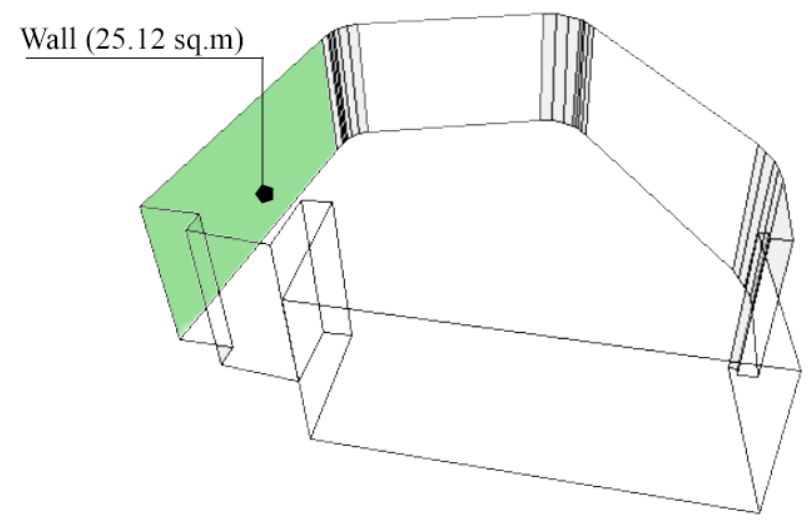

Figure 49: Gallery - Simulation 2 - 25.12 sqm living wall 
The increased surface area of the living wall simulated is not sufficient to provide the optimum reverberation time.

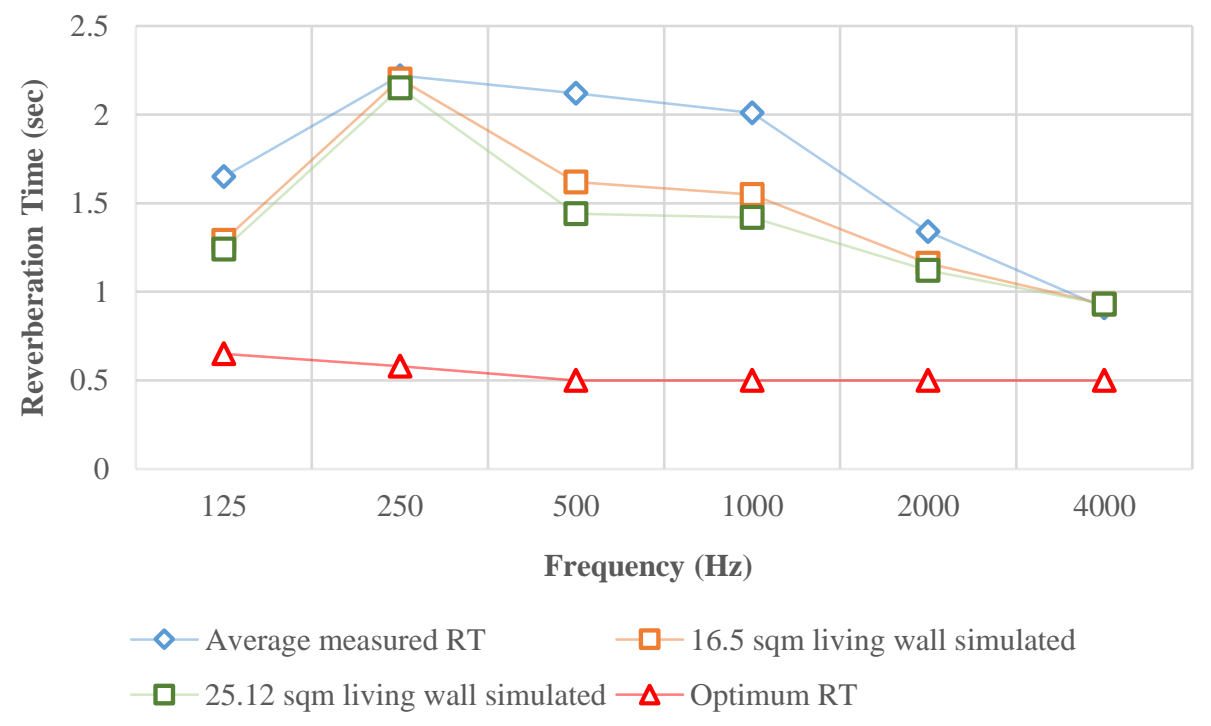

Figure 50: Gallery Reverberation time: simulation 1 and 2, measured and optimum

Further increasing the living area coverage, encompassing the walls in the first two simulations in addition to the semi-circular corner, the total coverage is $45.94 \mathrm{~m}^{2}$.

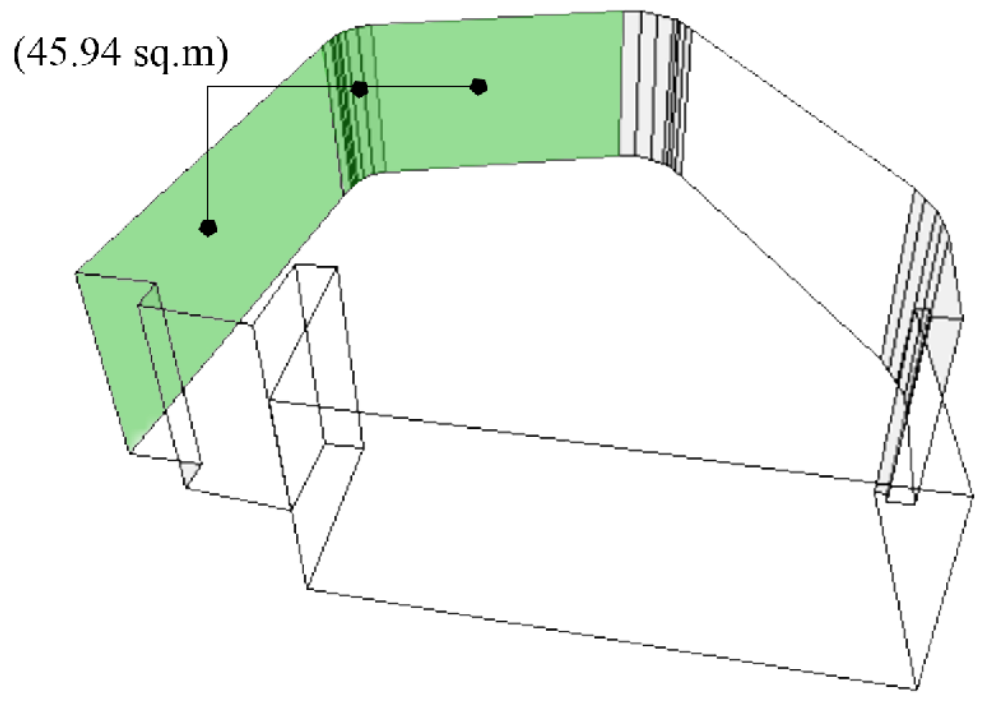

Figure 51: Gallery Living Wall Coverage for Simulation 3 
The simulation is run for this area and the results display an additional decrease in the reverberation time, yet not sufficient enough to reach the optimum values.

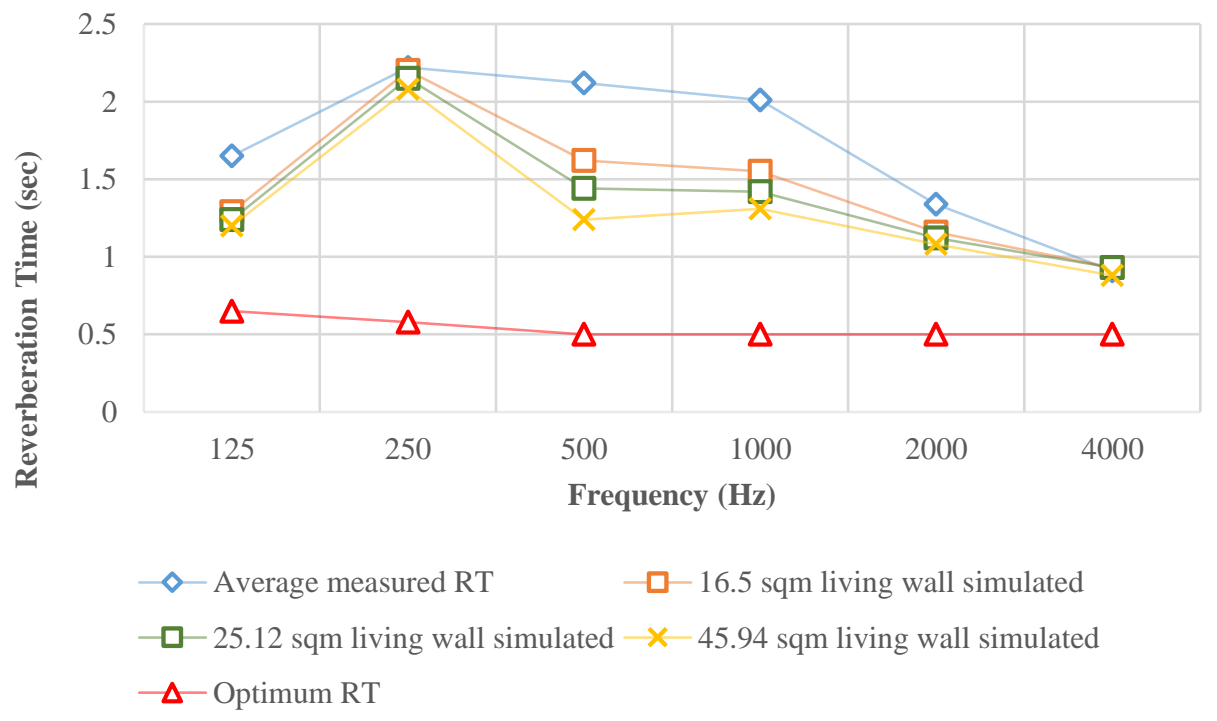

Figure 52: Gallery Reverberation time: simulation 1, 2 and 3, measured and optimum

Integrating the living wall within the Gallery space to provide acoustic comfort and high speech intelligibility is not achieved through the simulation, where the entire available wall area of 11.87 $\mathrm{m}^{2}$ is covered with the living wall. The application in the gallery space requires an increased area of the living wall due to the already poor acoustic conditions of the space, where the existing wall surfaces were not sufficient.

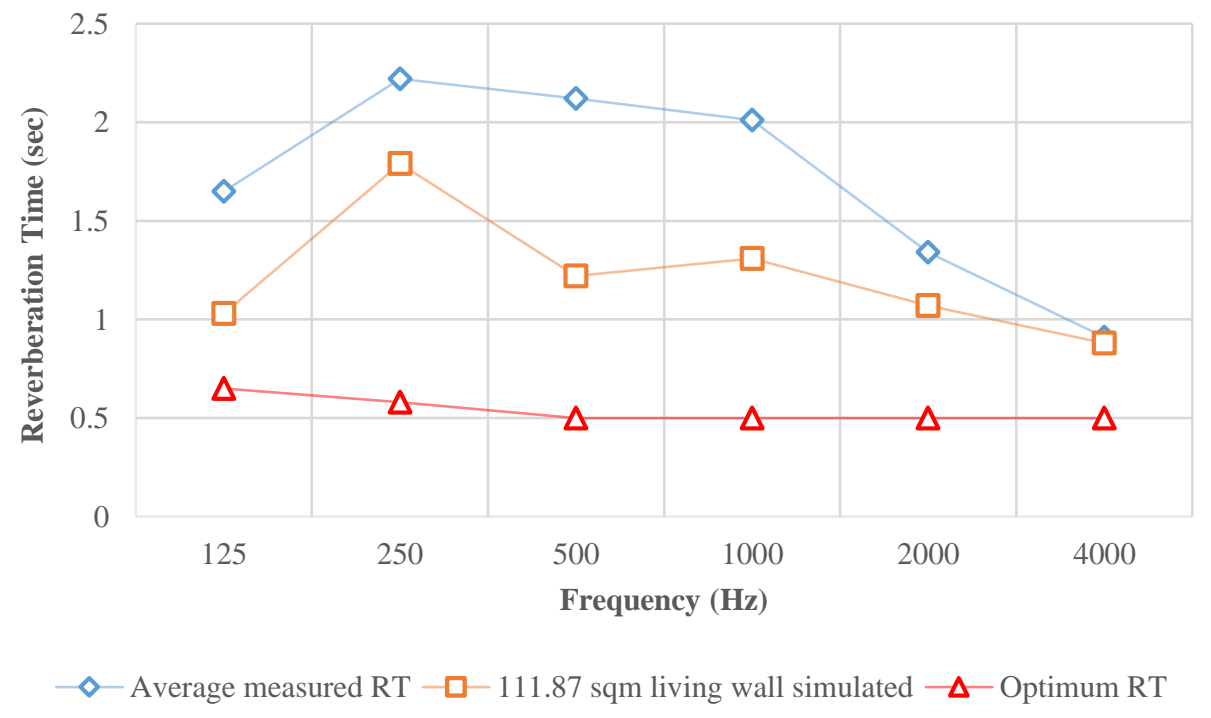

Figure 53: Final Simulation - Gallery Living Wall Application 


\section{CONCLUSION}

The aim of this research is to evaluate the potential of integrating living walls as passive interior insulation techniques to provide indoor acoustic comfort as the necessity of acoustic comfort reflects on the occupant productivity levels within the space [3]. This was assessed through a series of acoustic measurements and experimentations carried out on in-situ living walls.

Through the acoustic measurements and calculations carried out on the obtained results from location 1, it was difficult to obtain the absorption coefficient of the living wall due to the ambiguity in material sound absorption within the space and the volumetric composition where the living wall is installed in the location. Additionally, the values were predicted to be affected by the high background noise caused by the mechanical system running the living wall. The absorption coefficient used for the simulations was used according to those found by Thomazelli et al.'s experimentation results.

A portion of the living wall in location 2 was covered with a hard, sound-reflecting board to assess the effect on the overall reverberation time due to the sound absorption of the living wall. The outcome demonstrated an increase in reverberation time in the experimentation with the covered portion of the living wall, verifying the sound absorption capacity of the living wall. However, due to difficulty covering the entire wall, the overall sound absorption of the living wall was not possible to determine.

The RC rating evaluated for each of the four sites showed a higher value than the recommended design guideline for the spaces. The noise generated from the mechanical system of the living wall system and the presence of the waterfall in some of the cases are to be considered for noise control, in order for the living wall to provide the acoustic comfort, and its sound absorption be at full potential.

The application of the living wall within the case study simulation did not achieve the desirable guideline acoustic parameters, which includes the reverberation time of 0.5 seconds to be achieved at $500 \mathrm{~Hz}$ within the space. When comparing the gallery space (volume of $350 \mathrm{~m}^{3}$ ) used for the application case study to the restaurant dining room (Location 1), which has a volume of $570 \mathrm{~m}^{3}$ and a living wall total area of $20 \mathrm{~m}^{2}$, the dining space had more acoustic comfort provided as the overall acoustic performance of the space with the integration of the living wall is desirable.

The literature review conducted determined that the substrate (soil) absorbs sounds in the lower frequencies, while the vegetation scatters the sound in the higher frequencies [6,7]. It was observed that all the living wall under study in this research, at the four different locations, did not have a $100 \%$ full greenery coverage

Furthermore, as the living walls tested in this research all involve a geotextile base module with the plants and substrate held within, it can be deduced that the substrate used is low in density, and/or has low absorption capacities, justifying its lower acoustic absorption. 

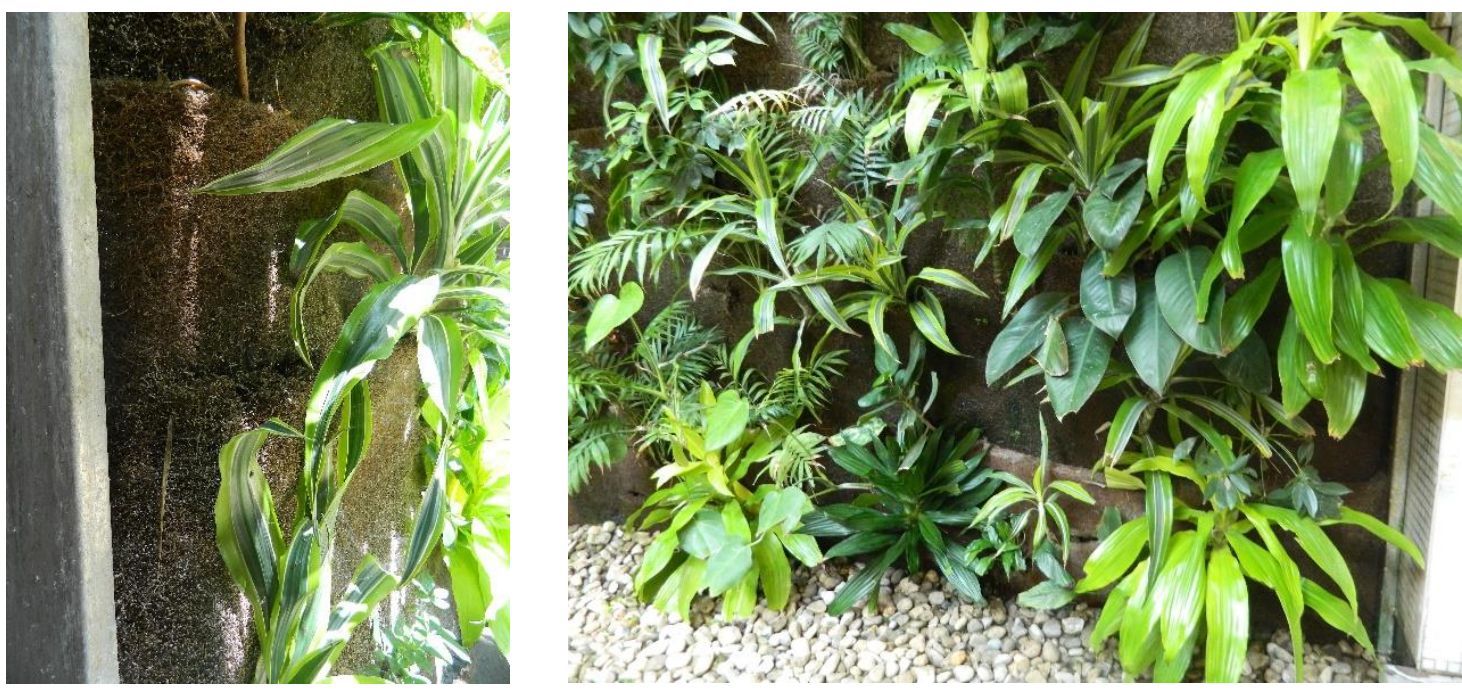

Figure 54: Living Wall investigated in this research, images showing the geotextile modules and the density of the vegetation

It is worth mentioning that all the living walls installed had direct sunlight access through skylight positioned directly on top of the wall, allowing for continuous growth of the plants. This could be an issue in maintaining the livelihood of the living wall in the case study location, as it does not have direct access to sunlight, affecting the growth of the plants. This is a concern to be accounted for if the application of this research is to be carried out in interior spaces with no direct sunlight. 


\section{BIBLIOGRAPHY}

[1] EPA, 2000. Indoor Air Quality and Student Performance. United States Environmental Protection Agency, Indoor Environments Division Office of Radiation and Indoor Air, Washington D.C, 402-K-03-006.

[2] M.J.M. Davis, M.J. Tenpierik, F.R. Ramirez, M.E. Perez. (2017). More than just a Green Facade: The sound absorption properties of a vertical garden with and without plants. Building and Environment, 116, 64-72. doi: http://dx.doi.org/10.1016/j.buildenv.2017.01.010

[3] Y. Alhorr, M. Arif, M. Katafygiotou, A. Mazroei, A. Kaushik, E. Elsarrag. (2016). Impact of Indoor Environmental Quality on Occupant well-being and Comfort: A review of the literature. International Journal of Sustainable Built Environment 5, 1 - 11. doi: https://doi.org/10.1016/j.ijsbe.2016.03.006

[4] H. Levin. (1995). Physical Factors in the Indoor Environment. Effects of the Indoor Environment on Health, Occupational Medicine: State of the Art Reviews, 10 (1). Philadelphia: Hanley \& Belfus, Inc.

[5] Z. Azkorra, G. Perez, J. Coma, L. F. Cabeza, S. Bures, J. E. Alvaro, A. Erkoreka, M. Urrestarazu. (2015, March). Evaluation of green walls as a passive acoustic insulation system for buildings. Applied Acoustics, 89, 46-56. doi: http://dx.doi.org/10.1016/j.apacoust.2014.09.010

[6] K. V. Horoshenkov, A. Khan, \& H. Benkreira. (2013). Acoustic Properties of Low Growing Plants. The Journal of the Acoustical Society of America. doi:10.1121/1.4798671

[7] N. H. Wong, A. Y.K. Tan, P. Y. Tan, K. Chiang, N. C. Wong. (2010). Acoustics evaluation of vertical greenery systems for building walls. Building and Environment, 45(2), 411-420. doi: http://dx.doi.org/10.1016/j.buildenv.2009.06.017

[8] G. Pérez, J. Coma, C. Barreneche, A. de Garcia, M. Urrestarazu, S. Bures, L. F. Cabeza (2016). Acoustic insulation capacity of Vertical Greenery Systems for buildings. Applied Acoustics, 110, 218-226. doi: http://dx.doi.org/10.1016/j.apacoust.2016.03.040

[9] A.M. Lacasta, A. Penaranda, I.R. Cantalapiedra, C. Auguet, S. Bures, M. Urrestarazu. (2016). Acoustic Evaluation of Modular Greenery Noise Barriers. Urban Forestry \& Urban Greening, (20), 172 - 179. doi: https://doi.org/10.1016/j.ufug.2016.08.010

[10] J. Kang, H. S. Yang, \& C. Cheal. (2013). Random-Incidence Absorption and Scattering Coefficients of Vegetation. Acta Acustica United with Acustica, 99, 379-388. doi: 10.3813/AAA.918619

[11] N. Fernandez-Bregon, M. Urrestarazu, D. L. Valera. (2012). Effects of a vertical greenery system on selected thermal and sound mitigation parameters for indoor building walls. Journal of Food, Agriculture, \& Environment,10(3\&4), 1025-1027.

[12] American Society of Heating, Refrigerating, and Air-Conditioning Engineers. (2013). 2013 ASHRAE handbook, Chapter 8: Sound and Vibration: Room Acoustics. Atlanata, GA, USA. 
[13] American Society of Heating, Refrigerating, and Air-Conditioning Engineers. (2015). 2015 ASHRAE handbook, Chapter 48: Noise and Vibration Control. Atlanata, GA, USA.

[14] A. Darlington, \& D. Schmitt. (n.d.). Interior Living Walls. Retrieved May 21, 2017, from http://www.sabmagazine.com/blog/2012/12/12/interior-living-walls/

[15] M. R. Ismail. (2013). Quiet Environment: Acoustics of Vertical Green Wall Systems of the Islamic Urban Form. Frontiers of Architectural Research, 162-177. doi: https://doi.org/10.1016/j.foar.2013.02.002

[16] M. Urrestarazu, \& S. Bures. (2012). Sustainable Green Walls in Architecture. Journal of Food, Agriculture, \& Environment,10(1), 792-794.

[17] P. D. Relf. (1990). Psychological and Sociological Response to Plants: Implications for Horticulture. HortScience, 25(1), 11-13.

[18] R. Thomazelli, F. Caetano, \& S. Bertoli. (2016). Acoustic Properties of Green Walls: Absorption and Insulation. 22 ${ }^{\text {nd }}$ International Congress on Acoustics, Buenos Aires.

[19] R. Paradis. (2016). Acoustic Comfort. Whole Building Design Guide: National Institute of Building Sciences. Retrieved May 19, 2017, from https://www.wbdg.org/resources/acoustic$\underline{\text { comfort }}$

[20] T. V. Renterghem, P. Jean, \& J. Defrance. (2012). Improving micro-climatology by trees, shrubs and bushes (Tech.) (J. Kang, Ed.). HOSANNA - Holistic and sustainable abatement of noise by optimized combinations of natural and artificial means.

[21] F. D'Alessandro, F. Asdrubali, N. Mencarelli. (2015) Experimental evaluation and modelling of the sound absorption properties of plants for indoor acoustic applications, Building and Environment 94, 913-923. doi: 10.1016/j.buildenv.2015.06.004

[22] M. Mehta, J. Johnson, J. Rocafort. (1999). Architectural Acoustics: Principals and Design. Prenctice-Hall Inc.

[23] D. D. Reynolds (1981). Engineering Principles of Acoustics: Noise and Vibration Control. Allyn and Bacon Inc, Boston, USA. 


\subsection{NOMENCLATURE}

$\alpha$-absorption coefficient

$\mathrm{dB}$ - decibel

dBA - A-weighted decibel

C(80) - Clarity

NC - Noise Criteria Curve

NR - Noise Reduction

PWL - Sound Power Level

$\mathrm{RC}$ - Room Criterion Curve

$\mathrm{RT}_{60}-$ Reverberation Time

SPL - Sound Pressure Level

STI - Speech Transmission Index

\subsection{Definitions [22]}

Absorption coefficient $(\alpha)$ - a measure of the sound absorbing property of a surface. More specifically, absorption coefficient is defined as the fraction of the incident sound energy absorbed (or otherwise not reflected) by a surface.

Ambient noise - also known as background noise - noise from all sources, unrelated to the sound that is object of interest.

Decibel $(d B)$ - a unit of measurement for sound pressure level, sound intensity level or sound power level. Decibel is a term to identify ten times the logarithm of the ratio of two like quantities.

Echo - a sound that has been reflected with sufficient time delay, and is of a sufficiently high level to be heard as distinct from the original sound.

Frequency $(\mathrm{Hz})$ - the number of full cycles per second measured. The unit of frequency is cycles per second (Hertz, Hz). A frequency of $500 \mathrm{~Hz}$ means 500 cycles per second.

Impulse noise - a noise of a short duration, particularly of high intensity. 
Noise reduction $(N R)$ - the reduction in sound pressure level of noise by any of the several means.

Reverberation - the continuation of a sound in an enclosed space after the initial source has been terminated.

Reverberation time $(R T)$ - the time it takes for sound intensity to decay by one millionth of its steady state value after the sound source has been terminated. The corresponding decrease in sound pressure level (or sound intensity level) is $60 \mathrm{~dB}$.

Sound attenuation - a reduction in sound level. It is usually given in $\mathrm{dB}$.

Sound insulation - the ability of a barrier, partition or a floor to prevent sound from reaching a given receiver.

Sound power level $(P W L)$ - a quantity expressed in decibels of airborne sound that is ten times the logarithm of the ratio of the sound power of interest to the standard reference power of $10^{-12}$ Watts.

Sound pressure level (SPL) - a quantity expressed in decibels of airborne sound that is ten times the logarithm of square of the sound pressure of interest to the square of the standard reference pressure of $2 \times 10^{-5} \mathrm{~Pa}$. 


\subsection{Measurement Results for All Locations}

\subsubsection{Acoustic Measurements for Location 1}

\begin{tabular}{|c|c|c|c|c|c|c|c|c|}
\hline \multirow{2}{*}{$\begin{array}{c}\text { Location 1_Measured } \\
\text { Background Noise Level } \\
\text { (dB) }\end{array}$} & \multicolumn{8}{|c|}{ Center Frequency } \\
\hline & 63 & 125 & 250 & 500 & 1000 & 2000 & 4000 & 8000 \\
\hline Point A & 65.7 & 58.2 & 52.3 & 48.9 & 48.4 & 46.6 & 43.3 & 38.3 \\
\hline Point B & 57.0 & 54.0 & 43.5 & 42.6 & 42.0 & 38.2 & 33.6 & 29.1 \\
\hline \multirow{2}{*}{$\begin{array}{c}\text { Location 1_Point A } \\
\text { (Measurement Set 1) }\end{array}$} & \multicolumn{8}{|c|}{ Center Frequency } \\
\hline & 63 & 125 & 250 & 500 & 1000 & 2000 & 4000 & 8000 \\
\hline Reverberation Time & 0.39 & $*$ & 0.67 & 0.72 & 0.83 & 0.79 & 0.80 & 0.66 \\
\hline $\begin{array}{l}\text { Relative Sound } \\
\text { Distribution }\end{array}$ & 36.1 & 32.3 & 20.2 & 17.8 & 19.2 & 10.7 & 8.0 & 12.0 \\
\hline Clarity & 13.6 & 11.6 & 13.0 & 11.5 & 9.7 & 11 & 11.2 & 12.6 \\
\hline \multirow{2}{*}{$\begin{array}{c}\text { Location 1_Point A } \\
\text { (Measurement Set 2) }\end{array}$} & \multicolumn{8}{|c|}{ Center Frequency } \\
\hline & 63 & 125 & 250 & 500 & 1000 & 2000 & 4000 & 8000 \\
\hline Reverberation Time & $*$ & $*$ & 0.64 & 0.74 & 0.80 & 0.82 & 0.79 & 0.67 \\
\hline $\begin{array}{l}\text { Relative Sound } \\
\text { Distribution }\end{array}$ & 36.0 & 32.1 & 19.5 & 18.1 & 18.6 & 11.4 & 8.3 & 11.4 \\
\hline decibel & 11.8 & 11.9 & 15.1 & 13.4 & 10.2 & 10.4 & 10.7 & 13.2 \\
\hline \multirow{2}{*}{$\begin{array}{l}\text { Location 1_Point B } \\
\text { (Measurement Set 1) }\end{array}$} & \multicolumn{8}{|c|}{ Center Frequency } \\
\hline & 63 & 125 & 250 & 500 & 1000 & 2000 & 4000 & 8000 \\
\hline Reverberation Time & $*$ & 0.48 & 0.75 & 0.73 & 0.79 & 0.81 & 0.79 & 0.67 \\
\hline $\begin{array}{l}\text { Relative Sound } \\
\text { Distribution }\end{array}$ & 40.3 & 35.6 & 26.8 & 25.7 & 22.7 & 16.5 & 14.1 & 18.5 \\
\hline decibel & 9.2 & 12.4 & 10.3 & 8.1 & 8.3 & 7.7 & 6.5 & 8.3 \\
\hline \multirow{2}{*}{$\begin{array}{c}\text { Location 1_Point B } \\
\text { (Measurement Set 2) }\end{array}$} & \multicolumn{8}{|c|}{ Center Frequency } \\
\hline & 63 & 125 & 250 & 500 & 1000 & 2000 & 4000 & 8000 \\
\hline Reverberation Time & $*$ & 0.51 & 0.62 & 0.69 & 0.80 & 0.80 & 0.76 & 0.65 \\
\hline $\begin{array}{l}\text { Relative Sound } \\
\text { Distribution }\end{array}$ & 39.5 & 36.9 & 28.2 & 23.9 & 23.0 & 16.3 & 13.3 & 17.9 \\
\hline Clarity & 9.1 & 10.5 & 6.9 & 7.7 & 7.9 & 7.8 & 7.8 & 8.6 \\
\hline
\end{tabular}




\subsubsection{Acoustic Measurements for Location 2}

\begin{tabular}{|c|c|c|c|c|c|c|c|c|}
\hline \multirow{2}{*}{$\begin{array}{c}\text { Location 2_Measured } \\
\text { Background Noise Level } \\
\text { (dB) }\end{array}$} & \multicolumn{8}{|c|}{ Center Frequency } \\
\hline & 63 & 125 & 250 & 500 & 1000 & 2000 & 4000 & 8000 \\
\hline Point A & 54.9 & 52.9 & 47.6 & 43.1 & 40 & 38.7 & 33.9 & 29.5 \\
\hline Point B & 55.5 & 51.4 & 45.8 & 42 & 39.5 & 38.1 & 32.6 & 28 \\
\hline Point C & 56.1 & 51.2 & 48 & 43.8 & 39.7 & 36.2 & 30 & 24.2 \\
\hline \multirow{2}{*}{$\begin{array}{c}\text { Location 2_Point A } \\
\text { (Measurement Set 1) }\end{array}$} & \multicolumn{8}{|c|}{ Center Frequency } \\
\hline & 63 & 125 & 250 & 500 & 1000 & 2000 & 4000 & 8000 \\
\hline Reverberation Time & $*$ & $*$ & 1.49 & 1.50 & 1.44 & 1.47 & 1.20 & 0.92 \\
\hline $\begin{array}{l}\text { Relative Sound } \\
\text { Distribution }\end{array}$ & 41.2 & 36.4 & 25.1 & 22.5 & 23.0 & 16.7 & 14.3 & 18.0 \\
\hline Clarity & 3.0 & 4.7 & 3.7 & 4.4 & 5.1 & 6.1 & 6.2 & 8.3 \\
\hline \multirow{2}{*}{$\begin{array}{c}\text { Location 2_Point A } \\
\text { (Measurement Set 2) }\end{array}$} & \multicolumn{8}{|c|}{ Center Frequency } \\
\hline & 63 & 125 & 250 & 500 & 1000 & 2000 & 4000 & 8000 \\
\hline Reverberation Time & $*$ & $*$ & 1.42 & 1.46 & 1.46 & 1.45 & 1.23 & 0.94 \\
\hline $\begin{array}{l}\text { Relative Sound } \\
\text { Distribution }\end{array}$ & 41.4 & 36.9 & 25.2 & 22.7 & 23.1 & 17.0 & 14.1 & 18.0 \\
\hline Clarity & 3.3 & 3.4 & 2.4 & 3.8 & 4.5 & 5.5 & 6.5 & 8.3 \\
\hline \multirow{2}{*}{$\begin{array}{l}\text { Location 2_Point B } \\
\text { (Measurement Set 1) }\end{array}$} & \multicolumn{8}{|c|}{ Center Frequency } \\
\hline & 63 & 125 & 250 & 500 & 1000 & 2000 & 4000 & 8000 \\
\hline Reverberation Time & $*$ & 1.31 & 1.38 & 1.51 & 1.45 & 1.46 & 1.23 & 0.97 \\
\hline $\begin{array}{l}\text { Relative Sound } \\
\text { Distribution }\end{array}$ & 40.7 & 37.8 & 28.2 & 27.3 & 26.8 & 21.5 & 18.9 & 23.4 \\
\hline Clarity & -1.2 & 3.0 & -0.9 & -0.8 & 2.3 & 1.2 & 2.4 & 4.3 \\
\hline \multirow{2}{*}{$\begin{array}{l}\text { Location 2_Point B } \\
\text { (Measurement Set 2) }\end{array}$} & \multicolumn{8}{|c|}{ Center Frequency } \\
\hline & 63 & 125 & 250 & 500 & 1000 & 2000 & 4000 & 8000 \\
\hline Reverberation Time & $*$ & 1.38 & 1.31 & 1.41 & 1.46 & 1.47 & 1.27 & 0.96 \\
\hline $\begin{array}{l}\text { Relative Sound } \\
\text { Distribution }\end{array}$ & 40.8 & 37.7 & 27.8 & 26.5 & 26.1 & 20.8 & 18.7 & 23.4 \\
\hline Clarity & 0.4 & 4.0 & 0.2 & 0.2 & 3.4 & 1.9 & 2.0 & 4.0 \\
\hline
\end{tabular}




\begin{tabular}{|c|c|c|c|c|c|c|c|c|c|}
\hline \multirow{2}{*}{\multicolumn{2}{|c|}{$\begin{array}{c}\text { Location 2_Point A } \\
\text { (Measurement Set 1_covered) }\end{array}$}} & \multicolumn{8}{|c|}{ Center Frequency } \\
\hline & & \multirow{2}{*}{$\frac{63}{*}$} & \multirow{2}{*}{$\frac{125}{*}$} & \multirow{2}{*}{$\frac{250}{1.52}$} & \multirow{2}{*}{$\frac{\mathbf{5 0 0}}{1.59}$} & \multirow{2}{*}{$\frac{1000}{1.47}$} & \multirow{2}{*}{$\frac{2000}{1.48}$} & \multirow{2}{*}{$\frac{4000}{1.24}$} & \multirow{2}{*}{$\frac{8000}{0.94}$} \\
\hline Reverberation Time & seconds & & & & & & & & \\
\hline $\begin{array}{l}\text { Relative Sound } \\
\text { Distribution }\end{array}$ & decibel & 41.3 & 36.5 & 25.4 & 23.2 & 23.5 & 16.5 & 13.9 & 17.4 \\
\hline Clarity & decibel & 3.3 & 4.9 & 2.8 & 3.6 & 4.3 & 5.5 & 5.8 & 8.9 \\
\hline \multirow{2}{*}{\multicolumn{2}{|c|}{$\begin{array}{c}\text { Location 2_Point A } \\
\text { (Measurement Set 2_covered) }\end{array}$}} & \multicolumn{8}{|c|}{ Center Frequency } \\
\hline & & 63 & 125 & 250 & 500 & 1000 & 2000 & 4000 & 8000 \\
\hline Reverberation Time & seconds & $*$ & $*$ & 1.52 & 1.61 & 1.48 & 1.45 & 1.22 & 0.91 \\
\hline $\begin{array}{l}\text { Relative Sound } \\
\text { Distribution }\end{array}$ & decibel & 41.3 & 36.0 & 25.4 & 23.3 & 23.2 & 16.7 & 14.0 & 17.1 \\
\hline Clarity & decibel & 3.2 & 5.2 & 3.2 & 3.8 & 4.9 & 5.5 & 5.9 & 9.4 \\
\hline \multirow{2}{*}{\multicolumn{2}{|c|}{$\begin{array}{c}\text { Location 2_Point B } \\
\text { (Measurement Set 1_covered) }\end{array}$}} & \multicolumn{8}{|c|}{ Center Frequency } \\
\hline & & 63 & 125 & 250 & 500 & 1000 & 2000 & 4000 & 8000 \\
\hline Reverberation Time & seconds & $*$ & $*$ & 1.46 & 1.56 & 1.50 & 1.50 & 1.25 & 0.91 \\
\hline $\begin{array}{l}\text { Relative Sound } \\
\text { Distribution }\end{array}$ & decibel & 41.0 & 37.8 & 28.6 & 26.7 & 26.3 & 20.7 & 18.3 & 23.6 \\
\hline Clarity & decibel & 0.5 & 4.4 & 0.7 & 1.1 & 2.9 & 1.6 & 2.3 & 3.9 \\
\hline \multirow{2}{*}{\multicolumn{2}{|c|}{$\begin{array}{c}\text { Location 2_Point B } \\
\text { (Measurement Set 2_covered) }\end{array}$}} & \multicolumn{8}{|c|}{ Center Frequency } \\
\hline & & 63 & 125 & 250 & 500 & 1000 & 2000 & 4000 & 8000 \\
\hline Reverberation Time & seconds & $*$ & $*$ & 1.55 & 1.52 & 1.53 & 1.50 & 1.30 & 0.94 \\
\hline $\begin{array}{l}\text { Relative Sound } \\
\text { Distribution }\end{array}$ & decibel & 41.6 & 37.6 & 30.0 & 26.8 & 26.4 & 20.9 & 18.8 & 23.6 \\
\hline Clarity & decibel & -0.3 & 5.6 & 0.9 & 1.6 & 2.4 & 1.5 & 1.8 & 3.6 \\
\hline
\end{tabular}


10.3.3 Acoustic Measurements for Location 3

\begin{tabular}{|c|c|c|c|c|c|c|c|c|c|}
\hline \multirow{2}{*}{\multicolumn{2}{|c|}{$\begin{array}{c}\text { Location 3_Measured } \\
\text { Background Noise Level } \\
\text { (dB) }\end{array}$}} & \multicolumn{8}{|c|}{ Center Frequency } \\
\hline & & 63 & 125 & 250 & 500 & 1000 & 2000 & 4000 & 8000 \\
\hline \multicolumn{2}{|l|}{ Point A } & 61.0 & 63.7 & 55.4 & 50.1 & 47.3 & 48.0 & 48.6 & 47.7 \\
\hline \multicolumn{2}{|l|}{ Point B } & 65.5 & 70.0 & 59.0 & 50.7 & 48.5 & 49.6 & 50.7 & 50.2 \\
\hline \multicolumn{2}{|l|}{ Point C } & 59.6 & 61.7 & 56.2 & 50.3 & 48.4 & 48.4 & 48.9 & 47.4 \\
\hline \multirow{2}{*}{\multicolumn{2}{|c|}{$\begin{array}{c}\text { Location 3_Point B } \\
\text { (Measurement Set 1) }\end{array}$}} & \multicolumn{8}{|c|}{ Center Frequency } \\
\hline & & 63 & 125 & 250 & 500 & 1000 & 2000 & 4000 & 8000 \\
\hline Reverberation Time & seconds & $*$ & $*$ & 1.09 & 1.26 & 1.35 & 1.26 & 1.19 & 1.07 \\
\hline $\begin{array}{l}\text { Relative Sound } \\
\text { Distribution }\end{array}$ & decibel & $*$ & 30.9 & 15.6 & 10.8 & 11.2 & 4.4 & 0.7 & 7.7 \\
\hline Clarity & decibel & $*$ & 8.6 & 9.2 & 5.7 & -7 & -33.5 & -40.3 & -36.1 \\
\hline \multirow{2}{*}{\multicolumn{2}{|c|}{$\begin{array}{c}\text { Location 3_Point B } \\
\text { (Measurement Set 2) }\end{array}$}} & \multicolumn{8}{|c|}{ Center Frequency } \\
\hline & & 63 & 125 & 250 & 500 & 1000 & 2000 & 4000 & 8000 \\
\hline Reverberation Time & seconds & $*$ & $*$ & $*$ & 1.24 & 1.39 & 1.29 & 1.22 & 1.01 \\
\hline $\begin{array}{l}\text { Relative Sound } \\
\text { Distribution }\end{array}$ & decibel & $*$ & $*$ & 21.3 & 16.0 & 13.9 & 8.7 & 5.7 & 9.8 \\
\hline Clarity & decibel & $*$ & $*$ & 4.7 & 3.5 & -5.3 & -28.3 & -35.5 & -34.2 \\
\hline \multirow{2}{*}{\multicolumn{2}{|c|}{$\begin{array}{l}\text { Location 3_Point C } \\
\text { (Measurement Set 1) }\end{array}$}} & \multicolumn{8}{|c|}{ Center Frequency } \\
\hline & & 63 & 125 & 250 & 500 & 1000 & 2000 & 4000 & 8000 \\
\hline Reverberation Time & seconds & $*$ & $*$ & 1.18 & 1.37 & 1.40 & 1.33 & 1.27 & 1.08 \\
\hline $\begin{array}{l}\text { Relative Sound } \\
\text { Distribution }\end{array}$ & decibel & $*$ & 35.2 & 21.5 & 18.5 & 17.0 & 10.4 & 6.5 & 11.7 \\
\hline Clarity & decibel & $*$ & 7.1 & 3.7 & -1.5 & -16.9 & -33 & -38.2 & -35.6 \\
\hline \multirow{2}{*}{\multicolumn{2}{|c|}{$\begin{array}{l}\text { Location 3_Point C } \\
\text { (Measurement Set 2) }\end{array}$}} & \multicolumn{8}{|c|}{ Center Frequency } \\
\hline & & 63 & 125 & 250 & 500 & 1000 & 2000 & 4000 & 8000 \\
\hline Reverberation Time & seconds & $*$ & $*$ & 1.17 & 1.33 & 1.37 & 1.24 & 1.18 & 1.05 \\
\hline $\begin{array}{l}\text { Relative Sound } \\
\text { Distribution }\end{array}$ & decibel & $*$ & $*$ & 28.6 & 25.9 & 24.6 & 18.1 & 14.3 & 19.4 \\
\hline Clarity & decibel & $*$ & $*$ & 3.5 & -1.6 & -16.4 & -31 & -35.6 & -31.8 \\
\hline
\end{tabular}




\subsubsection{Acoustic Measurements for Location 4}

\begin{tabular}{|c|c|c|c|c|c|c|c|c|}
\hline \multirow{2}{*}{$\begin{array}{c}\text { Location 4_Measured } \\
\text { Background Noise Level } \\
\text { (dB) }\end{array}$} & \multicolumn{8}{|c|}{ Center Frequency } \\
\hline & 63 & 125 & 250 & 500 & 1000 & 2000 & 4000 & 8000 \\
\hline Point A & 51.8 & 46.1 & 43.9 & 45.5 & 43.4 & 39.9 & 35.7 & 32.3 \\
\hline Point B & 54.8 & 48.2 & 45.1 & 43.6 & 39.6 & 36.0 & 33.0 & 29.5 \\
\hline Point C & 56.4 & 49.8 & 48.8 & 46.0 & 40.2 & 36.9 & 33.9 & 28.5 \\
\hline \multirow{2}{*}{$\begin{array}{c}\text { Location 4_Point A } \\
\text { (Measurement Set 1) }\end{array}$} & \multicolumn{8}{|c|}{ Center Frequency } \\
\hline & 63 & 125 & 250 & 500 & 1000 & 2000 & 4000 & 8000 \\
\hline Reverberation Time & 0.96 & 0.79 & 0.83 & 0.94 & 1.05 & 0.95 & 0.89 & 0.67 \\
\hline $\begin{array}{l}\text { Relative Sound } \\
\text { Distribution }\end{array}$ & 34.3 & 33.7 & 23.0 & 20.9 & 22.0 & 12.5 & 9.4 & 15.2 \\
\hline Clarity & 21.7 & 18.1 & 17.3 & 19.5 & 17.1 & 19.7 & 21.2 & 22.3 \\
\hline \multirow{2}{*}{$\begin{array}{l}\text { Location 4_Point A } \\
\text { (Measurement Set 2) }\end{array}$} & \multicolumn{8}{|c|}{ Center Frequency } \\
\hline & 63 & 125 & 250 & 500 & 1000 & 2000 & 4000 & 8000 \\
\hline Reverberation Time & $*$ & 1.01 & 0.82 & 0.96 & 1.01 & 0.94 & 0.89 & 0.69 \\
\hline $\begin{array}{l}\text { Relative Sound } \\
\text { Distribution }\end{array}$ & 34.3 & 33.7 & 23.0 & 20.9 & 22.1 & 12.2 & 9.4 & 15.2 \\
\hline Clarity & 21.6 & 18.5 & 17.6 & 19.4 & 16.8 & 19.9 & 21.1 & 22.1 \\
\hline \multirow{2}{*}{$\begin{array}{l}\text { Location 4_Point A' } \\
\text { (Measurement Set 1) }\end{array}$} & \multicolumn{8}{|c|}{ Center Frequency } \\
\hline & 63 & 125 & 250 & 500 & 1000 & 2000 & 4000 & 8000 \\
\hline Reverberation Time & 0.91 & 0.86 & 1.14 & 1.25 & 1.07 & 1.00 & 0.86 & 0.77 \\
\hline $\begin{array}{l}\text { Relative Sound } \\
\text { Distribution }\end{array}$ & 45.0 & 41.7 & 33.4 & 30.7 & 30.8 & 24.3 & 20.5 & 26.0 \\
\hline Clarity & 12.6 & 6.3 & 6.4 & 8.8 & 9.0 & 9.6 & 10.7 & 11.1 \\
\hline \multirow{2}{*}{$\begin{array}{l}\text { Location 4_Point A' } \\
\text { (Measurement Set 2) }\end{array}$} & \multicolumn{8}{|c|}{ Center Frequency } \\
\hline & 63 & 125 & 250 & 500 & 1000 & 2000 & 4000 & 8000 \\
\hline Reverberation Time & 1.06 & 0.83 & 1.04 & 1.08 & 1.09 & 8.99 & 6.63 & 2.67 \\
\hline $\begin{array}{l}\text { Relative Sound } \\
\text { Distribution }\end{array}$ & 34.4 & 28.4 & 20.7 & 16.6 & 15.5 & 9.1 & 5.6 & 12.2 \\
\hline decibel & 11.1 & 6.2 & 6.2 & 8.4 & 9.3 & 10.1 & 10.9 & 10.4 \\
\hline
\end{tabular}




\begin{tabular}{|c|c|c|c|c|c|c|c|c|c|}
\hline \multirow{2}{*}{\multicolumn{2}{|c|}{$\begin{array}{l}\text { Location 4_Point A" } \\
\text { (Measurement Set 1) }\end{array}$}} & \multicolumn{8}{|c|}{ Center Frequency } \\
\hline & & 63 & 125 & 250 & 500 & 1000 & 2000 & 4000 & 8000 \\
\hline Reverberation Time & seconds & 1.09 & 0.95 & 1.03 & 1.07 & 1.25 & 1.15 & 1.09 & 0.86 \\
\hline $\begin{array}{l}\text { Relative Sound } \\
\text { Distribution }\end{array}$ & decibel & 39.2 & 34.8 & 28.5 & 25.9 & 24.2 & 18.6 & 14.4 & 18.1 \\
\hline Clarity & decibel & 11.1 & 7.5 & 4.2 & 4.1 & 3.0 & 3.8 & 6.5 & 9.3 \\
\hline \multirow{2}{*}{\multicolumn{2}{|c|}{$\begin{array}{l}\text { Location 4_Point A" } \\
\text { (Measurement Set 1) }\end{array}$}} & \multicolumn{8}{|c|}{ Center Frequency } \\
\hline & & 63 & 125 & 250 & 500 & 1000 & 2000 & 4000 & 8000 \\
\hline Reverberation Time & seconds & 1.09 & 0.96 & 1.04 & 1.09 & 1.25 & 1.16 & 1.09 & 0.85 \\
\hline $\begin{array}{l}\text { Relative Sound } \\
\text { Distribution }\end{array}$ & decibel & 39.2 & 34.8 & 28.5 & 25.9 & 24.2 & 18.6 & 14.5 & 18.0 \\
\hline Clarity & decibel & 11.1 & 7.4 & 4.2 & 4.1 & 2.9 & 3.7 & 6.6 & 9.3 \\
\hline
\end{tabular}

